\title{
Effects of Porosity Wall Thickness and Length on the Filtration Efficiency of Gasoline Particulate Filters
}

\author{
by
}

\section{Fadi Araji}

A thesis submitted to the Faculty of Graduate and Postdoctoral Affairs in partial fulfillment of the requirements for the degree of

Master of Applied Science

in

Mechanical Engineering

Carleton University

Ottawa, Ontario

(C) 2021

Fadi Araji 


\section{Abstract}

The objective of this study was to understand the Gasoline Particulate Filter (GPF) filtration process and examine the effects of GPF parameters like wall thickness, porosity, Mean Pore Size (MPS) and length on the filtration efficiency (FE). It also aimed to investigate the implications of installing a GPF on a Gasoline Direct Injection (GDI) engine. Four filters were tested, first on a bench setup with a soot generator as source for the particle emissions and then installed on a GDI engine on a dynamometer where the overall emissions and filtration efficiencies were investigated. Soot concentrations, particle number emissions and gaseous emissions were measured. Particle morphology and soot deposition were analyzed using a Transmission Electron Microscope (TEM) and a Scanning Electron Microscope (SEM). Results showed an increasing filtration efficiency with increasing soot deposition. Results also showed a greater effect of MPS on filtration efficiency than wall thickness and filter length. 


\section{Acknowledgements}

I would like to thank, first and foremost, Professors Edgar Matida and Xiao Huang for providing me the opportunity to pursue a Masters degree and for their guidance and support throughout the conceptualization, execution and reporting of this thesis. Their knowledge, expertise and continuous motivation were crucial for the completion of this project.

I would also like to thank the managers, the technologists and the machine shop of the Emissions Research and Measurement Section of Environment and Climate Change Canada for their tireless efforts in insuring this project was a success.

I thank our industry partner for providing the materials to make this project possible in addition to their invaluable expertise throughout the whole process.

A final special thank you to my friends and family for enduring with me throughout the ups and downs of pursuing a Masters degree. 


\section{Table of Contents}

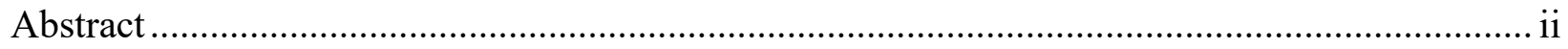

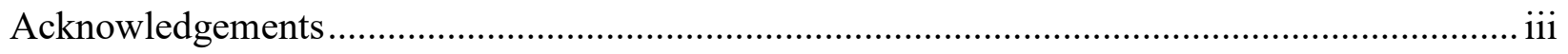

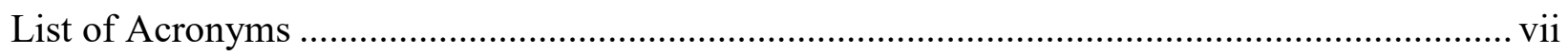

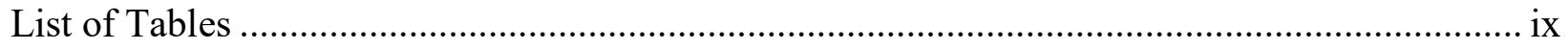

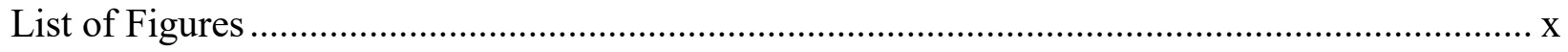

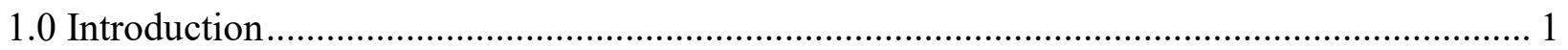

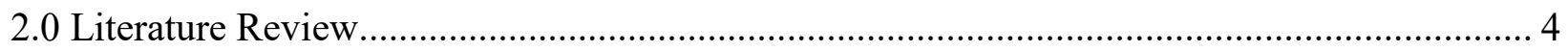

2.1 Particles Emitted by Combustion Engines ............................................................ 4

2.2 Soot and Particle Number Emissions from Gasoline Direct Injection Engines .................. 5

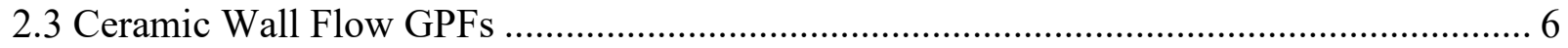

2.3.1 Non-catalyzed (Uncoated) Gasoline Particulate Filters ....................................... 8

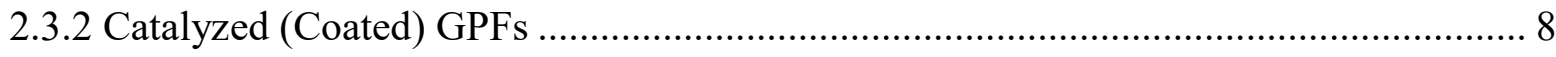

2.4 GPF Function ............................................................................................ 10

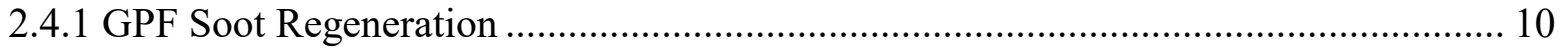

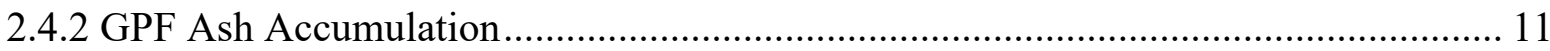

2.4.3 Effect of Accumulated Soot and Ash on Filtration and Pressure Drop..................... 11

2.5 Particle Number (PN) Filtration Efficiency (FE) .................................................... 13

2.5.1 Effect of Changing Mean Pore Size (MPS) on the PN Filtration Efficiency in a

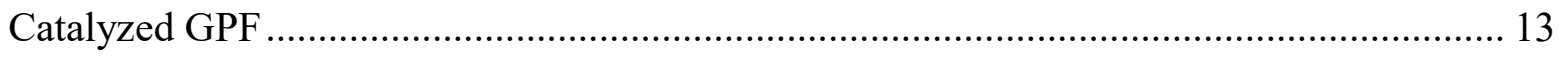


2.5.2 Effect of Changing Wall Thickness and Cell Density on PN Filtration Efficiency ..... 14

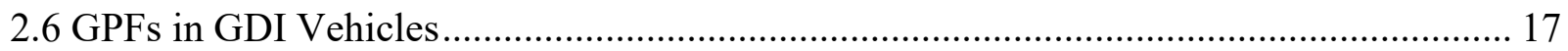

2.6.1 Particle Number Emission Rate............................................................................ 18

2.6.2 Effect of GPF on the Size and Morphology of Soot Particles from a GDI Vehicle..... 20

2.7 Soot Layer Deposition in Particulate Filters ............................................................ 23

2.8 Gasoline Particulate Filter Development ............................................................ 25

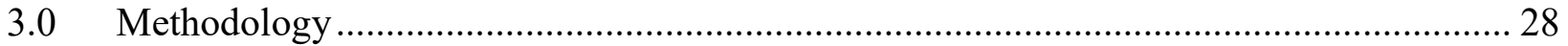

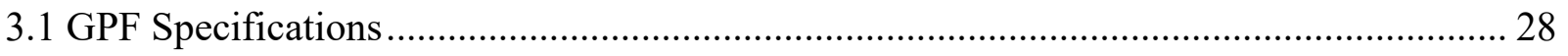

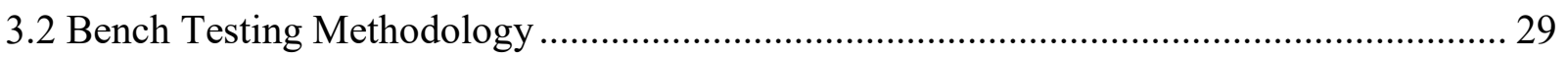

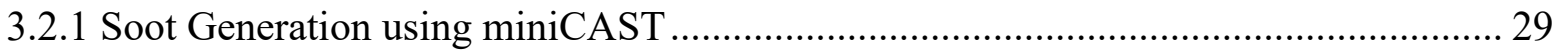

3.2.2 Bench Test Procedure using miniCAST ............................................................ 32

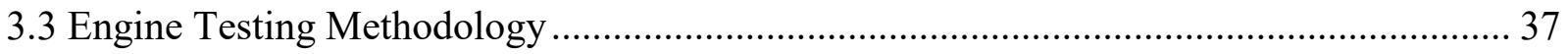

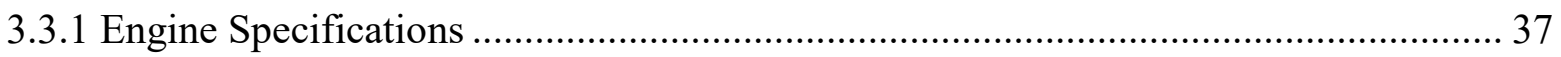

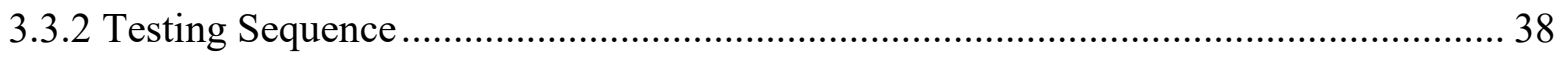

3.4 Test Cell Constant Volume Sampling (CVS) System................................................. 39

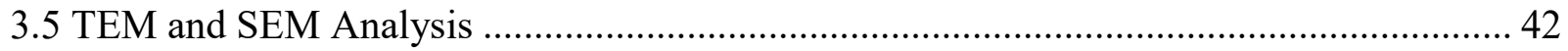

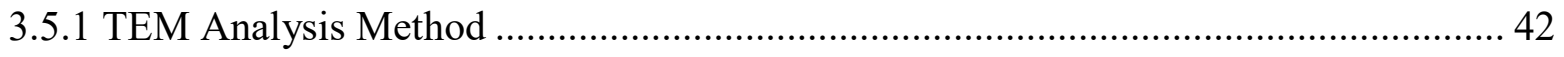

3.5.2 SEM Analysis Method................................................................................ 43

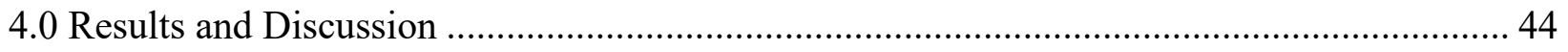

4.1 Bench Testing Results .................................................................................... 44 


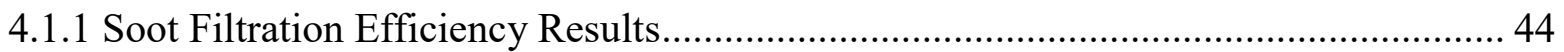

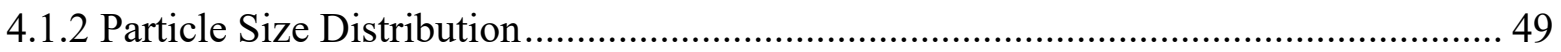

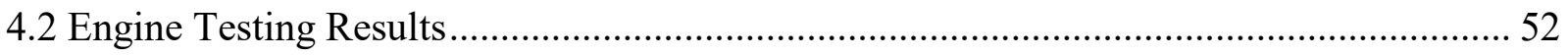

4.2.1 Soot Filtration Efficiency Results for Engine Testing................................................ 52

4.2.2 PN Filtration Efficiency Results for Engine Setup.................................................. 56

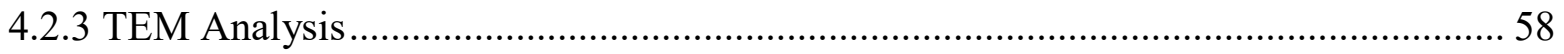

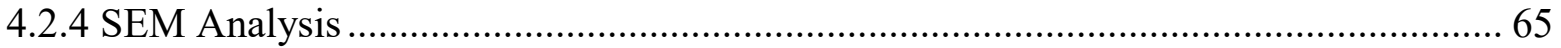

4.2.5 High Soot Loading Effects on Soot Layer Formation ................................................ 70

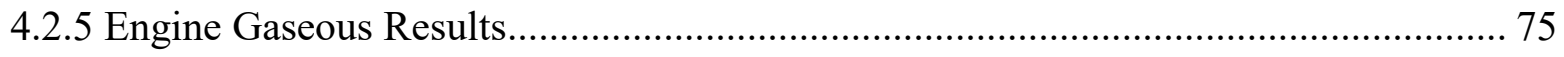

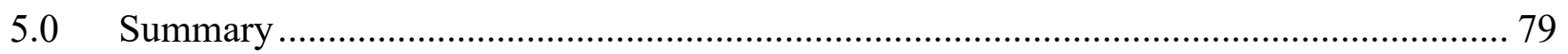

5.1 Bench Setup Results Summary ……………………………............................................ 80

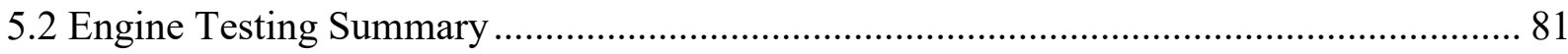

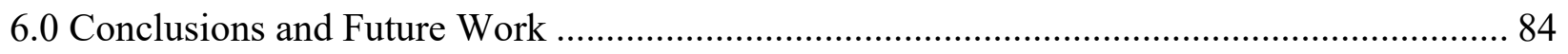

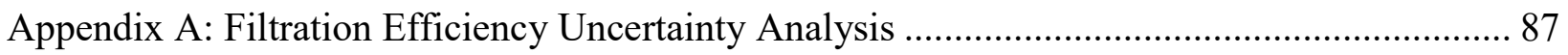

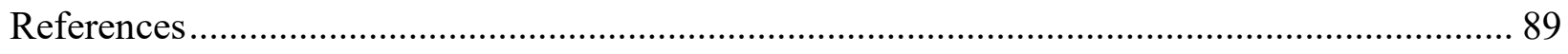




\section{List of Acronyms}

\begin{tabular}{ll} 
Ba & Barium \\
BC & Black Carbon \\
Ca & Calcium \\
CO 2 & Carbon Dioxide \\
CO & Carbon Monoxide \\
cpsi & Cells Per Square Inch \\
CH 4 & Methane \\
CLD & Chemiluminescence Detection \\
CFV & Constant Flow Venturi \\
CVS & Constant Volume Sampling \\
ESP & Electrostatic Precipitator \\
ERMS & Emissions Research and Measurement Section \\
EECPC & Engine Exhaust Condensation Particle Counter \\
EEPS & Engine Exhaust Particle Sizer \\
ECCC & Environment and Climate Change Canada \\
FE & Filtration Efficiency \\
FID & Flame Ionization Detection \\
GC-FID & Gas Chromatography - Flame Ionization Detection \\
GDI & Gasoline Direct Injection \\
GPF & Gasoline Particulate Filter \\
ICP-MS & Inductively Coupled Plasma Mass Spectrometry \\
LDV & Light Duty Vehicle \\
MPS & Mean Pore Size \\
MSS & Micro-Soot Sensor \\
NO & Nitric Oxide \\
\hline
\end{tabular}




\begin{tabular}{ll} 
NO2 & Nitrogen Dioxide \\
NOx & Nitrogen Oxide \\
NDIR & Non-Dispersive Infrared Detection \\
OFA & Open Frontal Area \\
O2 & Oxygen \\
PM & Particulate Matter \\
PMP & Particle Measurement Program \\
PN & Particle Number \\
PGM & Platinum Group Metal \\
PFI & Port Fuel Injection \\
SEM & Scanning Electron Microscope \\
SPN & Solid Particle Number \\
TWC & Three-Way Catalyst \\
THC & Total Hydrocarbons \\
TEM & Transmission Electron Microscope \\
UCPC & Ultrafine Condensation Particle Counter \\
VPR & Volatile Particle Remover \\
\hline
\end{tabular}




\section{List of Tables}

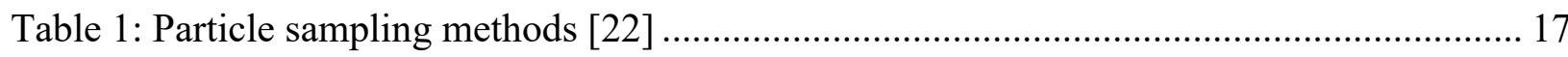

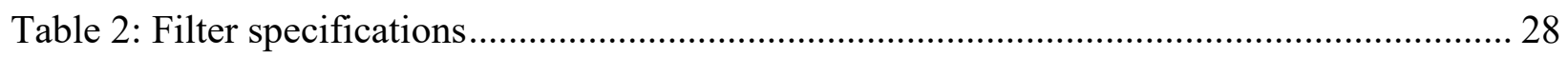

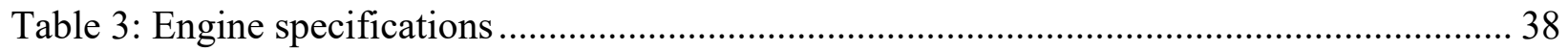

Table 4: Exhaust components measured in engine testing .......................................................... 40

Table 5: Summary of GPF filtration efficiency for the bench setup............................................. 48

Table 6: Filtration efficiency results for engine setup. The minimum filtration efficiency was calculated at beginning of the test and the maximum filtration efficiency at the end of the test

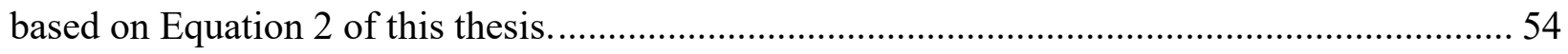

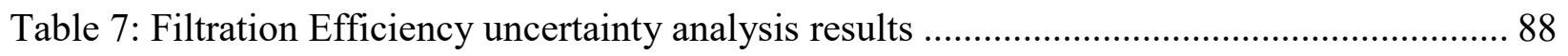




\section{List of Figures}

Figure 1: Schematic of particulate matter agglomerate …………............................................. 5

Figure 2: (a) Engine exhaust through wall-flow filter [15], (b) Cordierite particulate filter [16] .. 7

Figure 3: Potential Gasoline Particulate Filter (GPF) positions along the exhaust stream relative

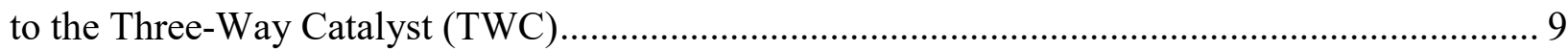

Figure 4: Effect of ash accumulation on the filtration efficiency of a particulate filter [8]......... 12

Figure 5: Impact of Mean Pore Size (MPS) on Particle Number (PN) [20] (written permission

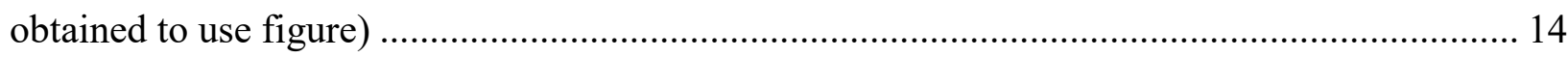

Figure 6: (a) Impact of wall thickness on particle number filtration efficiency (65\% porosity) (b) Impact of cell density on particle number filtration efficiency (65\% porosity) [20] (written

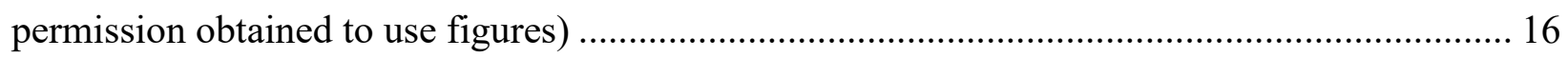

Figure 8: Particle number emission rates for the FTP-75 drive cycle. The Gasoline Particulate Filter filtration efficiency is represented by the circle markers [22] (written permission obtained

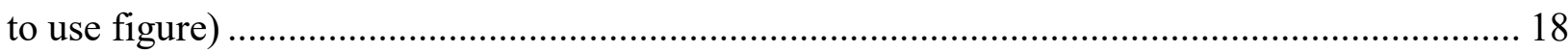

Figure 9: Effects of a Three-Way Catalyst (TWC) alone compared to a Three-Way Catalyst + Gasoline Particulate Filter (GPF) on the Particle Number (PN) emissions................................. 20

Figure 10: TEM images of soot particles produced by the stock GDI (a-h) and the GPF-equipped (i-p) vehicles at magnifications of 61,000 time (a-d and i-l) and 4,500 times (e-h and m-p) emitted over FTP-75 and US06 drive cycles [28]. (written permission obtained to use figure) .. 21 Figure 11: High-contrast spots, most likely solid non-volatile cores seen within many of the nucleation mode particles emitted by the GPF equipped vehicle over the US06 drive cycle [28].

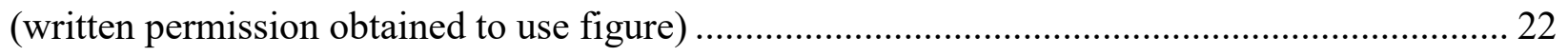

Figure 12: SEM image showing the accumulation of ash and soot in a GPF [8] ....................... 23 
Figure 13: Soot layer thickness in particulate filters.

Figure 14: Average soot layer thickness with $3 \mathrm{~g} / \mathrm{L}$ of soot loading on a particulate filter [29].. 25

Figure 15: Gasoline Particulate Filters (GPFs) used during testing both canned and uncanned.

The GPFs were fitted in a steel can in order to mount on the bench setup and on the engine. .... 29

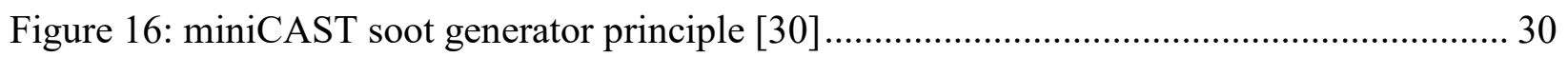

Figure 17: Particle size distribution for gasoline direct injection compared to propane [31]...... 31

Figure 18: EC/OC soot ratios at different mean particle electric mobility diameter for the soot

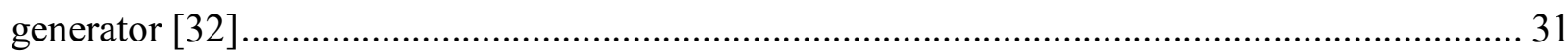

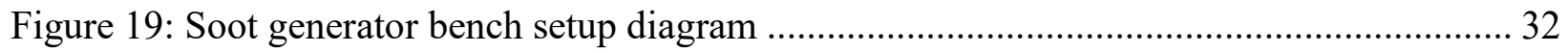

Figure 20: Soot generator bench setup picture. The setup was designed by the current

investigator and the components built with the help of the machine shop at the Emissions

Research and Measurement Section of Environment Canada. ............................................... 32

Figure 21: Gasoline Particulate Filter (GPF) baking sequence ........................................... 34

Figure 22: Photoacoustic measurement method diagram ................................................. 35

Figure 23: EEPS electrostatic principle diagram ....................................................... 36

Figure 24: Electrostatic precipitator instrument for PM collection on TEM copper grids ........... 37

Figure 25: Dynamometer test cell sampling system .................................................. 41

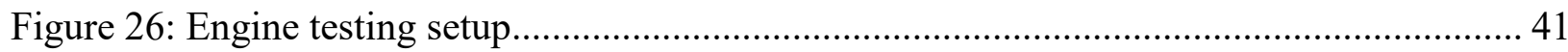

Figure 27: Filtration efficiency and soot loading versus time ......................................... 46

Figure 28: Changing soot concentration with time for bench setup ................................... 49

Figure 29: Particle Size Distribution post filters........................................................ 50

Figure 30: The change of particle number emissions with time for the bench setup ................ 51

Figure 31: Soot filtration efficiency versus time for the engine setup ................................ 53 
Figure 32: Engine cumulative soot loading and engine speed versus time

Figure 33: Particle size distribution post filters for engine setup ........................................ 56

Figure 34: Filtration efficiency per particle size for the engine setup ................................. 57

Figure 35: Pre-GPF particle size distribution (obtained using the TSI EEPS) ......................... 59

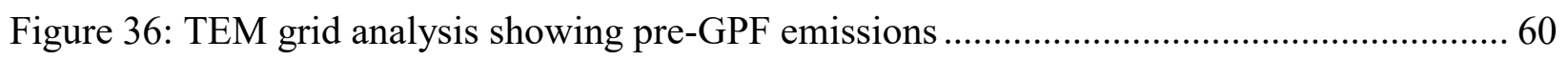

Figure 37: TEM grid analysis showing post GPF A emissions ......................................... 60

Figure 38: TEM grid analysis showing post GPF B emissions ......................................... 61

Figure 39: TEM grid analysis showing post GPF C emissions ........................................... 61

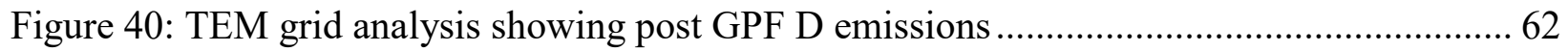

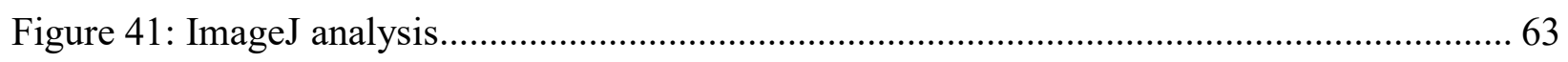

Figure 42: Average primary particle diameter using ImageJ analysis tool for both pre-filters and

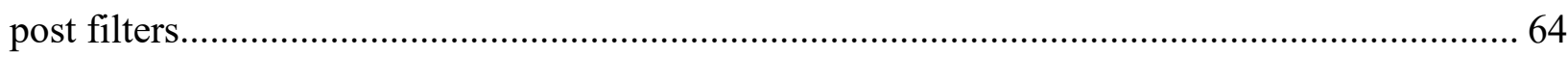

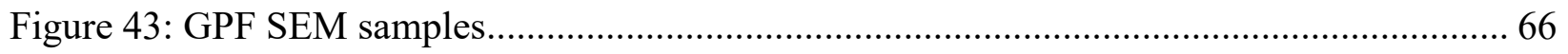

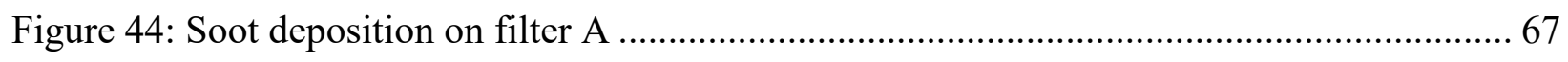

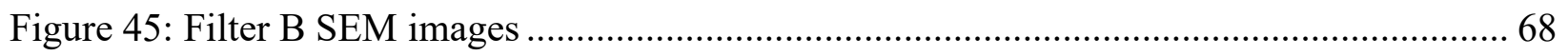

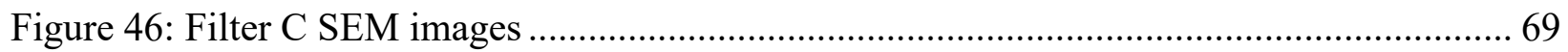

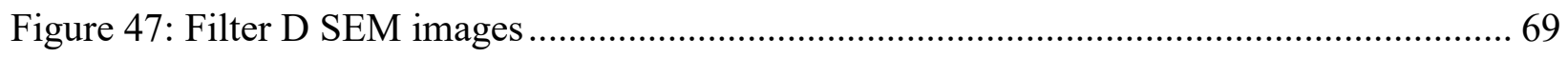

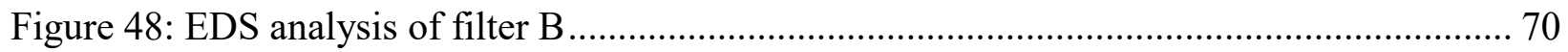

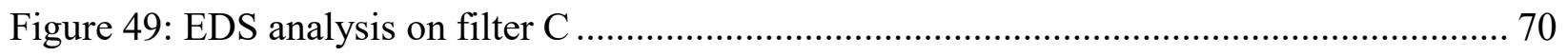

Figure 50: Bench soot loading for filter with 200/8 55\% specifications ............................... 71

Figure 51: 15x magnification SEM image showing soot layer formation in the filter open channels from $3 \mathrm{~g} / \mathrm{L}$ of soot loading. The red arrows show the direction of accumulation of soot. 
Figure 52: SEM images showing soot layer resulting from $3 \mathrm{~g} / \mathrm{L}$ of soot loading .................... 72

Figure 53: SEM image comparison between $0.05 \mathrm{~g} / \mathrm{L}$ soot loading and $3 \mathrm{~g} / \mathrm{L}$ soot loading....... 74

Figure 54: Carbon Dioxide concentrations versus time for the engine setup ......................... 75

Figure 55: Carbon Monoxide concentrations versus time for the engine setup ....................... 76

Figure 56: Total Hydrocarbon concentrations versus time for the engine setup ..................... 77

Figure 57: Nitrogen Oxide concentrations versus time for the engine setup.......................... 78 


\subsection{Introduction}

In recent years, there have been ever increasing strict fuel economy and emission standards imposed by governments. The current California LEVIII and US Tier 3 regulations set a maximum particulate matter (PM) emission rate to $3 \mathrm{mg} / \mathrm{mile}(1.86 \mathrm{mg} / \mathrm{km})$ in 2017 for Light Duty Vehicles (LDV) [1]. Starting 2025, LEVIII PM standards will be set to an even tighter level of $1 \mathrm{mg} / \mathrm{mile}$ $(0.62 \mathrm{mg} / \mathrm{km})[1]$. In the EU, the Euro 6a particle number (PN) standard for Gasoline Direct Injection (GDI) vehicles was reduced to $6 \times 10^{11}$ particles $/ \mathrm{km}$ in 2017 [1]. Studies have shown that the US mass based approach and the EU number based approach show a good correlation for high particle concentrations [2]. There are fundamental differences in the two approaches where the particle mass concentration is dominated by larger accumulation mode particles whereas the particle number concentration is dominated by smaller nuclei mode particles. In order to achieve repeatable particle number measurements the volatile particles are removed (by a thermal denuder for example) in addition to particles with a diameter smaller than $23 \mathrm{~nm}$. This is done to eliminate the effects of temperature, dilution ratio and the lower size limit of the particle number measurement instruments on the particle number measurements [2]. Particle mass can be approximated from particle number by using the particle diameter and the particle density.

In recent years, there has been an increased market influx of GDI vehicles. GDI engines have shown to have significantly improved fuel economy and ultimately reduce carbon dioxide emissions while providing more power compared to traditional Port Fuel Injection (PFI) engines [3]. GDI engines, however, produce higher PM emissions than PFI engines. In GDI engines, fuel is sprayed directly into the combustion chamber leading to incomplete fuel evaporation due to the 
limited time available for the fuel and air to mix [1]. This results in regions with high temperatures but insufficient oxygen which leads to a pyrolysis reaction and soot formation [1]. PM could also be formed due to the direct contact of fuel with the cold cylinder walls and piston. A small amount of fuel may impinge on the piston and lead to diffusion combustion during evaporation [1].

Because of this, PM reduction strategies are needed by automotive manufacturers in order to meet the current and future PM standards. Gasoline Particulate Filters (GPF) are a potential strategy and there has been an increasing number of studies to investigate the implications of installing them on GDI vehicles. Some studies have shown that the installation of GPFs in GDI vehicles is both feasible and cost-effective. In fact, it has been shown that large reductions in black carbon (BC) and solid particle number (SPN) emissions have resulted from the use of a GPF on a GDI vehicle [1]. It has also been reported that GPFs have a PM filtration efficiency of 60-80 \% [4].

In addition to regulatory considerations, the adverse health effects of gasoline exhaust particles must be taken into account. The deposition of these particles inside the human body depends on their aerodynamic diameter. With an aerodynamic diameter smaller than $10 \mu \mathrm{m}$, the particle may enter the lungs, and if it is in the range of $10 \mathrm{~nm}$ and $100 \mathrm{~nm}$ there is a high probability it is deposited in the nasopharyngeal region [5]. Inside the cells, particles may have several biological responses such as oxidative stress, inflammation and genotoxicity [6]. It has also been shown that exposure to PM may cause DNA strand breakage [7]. These negative health effects further highlight the importance of PM reduction strategies.

The objective of this study was to understand the GPF filtration process in general and examine the effects of certain GPF parameters like filter wall thickness, porosity, and length on the filtration efficiency. The study also aimed to further investigate the implications of installing a GPF on the 
emission profile of a GDI engine. Four filters were tested first on a bench setup with a soot generator as source for the particle emissions. Filter A had an $8 \mathrm{mil}(0.2032 \mathrm{~mm})(\mathrm{mil}$ is a measure of wall thickness and 1 mil is equal to 0.001 inches) wall thickness, cell density of 200 cells per square inch (cpsi) and a 55\% porosity by volume. Filter A was used as a reference as it was optimized for LDV applications as per manufacturer recommendations. Filter B had a wall thickness of $8 \mathrm{mil}(0.2032 \mathrm{~mm})$, a cell density of $300 \mathrm{cpsi}$ and a $65 \%$ porosity which was used to observe the effects of changing porosity on filtration efficiency. Filter $\mathrm{C}$ had a wall thickness of $12 \mathrm{mil}(0.3048 \mathrm{~mm})$, a cell density of $300 \mathrm{cpsi}$ and a $65 \%$ porosity and was tested to observe the effects of changing wall thickness on filtration efficiency. Finally, filter D had similar specifications to filter A except the length was reduced in order to observe the effects of changing length on the overall filtration efficiency. The filters were then installed on a GDI engine on a dynamometer where the overall emission profile and filtration efficiencies were investigated. Gaseous emissions, particle number, and particle mass were measured. PM was also collected on Transmission Electron Microscope (TEM) grids for particle morphology analysis. The GPFs were also analyzed under a Scanning Electron Microscope (SEM) for soot deposition analysis.

Chapter 2 of this thesis includes a literature review which explores particulate matter (PM) emissions from Gasoline Direct Injection (GDI) engines in addition to previous research on Gasoline Particulate Filter (GPF) function, filtration efficiency, and effect on particle morphology. Chapter 3 describes the methodology used in this research including GPF specifications, bench testing and engine testing methodology, as well as instrumentation used. Chapter $\mathbf{4}$ provides a comprehensive explanation and discussions of the results. Chapter 5 provides a summary of the findings and Chapter 6 elaborates some conclusions and potential future work to be built upon this thesis. 


\subsection{Literature Review}

\subsection{Particles Emitted by Combustion Engines}

There are three modes of particles emitted by combustion engines: 1) Nucleation Mode, 2) Accumulation Mode, and 3) Course Mode [8]. Accumulation Mode particles consist of smaller primary particles ranging from 20 to $50 \mathrm{~nm}$. Nucleation Mode particles have been less studied as they are at the limit of detection of the measurement instruments used [8]. Course Mode particles, such as rust from the exhaust system, are not emitted directly but rather formed from the other two modes. It is suggested that Coarse Mode particles have a solid core with a layer of volatile material on the outside [8].

According to Eastwood [9], particles consist of two main components, volatile (soluble) and nonvolatile (insoluble), each in turn consisting of fraction components. The volatile component consists of the organic fraction made of several hundred compounds like alkenes, alkanes, alcohols, sulfate fraction that is water soluble in addition to the nitrate fraction, also water soluble. The non-volatile component of particles consists of the carbonaceous fraction also referred to as soot, elemental or black carbon, and the ash fraction which consists of inorganic compounds or elements such as metals. The ratio of each of these fractions to the total particle emissions depends on several factors such as the composition of the working fluids and the engine operating parameters [9].

Particles are also classified by their diameter where PM10 refers to particles with a diameter not exceeding $10 \mu \mathrm{m}$ [9]. PM2.5 (fine particles) refers to particles with a diameter not exceeding 2.5 
$\mu \mathrm{m}$ and PM0.1 (ultrafine particles) is for particles with diameter not exceeding $100 \mathrm{~nm}$. Particles with a diameter not exceeding $50 \mathrm{~nm}$ are referred to as nanoparticles [9]. A schematic of a possible particulate matter agglomerate is shown in Figure 1.

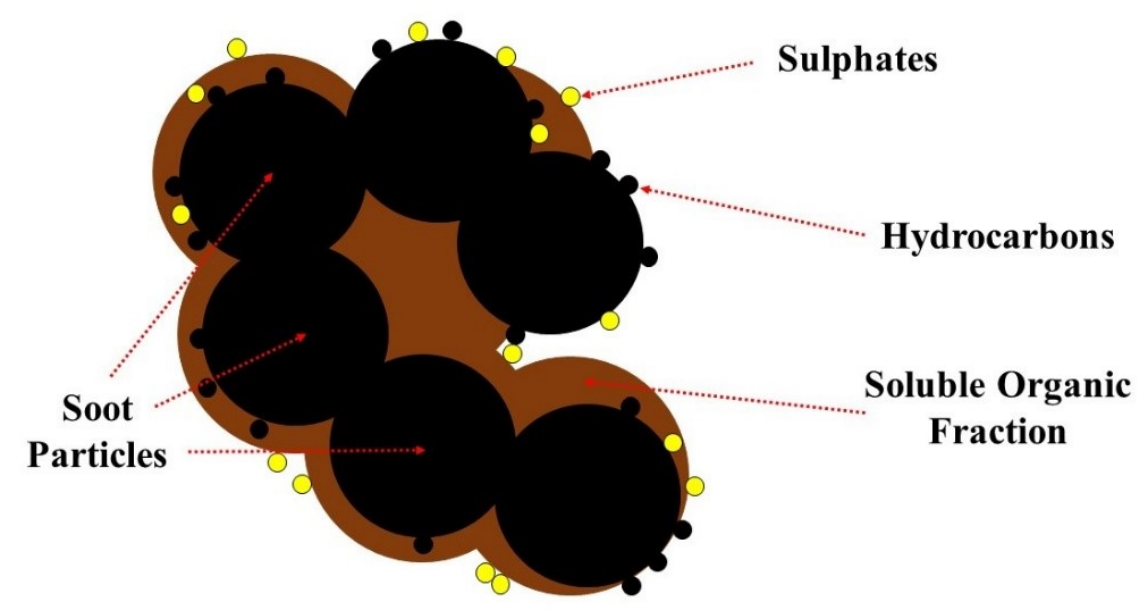

Figure 1: Schematic of a particulate matter agglomerate

\subsection{Soot and Particle Number Emissions from Gasoline Direct}

\section{Injection Engines}

There are several factors that influence the formation of soot in GDI engines as described by Bertsch et al. [10]. The impingement of liquid fuel on the piston and liner due to spray-wall interactions results in insufficient air-fuel mixture which in turn results in a diffusive combustion and increased soot emissions. Diffusive combustion occurs when the Oxygen and the fuel come together in the combustion chamber through molecular diffusion where the burning rate depends on the rate of the diffusion [11]. In typical GDI engine applications, the diffusion does not allow 
for sufficient oxidizer to burn the fuel resulting in incomplete combustion and consequently higher soot emissions.

In multi-hole fuel injectors, the deposit liquid fuel formation at the injector tip with insufficient evaporation of the liquid is a major source of particle number emissions. Another major reason for particle emissions in GDI engines are the inhomogeneities caused by spray-wall interactions, spray-valve interactions or late injection timings resulting in insufficient mixing [8].

\subsection{Ceramic Wall Flow GPFs}

High-efficiency particulate filters are commonly made of ceramic materials such as cordierite, aluminum titanate, mullite or silicon carbide [12]. The basis for the design of wall-flow filters is a honeycomb structure where, as shown in Figure 2, gases pass into the open end of a channel, the plug at the opposite end forces the gases through the porous wall of the honeycomb channel and out through the neighboring channel [12]. Wall-flow filters capture particulate matter by interception and impaction of the solid particles across the porous wall [12]. Interception involves the particulate making physical contact and becoming attached to the filter media [13]. Intercepted particles are smaller (in the range of $100 \mathrm{~nm}$ to $400 \mathrm{~nm}$ in diameter) with an inertia not strong enough to cause the particle to continue in a straight line [13]. Impaction on the other hand uses the rapid change in fluid direction and inertia to separate the particulate from the fluid stream [13]. Impaction is normally applied when there is a high concentration of coarse particles (larger than $400 \mathrm{~nm}$ in diameter) that tend not to remain at fluid velocity and travel in a continuous direction [13]. GPFs are designed to provide a clean slate filtration efficiency of between $70 \%$ and $80 \%$ and 
can be increased to $90 \%$ with an added layer of submicron alumina particles also known as artificial ash [14].

(a)

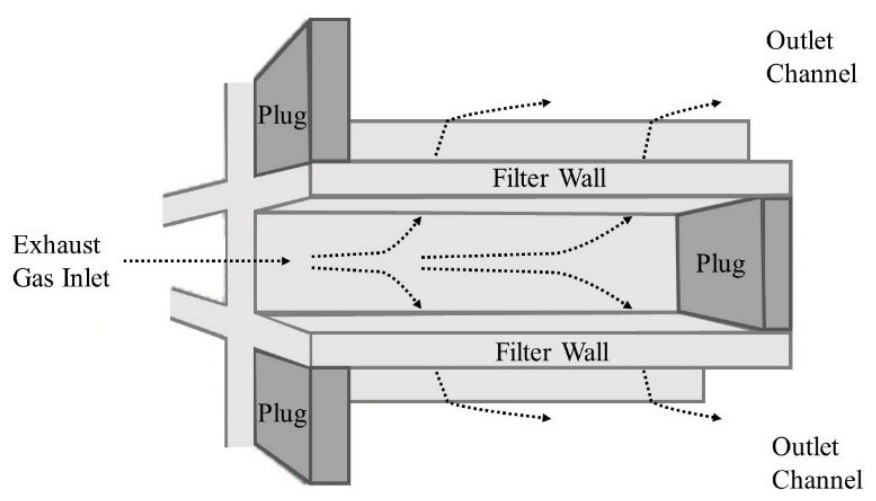

(b)

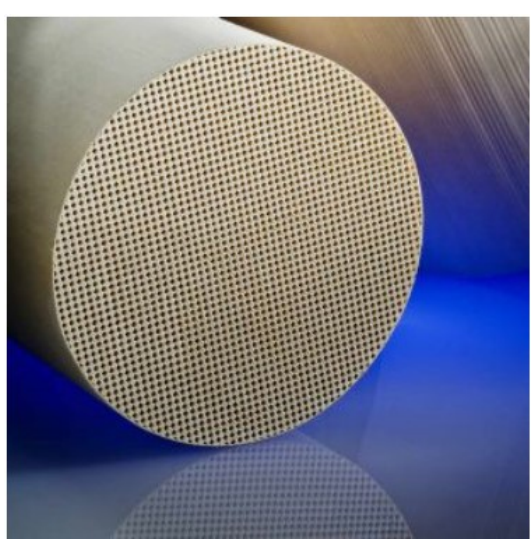

Figure 2: (a) Engine exhaust through wall-flow filter [15], (b) Cordierite particulate filter [16]

Gasoline Particulate Filters technologies are related to Diesel Particulate Filter (DPF) technologies (wall flow design for example), where GPF design is based on DPF design, however there are some notable differences. Materials with higher thermal durability, such as silicon carbide, are typically used in DPFs (compared to Cordierite in GPFs) due to the higher frequency and temperature of regenerations in DPFs [14]. Regeneration of both GPFs and DPFs will be compared in more detail in section 2.4.1 of this thesis. DPFs also typically have a higher thermal mass compared to GPFs in order to protect the DPF substrate from thermal damage during regeneration [14]. Compared to GPF filtration efficiencies (between 70-80\%), DPFs show a filtration efficiency greater than $90 \%$ for both particle mass and particle number [17]. 


\subsubsection{Non-catalyzed (Uncoated) Gasoline Particulate Filters}

Non-catalyzed GPFs have the sole function of PM filtration without any gaseous conversion capabilities. For optimum GPF design, material selection plays an important role. The chosen material is required to possess high thermomechanical robustness (high thermal shock resistance, low thermal expansion, and high temperature performance). For these reasons Cordierite was chosen as the most commonly used material for GPFs $\left(10^{-6} \mathrm{~m} / \mathrm{mK}\right.$ rate of thermal expansion and over $1300{ }^{\circ} \mathrm{C}$ temperature capability) [8]. The material is also required to possess low material density (Cordierite density is approximately $2500 \mathrm{~kg} / \mathrm{m}^{3}$ ) and high intrinsic strength (in order to achieve a high porosity, in some cases $65 \%$, while maintaining a compact size) [8].

\subsubsection{Catalyzed (Coated) GPFs}

Coated or catalyzed GPFs (cGPFs) on the other hand have the dual function of PM filtration in addition to gaseous conversion as their purpose would be to replace all or part of the OEM threeway catalyst (TWC) on the vehicle, as shown in Figure 3. The top schematic shows the GPF and Three-Way Catalyst (TWC) in separate cans where the GPF is upstream of the TWC. The bottom schematic shows the Catalyzed GPF (cGPF) in a closed coupled position with the TWC. There are several benefits to coating a GPF which include smaller space requirements (in the case where the coated GPF replaces the TWC) in addition to enhancing the soot combustion [18]. Studies have shown that soot combustion increases rapidly in a coated filter at temperatures above $550{ }^{\circ} \mathrm{C}$ and therefore reducing the soot combustion temperature by approximately $100{ }^{\circ} \mathrm{C}[19]$. 


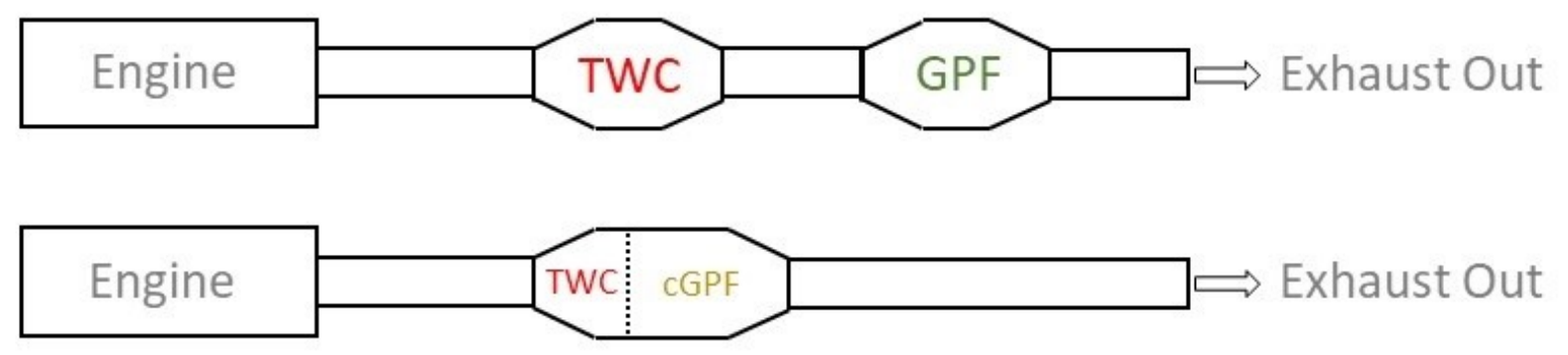

Figure 3: Potential Gasoline Particulate Filter (GPF) positions along the exhaust stream relative to the Three-Way Catalyst (TWC)

Catalyzed GPFs typically contain a Platinum Group Metal (PGM) coating containing Platinum, Palladium and Rhodium. Coating concentrations vary based on application (which takes into account vehicle manufacturer PGM coating and emission standards). PGM coating concentrations vary depending on the desired level of gaseous conversion which depends on the emission standards enforced at the time of the cGPF manufacturing. Coating methods are usually proprietary and therefore there is not much information in literature about the techniques used. The added catalyst coating however will increase pressure drop (due to the partial blocking of the filter pores caused by the added coating inside the filter) [20]. Because of the added pressure drop, a higher porosity is desired in coated filters. 


\subsection{GPF Function}

\subsubsection{GPF Soot Regeneration}

In order to reduce exhaust pressure drop, the soot collected on the GPF needs to be oxidized and the filter regenerated. In this regeneration process, Oxygen $\left(\mathrm{O}_{2}\right)$, Nitric Oxide (NO) and Nitrogen Dioxide $\left(\mathrm{NO}_{2}\right)$ are the most effective oxidants of soot under normal exhaust operating temperatures [8]. At stoichiometric conditions, it can be assumed that there is no Oxygen available and therefore the rate of soot burning will be minimal especially when Nitrogen Oxide $\left(\mathrm{NO}_{\mathrm{x}}\right)$ levels are also low (NOx emissions are typically lower than $0.046 \mathrm{~g} / \mathrm{km}$ as per light duty vehicle Tier III NOx emission standards [21]) than upstream of a three-way catalyst (TWC). Fuel cuts, where the fueling is stopped and intake air containing Oxygen passes through the engine and the exhaust system, is a condition under which soot can be oxidized. Fuel cuts occur when the driver lets go of the fuel pedal, typically after an acceleration. Gasoline soot contains mostly elemental carbon and some organic material that evaporates with elevated exhaust temperatures [8]. The elemental carbon can only be oxidized either totally to Carbon Dioxide $\left(\mathrm{CO}_{2}\right)$ or partially to Carbon Monoxide $(\mathrm{CO})$ as shown in the following reactions:

$$
\begin{aligned}
& \mathrm{C}+1 / 2 \mathrm{O}_{2} \longrightarrow \mathrm{CO} \\
& \mathrm{C}+\mathrm{O}_{2} \longrightarrow \mathrm{CO}_{2}
\end{aligned}
$$

The rate of both reactions is determined by the Oxygen availability and the exhaust temperature [8]. The oxidation of soot in a GPF occurs passively however it can be forced by running the engine periodically in lean mode [8]. Several studies have shown that soot oxidation or filter 
regeneration is most likely to occur when the exhaust temperature exceeds $650{ }^{\circ} \mathrm{C}[19,22]$. As discussed, in practice, most GPF regeneration occurs passively through regular vehicle operation typically after accelerations.

For comparison, Diesel Particulate Filters typically employ an active regeneration method for soot oxidation where fuel is injected in the exhaust and results in the burning of the soot. The reason for this "active regeneration" in DPFs is the presence of much more carbonaceous particles in diesel exhaust compared to gasoline exhaust making DPFs harder to regenerate [14]. The presence of less carbonaceous particles in gasoline exhaust is what makes passive regeneration often enough to oxidize the accumulated soot [14].

\subsubsection{GPF Ash Accumulation}

In addition to collecting soot, particulate filters also collect inorganic ash particles that, as studies have shown [23], deposit as a fine porous layer on top of the filter wall and do not penetrate into the porous filter structure. The ash does not oxidize like soot and acts as a highly efficient filtration medium [23]. Accumulated ash in the filter leads to improved filtration efficiency.

\subsubsection{Effect of Accumulated Soot and Ash on Filtration and Pressure Drop}

As the porous walls of the filter become saturated with soot, a layer of soot (typically called a soot cake) starts forming on the surface of the wall, forming a highly effective filtration medium [24]. The filtration efficiency of the filter increases with the increasing formation of the soot cake and approaches $100 \%$. Under certain temperature and load conditions, the GPF regenerates and the 
accumulated soot burns off (explained in more detail in Section 2.4.1). As more mileage is accumulated on a vehicle equipped with a GPF, the filter collects soot in addition to ash (an inorganic constituent of PM). Unlike soot, ash is not removed through regeneration and remains in the filters. As the quantity of ash increases in the filter, $100 \%$ filtration efficiency is reached earlier [25]. Laboratory results have shown this experimentally where mileage was accumulated on a vehicle equipped with a particulate filter and the mass based filtration efficiency measured at different intervals ( $0 \mathrm{~km}$ to $240,000 \mathrm{~km}$ ). Figure 4 displays the results showing increasing clean slate filtration efficiency (at $0 \mathrm{~g} / \mathrm{L}$ soot loading) with increasing mileage and increasing ash quantities [8]. Results also showed the robustness of particulate filters at maintaining high filtration efficiencies even at high mileages.

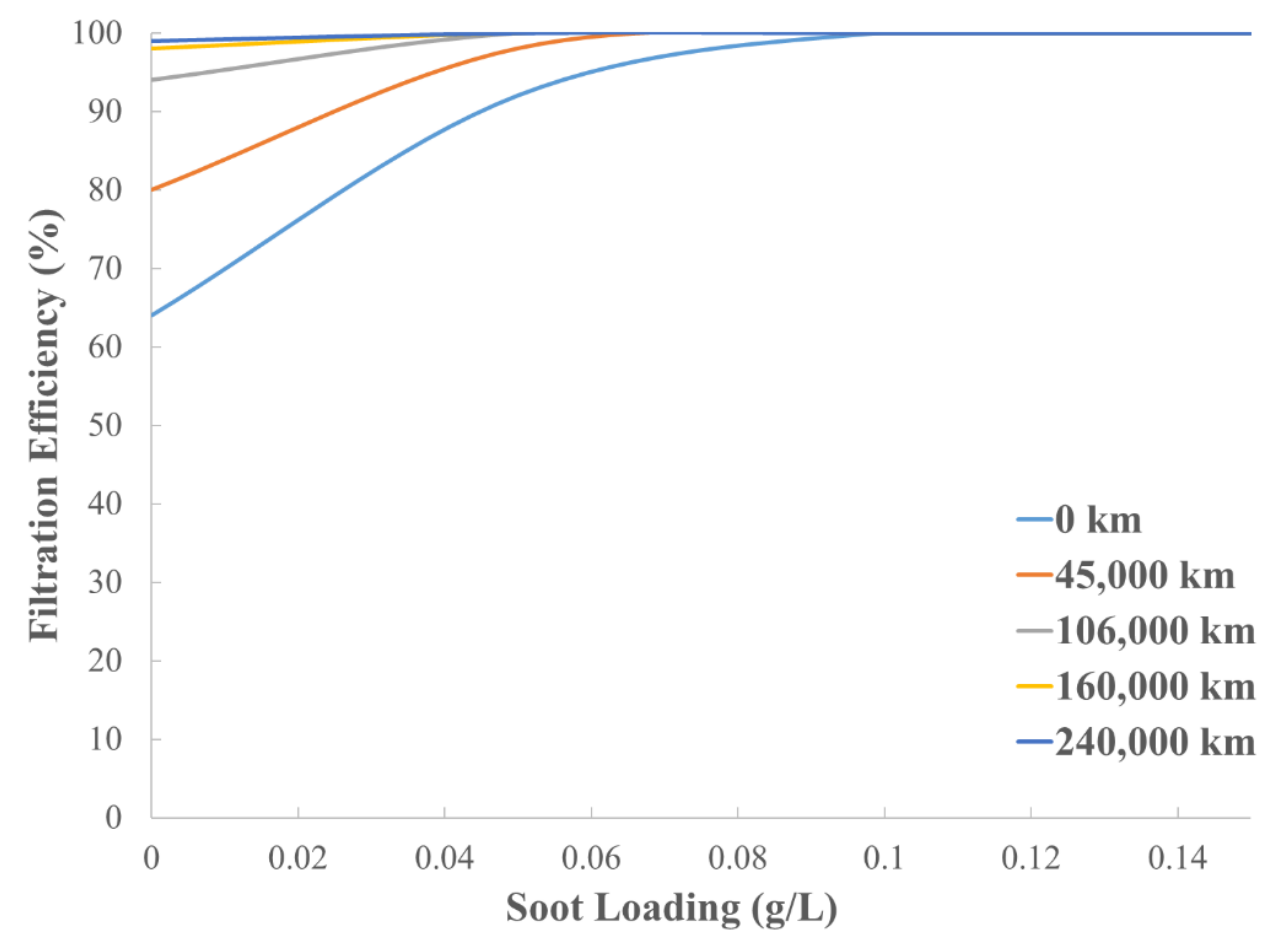

Figure 4: Effect of ash accumulation on the filtration efficiency of a particulate filter [8] 
In addition to the improvements in filtration efficiency, the accumulated soot and ash result in an increased pressure drop across the filter. Pressure drop can affect the overall performance of the engine in terms of reduced power and increased $\mathrm{CO}_{2}$ emissions (which differs depending on several factors including engine size and exhaust system size and complexity). The accumulated soot can oxidize and burn off through passive regeneration whereas the accumulated ash stays in the filter throughout its life cycle and increases as more mileage is accumulated. Typically, GPFs are designed for the lifetime of the vehicle and optimized to account for the pressure drop through design parameters (wall thickness, porosity, cell density, diameter, length) specific to each application, in addition to On-Board Diagnostics (OBD) controls.

\subsection{Particle Number (PN) Filtration Efficiency (FE)}

\subsubsection{Effect of Changing Mean Pore Size (MPS) on the PN Filtration Efficiency in a Catalyzed GPF}

The following study, [20], examined the effect of MPS (measured using mercury porosimetry), on the pressure drop across a catalyzed GPF. The GPFs tested had the same porosity range ( $60 \%$ to 65\%) but different MPS (where an MPS lower than $10 \mu \mathrm{m}$ is considered small and bigger than 25 $\mu \mathrm{m}$ is considered large) and different levels of coating. Porosity is the ratio of volume of voids or pores to the total volume typically expressed in percentage [26]. For both low and high levels of coating, larger MPS led to a lower pressure drop after coating. As shown in Figure 5, an increase in PN after the filter is measured with increasing MPS which indicated a decrease in filtration efficiency. Therefore it is necessary to determine a balanced MPS in view of pressure drop and PN 
filtration efficiency [20]. For these reasons, Filters B and C were selected in this research, which have a larger MPS than filters A and D and the findings will be discussed in the results section of this thesis.

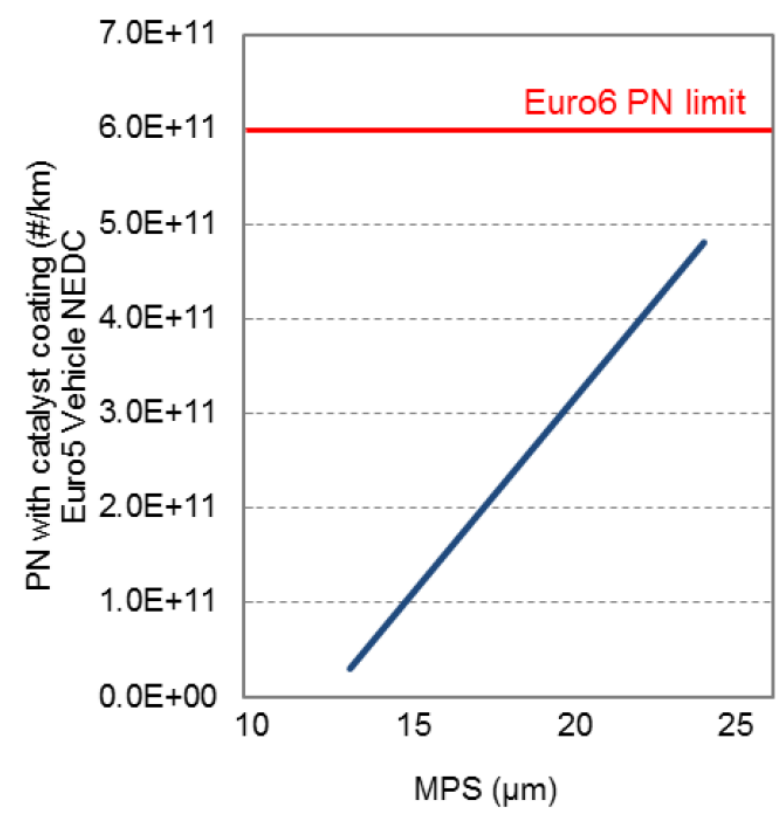

Figure 5: Impact of Mean Pore Size (MPS) on Particle Number (PN) emissions [20] (written permission obtained to use figure)

\subsubsection{Effect of Changing Wall Thickness and Cell Density on PN Filtration Efficiency}

There are two other important factors to consider when optimizing GPF filtration efficiency which are cell density (in cpsi or cells per square inch) and wall thickness (in mil where 1 mil is equal to 0.001 in or $0.0254 \mathrm{~mm}$ ). Cell density, in cpsi, is the number of channels per unit of cross sectional area and calculated (for square cell geometry as used in this study) according to Equation 1 [27].

$$
N=\frac{1}{s^{2}}
$$


where: $\mathrm{N}$ is the cell density in cells per square inch (cpsi), and $\mathrm{s}$ is the sum of cell length and wall thickness.

A study was conducted to investigate these effects, first by maintaining the cell density at 300 cpsi and changing the wall thickness and the second by maintaining the wall thickness at 12 mil and changing the cell density [20].

PN filtration efficiency was determined according to Equation 2:

$$
G P F_{P N F E}=\frac{P N_{\text {stock } G D I}-P N_{\text {post }-G P F}}{P N_{\text {stock } G D I}} \times 100 \%
$$

where $P N_{\text {stock GDI }}$ and $P N_{\text {post-GPF }}$ represent the particle number emission rates for stock GDI and post GPF configuration, respectively. 
(a)

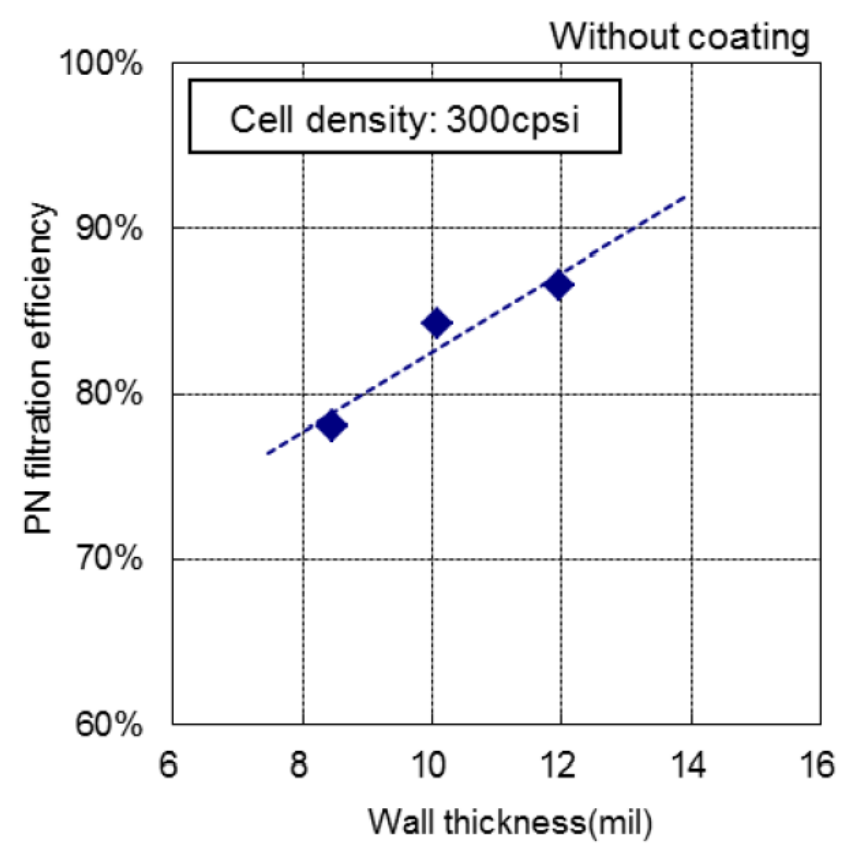

(b)

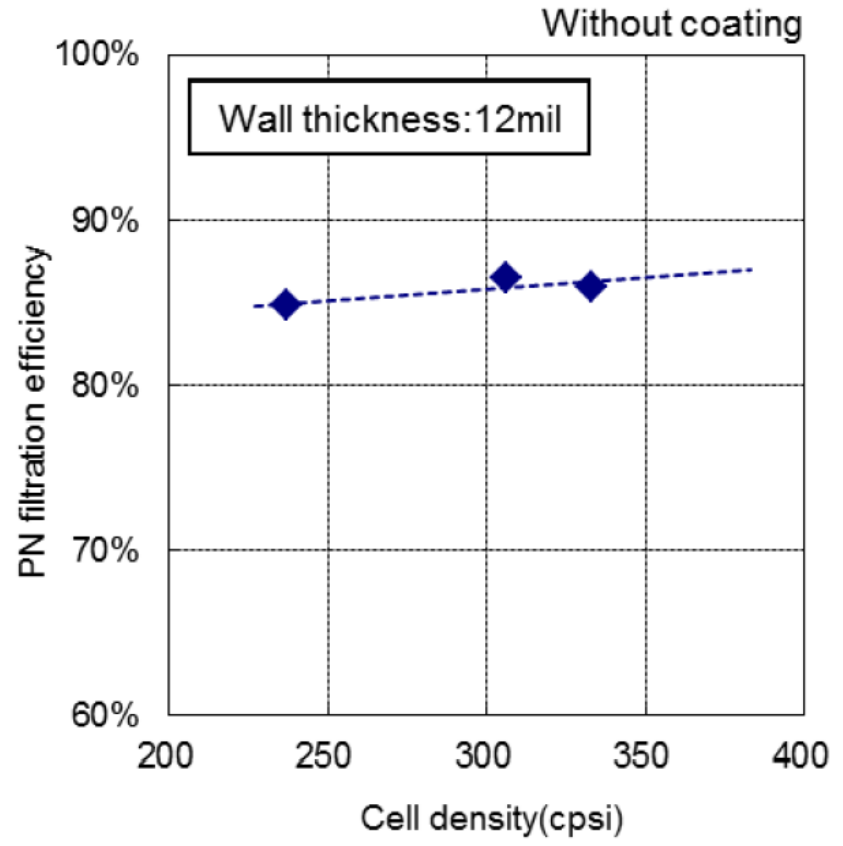

Figure 6: (a) Impact of wall thickness on particle number filtration efficiency (65\% porosity) (b) Impact of cell density on particle number filtration efficiency (65\% porosity) [20] (written permission obtained to use figures)

As Figure 6 (a) shows, wall thickness had a greater effect on filtration efficiency compared to the impact of cell density shown in Figure 6 (b). This suggests that an excessively thin wall would not be a preferable design in terms of filtration efficiency considerations [20]. As part of this research, Filter $\mathrm{C}$ was chosen with a larger wall thickness of 12 mil (12 thousands of an inch or $0.3048 \mathrm{~mm}$ ) in order to observe the effect of thickness on the emission profile and filtration efficiency. 


\subsection{GPFs in GDI Vehicles}

After investigating various GPF design considerations, it is realized that the effects of installing an already optimized GPF on the emission profile of GDI vehicles shall be investigated, considering that most GPF applications will be on GDIs.

Chan et al. [15] evaluated the particle emission reduction from a wall-guided GDI vehicle with the use of a GPF. Table 1 summarizes how the particle measurements were conducted in their research.

Table 1: Particle sampling methods [22]

\begin{tabular}{|l|l|}
\hline \multicolumn{1}{|c|}{ Measurement Method } & \multicolumn{1}{|c|}{ Comments } \\
\hline $\begin{array}{l}\text { Particle Measurement Program } \\
\text { (PMP) system which included an } \\
\text { Engine Exhaust Condensation } \\
\text { Particle Counter (EECPC) and an } \\
\text { Ultrafine Condensation Particle } \\
\text { Counter (UCPC) }\end{array}$ & $\begin{array}{l}\text {-Sampled exhaust diluted using a Constant Volume } \\
\text {-Coarse particle were removed by a } 2.5 \mu \mathrm{m} \text { cyclone } \\
\text {-Remaining particles were introduced into a Volatile } \\
\text { Particle Remover (VPR) which removed the majority of } \\
\text { the volatile materials }\end{array}$ \\
\hline \multirow{5}{*}{-EECPC had a 50\% counting efficiency at $23 \mathrm{~nm}$} \\
& -UCPC had a minimum detection limit 3 nm \\
\hline & $\begin{array}{l}\text {-Particles were electrically charged by a corona and then } \\
\text { exposed to a uniform electric field where positively } \\
\text { charged particles were expelled toward different } \\
\text { electrometers based on their electric mobility. Charges on } \\
\text { the particles were transferred and measured upon the } \\
\text { contact of the particles onto the electrometers } \\
\text {-A lower dilution ratio was used to lower the impact of } \\
\text { electrical noise on the measurement signals } \\
\text {-A thermodenuder was used to remove volatile } \\
\text { components from the particles }\end{array}$ \\
\hline Teflon and fired quartz filters & $\begin{array}{l}\text {-Teflon samples were used for gravimetric analysis } \\
\text {-Inductively Coupled Plasma Mass Spectrometry (ICP- } \\
\text { MS) was used on select Teflon samples for metal analysis } \\
\text {-Thermal analysis was conducted on the quartz filters to } \\
\text { determine organic and elemental carbon content fractions }\end{array}$ \\
\hline
\end{tabular}


In this thesis, a similar Engine Exhaust Particle Sizer (EEPS) configuration was chosen to measure the particle size distribution (particle number concentration vs electric mobility diameter) to observe the effects of different GPFs on the particle number filtration efficiency at different particle electric mobility diameters.

\subsubsection{Particle Number Emission Rate}

Figure 7 compares particle number emission rates between stock and post-GPF configurations using two fuels E0 ( $0 \%$ ethanol) and E10 (10\% ethanol). It shows how effective an optimized GPF can be at reducing particle emissions from GDI vehicles.

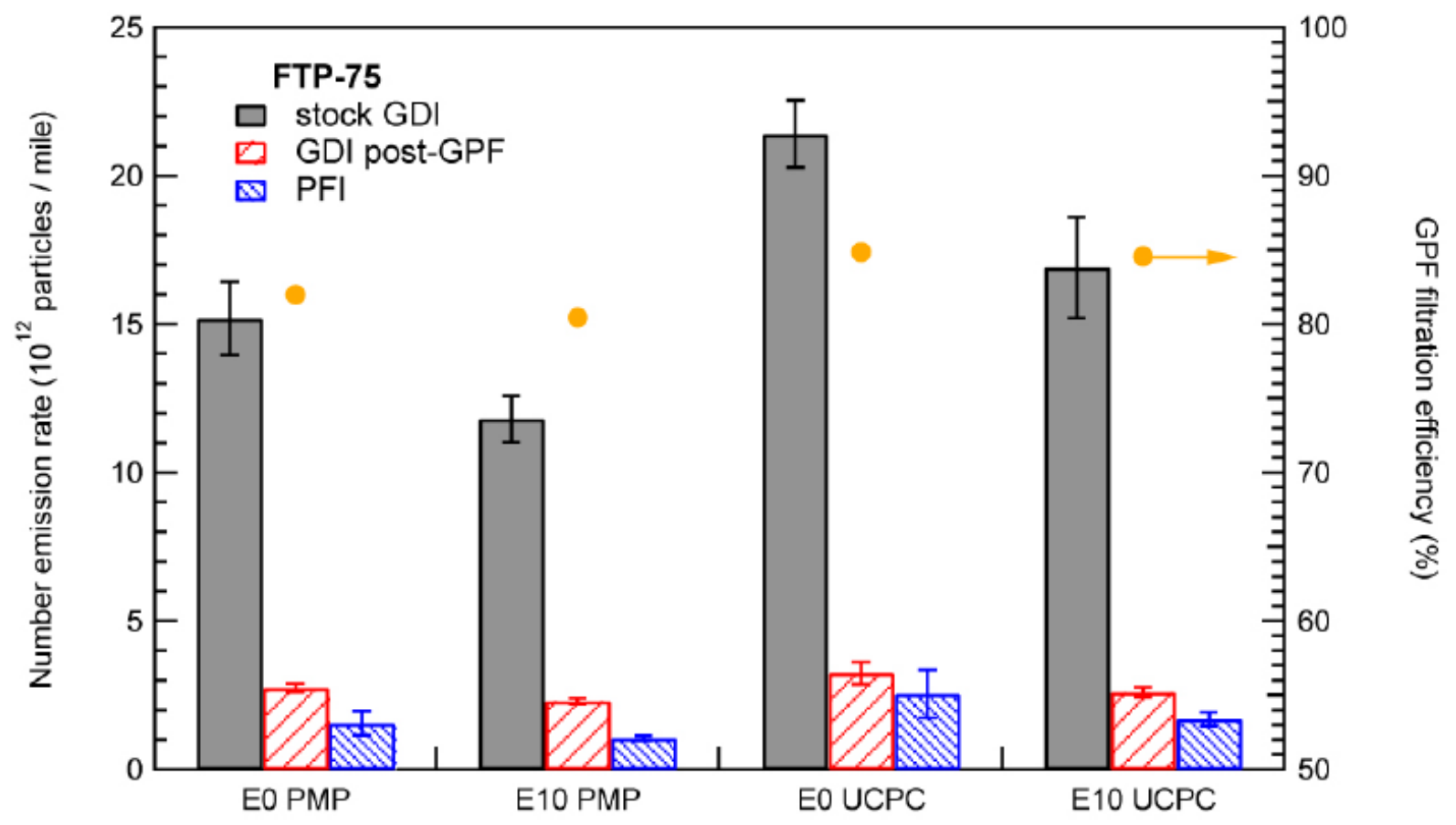

Figure 7: Particle number emission rates for the FTP-75 drive cycle. The Gasoline Particulate

Filter filtration efficiency is represented by the circle markers [22] (written permission obtained to use figure) 
Results showed a significant reduction in particle number emissions in the post-GPF GDI configuration with a filtration efficiency of $82-85 \%$ for E0 ( $0 \%$ fuel Ethanol content) and $80-85 \%$ for E10 (10\% fuel Ethanol content) [22]. The results also support other studies that have shown that GDI engines produce higher PN emissions than PFI engines [1]. The PN emissions post GPF for the GDI vehicle were more comparable to those from the PFI vehicle indicating that a GDI + GPF configuration is a potential alternative to a PFI configuration. This insures higher efficiency while maintaining lower PN emissions. Filtration efficiency was calculated using the following equation [22]:

$$
G P F_{\text {eff }}=\frac{N_{\text {stock } G D I}-N_{\text {post }-G P F}}{N_{\text {stock } G D I}} \times 100 \%
$$

where $N_{\text {stock GDI }}$ and $N_{\text {post-GPF }}$ represent the particle number emission rates for stock GDI and post GPF configuration consecutively.

Other studies have shown the effects of adding a GPF in a closed coupled position (as shown in Figure 3) on the PN emissions of a turbocharged 1.2 L gasoline direct injected (GDI) light duty vehicle. Figure 8 shows a reduction in PN emissions for both drive cycles used, the WLTC (The Worldwide harmonized Light Vehicles Test Cycle) and the RTS-95 (based on the WLTC cycle but represents more aggressive driving) [8]. This study displayed the efficiency of GPFs at reducing $\mathrm{PN}$ emissions at different driving conditions. 

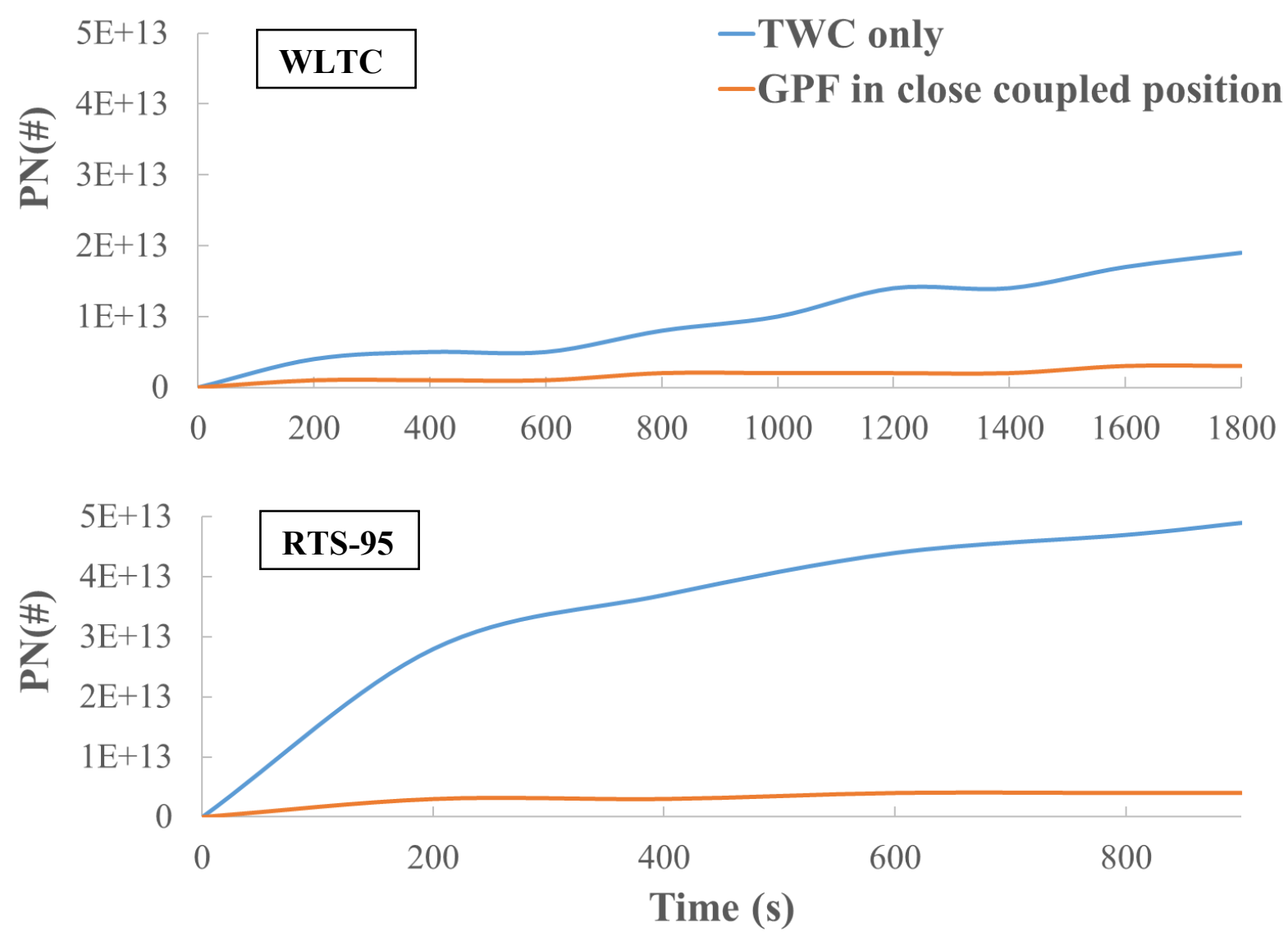

Figure 8: Effects of a Three-Way Catalyst (TWC) alone compared to a Three-Way Catalyst + Gasoline Particulate Filter (GPF) on the Particle Number (PN) emissions

\subsubsection{Effect of GPF on the Size and Morphology of Soot Particles from a GDI Vehicle}

In a different study, Saffaripour et al. [28] investigated the effects of a custom coated GPF on the size and morphology of soot particles characterized by Transmission Electron Microscope (TEM) image analysis. A point to plane electrostatic precipitator (ESP) was used for collecting particle samples where a carbon-coated copper TEM grid was used as the sampling substrate. The particulate samples were characterized using a Philips CM20 TEM operating at an accelerating 
voltage of $120 \mathrm{kV}$ and under high vacuum condition. TEM images were captured using a Gatan CCD camera with 1024 x 1024-pixel dimension and analyzed using ImageJ 1.47 software [28].
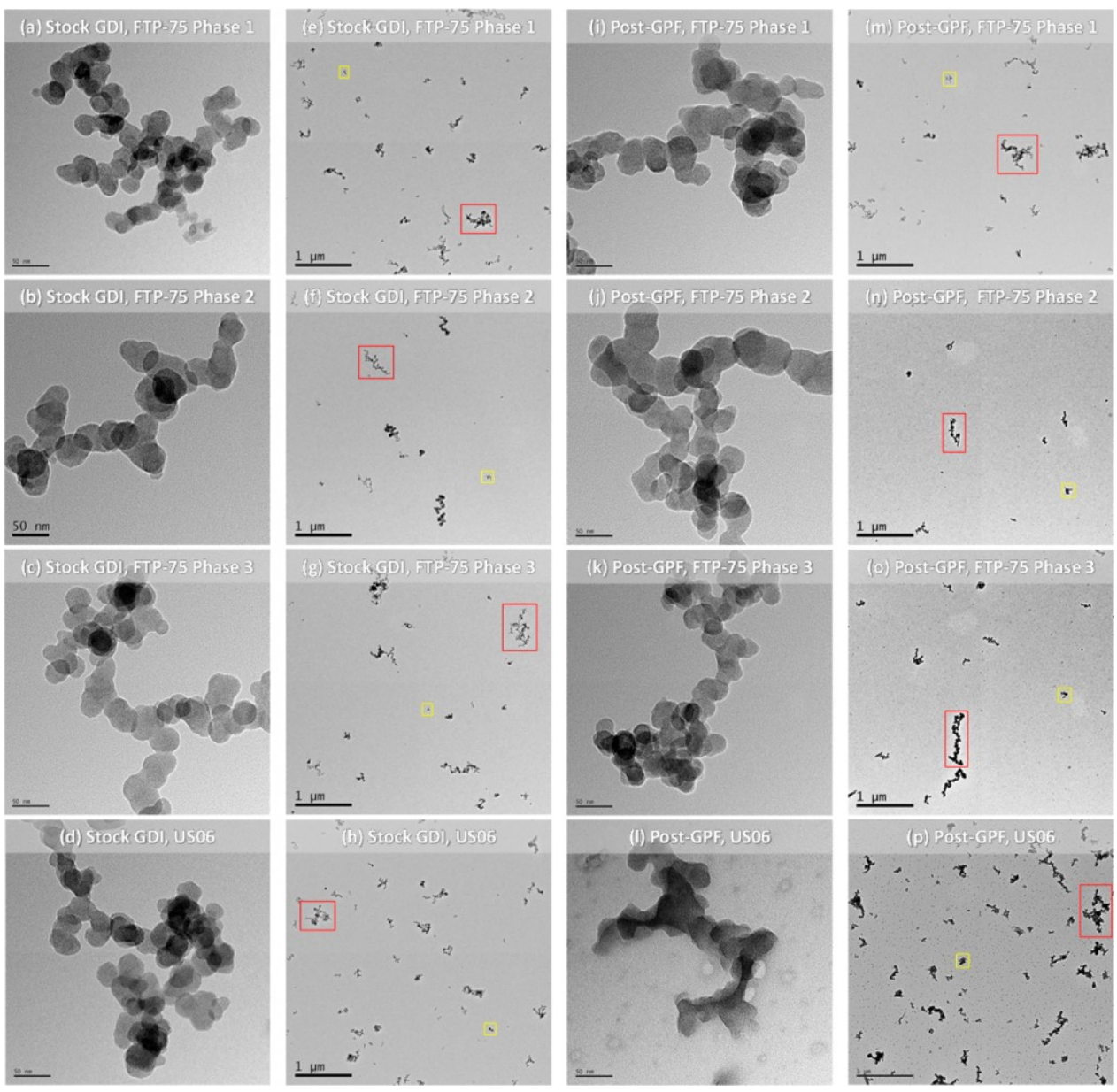

Figure 9: TEM images of soot particles produced by the stock GDI (a-h) and the GPF-equipped (i-p) vehicles at magnifications of 61,000 time (a-d and i-l) and 4,500 times (e-h and m-p) emitted over FTP-75 and US06 drive cycles [28]. (written permission obtained to use figure)

Figure 9 shows the TEM images of soot particles produced by a GDI vehicle. The red squares show the very large aggregates emitted by the vehicle and the yellow squares show the small aggregates [28]. FTP-75 (Federal Test Procedure used to measure tailpipe emissions) results showed carbonaceous particles for both stock and post GPF configurations. However for the US06 
(supplemental federal test procedure, typically characterized by harder accelerations), results showed carbonaceous particles for the stock configuration and amorphous aggregate coated with semi-volatile material and nucleation mode particles for the post-GPF configuration [28]. The formation of nucleation mode particles could be attributed to several mechanisms including: sulfuric-acid and water droplets acting as condensation sites, homogeneous nucleation of organic species, and GPF regeneration [28]. Within the nucleation mode particles, solid non-volatile cores were observed as seen in Figure 10.

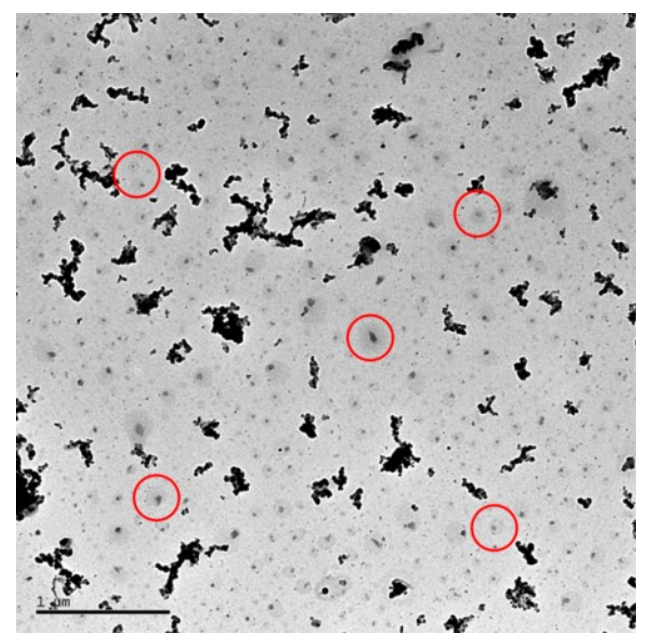

Figure 10: High-contrast spots, most likely solid non-volatile cores seen within many of the nucleation mode particles emitted by the GPF equipped vehicle over the US06 drive cycle [28]. (written permission obtained to use figure)

The formation of these core structures could be attributed to the following reasons: the partial carbonization of incipient soot particles, condensation of organic material on pre-existing nonvolatile carbonaceous cores, condensation of organic material on metal nanoparticles, and evaporation of volatile material from the collected samples [28]. 
Other studies have used SEM analysis to show the soot and ash accumulation on the filter wall as shown in Figure 11 [8]. As more mileage is accumulated on a vehicle equipped with a GPF, ash starts to accumulate inside the filter in addition to soot. As the ash layer starts of form and becomes more developed, soot starts to deposit on the ash layer as opposed to on the filter wall. In this research, not enough operating hours were accumulated on the engine in order to observe an ash layer, however a developed soot layer could be observed on the filter wall (Section 4.2.4).

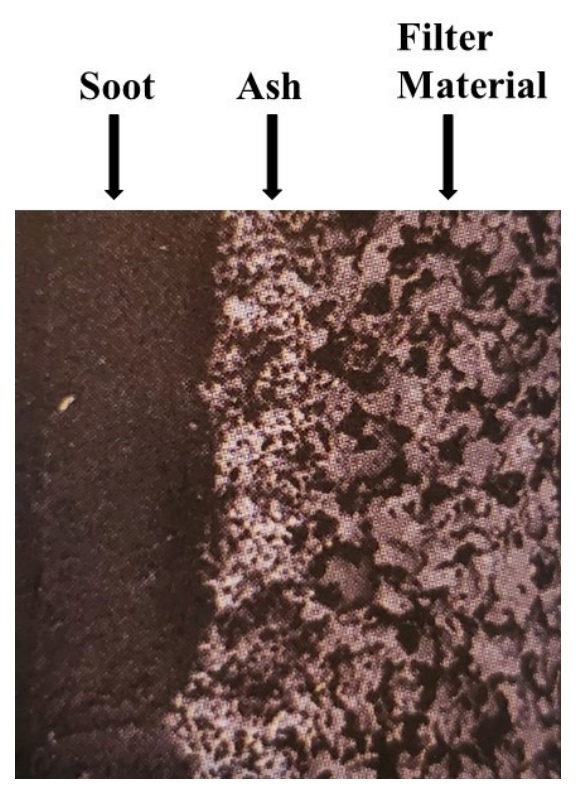

Figure 11: SEM image showing the accumulation of ash and soot in a GPF [8]

\subsection{Soot Layer Deposition in Particulate Filters}

As discussed in Section 2.3, in particulate filters, the exhaust enters the filter through the inlet channels and is forced through the porous filter wall where some of the soot is deposited in the pores and on the wall, i.e. being filtered. The exhaust stream then exits the filter through the outlet channels. There are several studies that examined the soot deposition in terms of the soot layer 
(also called "soot cake") thickness. Toops et al. [29] investigated the soot layer properties in diesel particulate filters. Ceramic diesel particulate filters may differ from ceramic gasoline particulate filters in terms of wall thickness and mean pore size however the wall flow filtration mechanism and soot cake deposition are comparable [29].

As shown in Figure 2, particulate filters have a honeycomb structure consisting of inlet and outlet channels. According to Toops et al. [29], the particulate layer thickness, Tp, is calculated using the average wall length of the closed channel, L1, and the average wall length of the open channel, $\mathrm{L} 2$, where $\mathrm{Tp}=(\mathrm{L} 1-\mathrm{L} 2) / 2$. Figure 12 shows the dimensions of L1, L2 and Tp. The reduction in the average channel length (L2 < L1) is due to the accumulated soot on the inlet channels represented by the black border around the open channel diagram. Tp represents the average thickness of the accumulated soot layer around the inlet channels.

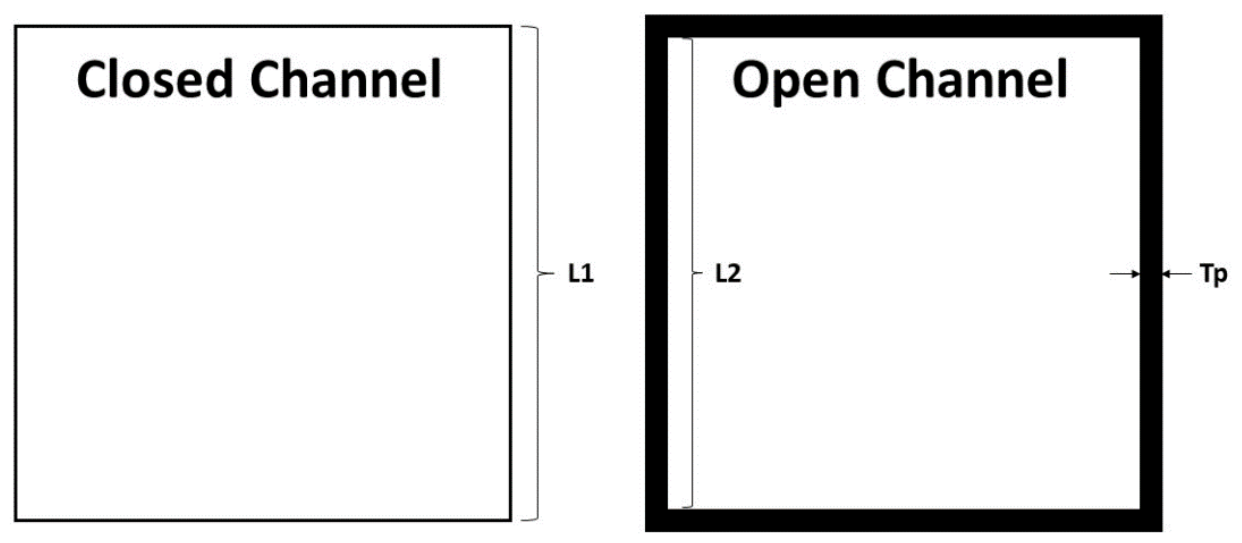

Figure 12: Soot layer thickness in particulate filters.

In this thesis, Scanning Electron Microscope (SEM) images were analyzed in order to approximate the particulate layer thickness and compare the results to that published by Toops et al. [29], as shown in Figure 13. 


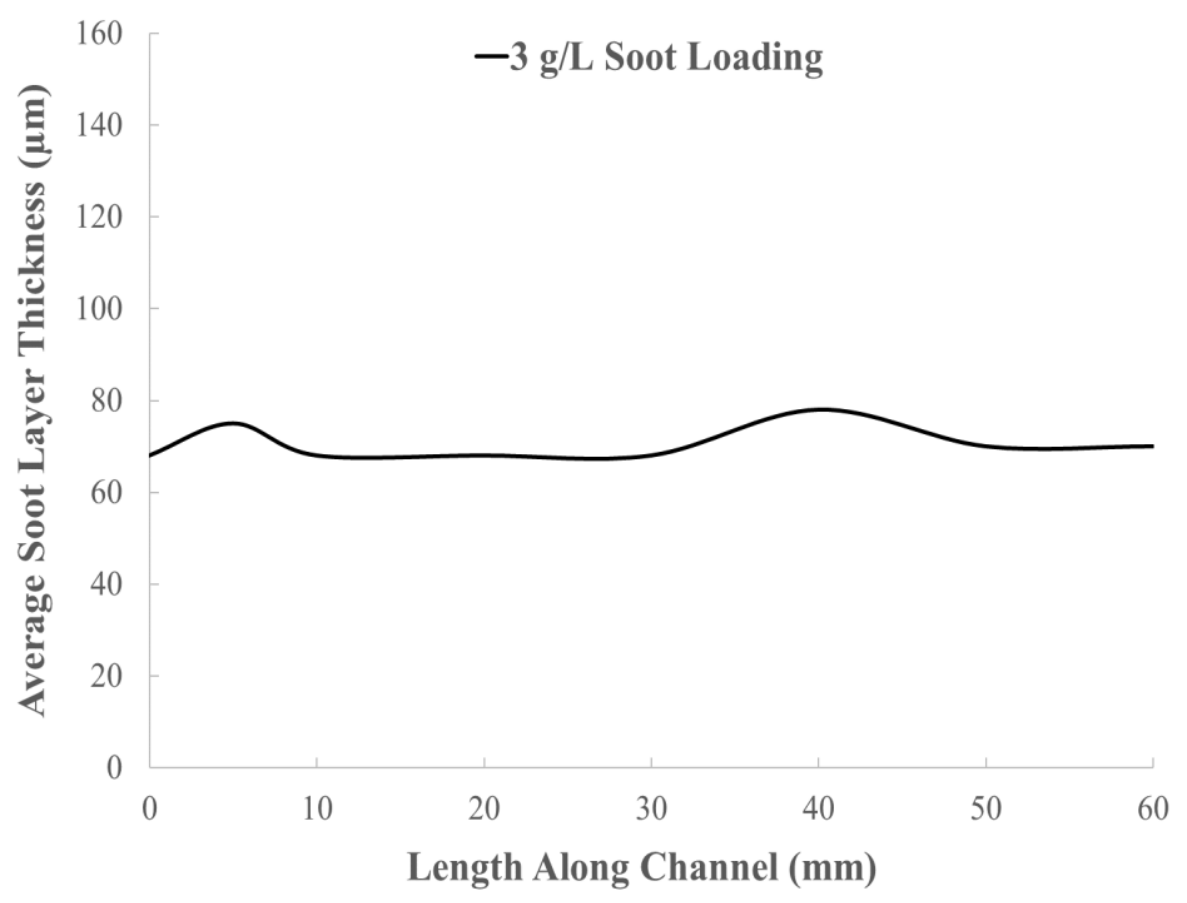

Figure 13: Average soot layer thickness with $3 \mathrm{~g} / \mathrm{L}$ of soot loading on a particulate filter [29]

\subsection{Gasoline Particulate Filter Development}

As discussed in the Introduction of this thesis, tightened particulate matter (PM) emission standards due to the high market influx of gasoline direct injection vehicles in addition to an overall better understanding of the negative health implications of PM are the main driving factors for GPF development. The early stages of GPF development (starting in 2008) were characterized by adopting diesel particulate filter (DPF) technology [8]. Early GPFs resulted in the reduction of gasoline vehicle PM emissions but at a much reduced efficiency compared to DPFs in diesel vehicles. The early GPF designs also resulted in a high pressure drop across the exhaust systems which was amplified by the lack of an active regeneration process to limit that pressure drop [8]. These issues highlighted the importance of focusing on the GPF material and configuration and 
optimize GPF parameters to account for the differences in PM characteristics in addition soot regeneration processes between gasoline vehicles equipped with GPFs and diesel vehicles equipped with DPFs. Since then, there have been significant improvements in GPF design resulting in PM filtration efficiencies higher than $80 \%$ with no significant effect on exhaust pressure drop and engine performance [8].

As discussed in the Literature Review section of this thesis, there are many parameters to consider when designing an optimized GPFs system such as material selection, wall thickness, mean pore size, porosity and physical size. The Literature Review also highlighted the importance of achieving a balance between these parameters and how changing one parameter can have a significant effect on the overall performance of the GPF. Despite the importance of all the parameters described, in practice there are two optimization limiting factors which are the packaging size (to allow the GPF to fit along the exhaust system neatly) and pressure drop (in order not to affect the performance of the engine and the fuel consumption).

As more progress is made in the field of GPF development, the optimization of parameters will remain to be a main focus area for manufacturers and researchers (focus of this thesis being an example of that). Two important focus areas which have gained traction in recent years are increasing the clean slate filtration efficiency, and expanding the filtration efficiency capability to target nanoparticles.

In terms of improving the clean slate filtration efficiency, several advancements have been made which include spraying the walls of a new GPF with an artificial ash. An ash layer forms as more mileage is accumulated on the GPF and the ash layer has been shown to improve the filtration efficiency of the GPF throughout its lifespan (as shown in Section 2.4.3). So in theory, adding an 
artificial ash layer to a new GPF should improve the filtration efficiency from the start without having to wait for an ash layer to develop naturally.

In terms of widening the filtration capability of GPFs to target nanoparticles, the research is still relatively new. Study results (including the results of this study, refer to Section 4.2.3.1) have shown that smaller particles (below $20 \mathrm{~nm}$ in primary diameter) can slip through unfiltered, even in an optimized GPF. It is important to capture these particles due to their ability to deposit on the lungs causing several adverse health effects.

The Introduction and Literature Review section in this thesis served as a source of information to better understand PM emissions from GDI engines, in addition to the importance of having a balanced GPF design in order to efficiently reduce those emissions. Four GPFs of different parameters were chosen as the basis for this thesis in order to continue the research in GPF development and highlight any limitations (such as nanoparticles slipping through unfiltered for example) that GPFs have. The results of this study, which demonstrate the effects of certain parameters on the performance of a GPF system were submitted to the GPF manufacturer to aid in their development efforts. 


\subsection{Methodology}

\subsection{GPF Specifications}

All the filters used in this study were made of cordierite. Filter specifications are shown in Table

2. The name of the supplier of the filters cannot be provided in this thesis due to a non-disclosure agreement.

Table 2: Filter specifications

\begin{tabular}{|c|c|c|c|c|}
\hline Filter & $\begin{array}{c}\text { Wall } \\
\text { Thickness } \\
(\mathbf{m i l}) *\end{array}$ & $\begin{array}{c}\text { Filter Size (D x L) } \\
(\mathbf{m m} \text { x mm) }\end{array}$ & $\begin{array}{c}\text { Porosity } \\
(\mathbf{\%})\end{array}$ & $\begin{array}{c}\text { Cell Density } \\
\text { (cpsi)** }\end{array}$ \\
\hline $\mathrm{A}$ & 8 & $\Phi 132.1 \mathrm{~mm} \times 127 \mathrm{~mm}$ & 55 & 200 \\
\hline $\mathrm{B}$ & 8 & $\Phi 132.1 \mathrm{~mm} \times 127 \mathrm{~mm}$ & 65 & 300 \\
\hline $\mathrm{C}$ & 12 & $\Phi 132.1 \mathrm{~mm} \times 127 \mathrm{~mm}$ & 65 & 300 \\
\hline $\mathrm{D}$ & 8 & $\Phi 101.6 \mathrm{~mm} \times 127 \mathrm{~mm}$ & 55 & 200 \\
\hline
\end{tabular}

* 1 mil is 1 thousandths of an inch or $1 / 40$ of a $\mathrm{mm}$ which is the standard unit for filter wall thickness

** cpsi is cells per square inch which is a standard unit for filter cell density

Cell density, in cpsi, is the number of channels (seen as square ducts on the face of the filters) per unit of cross sectional area and calculated (for square cell geometry as used in this study) as described in Equation 1 of this thesis. Cell density is different from porosity, which is the volume of voids over the total volume of the filter material where the voids or pores are in the filter wall. 

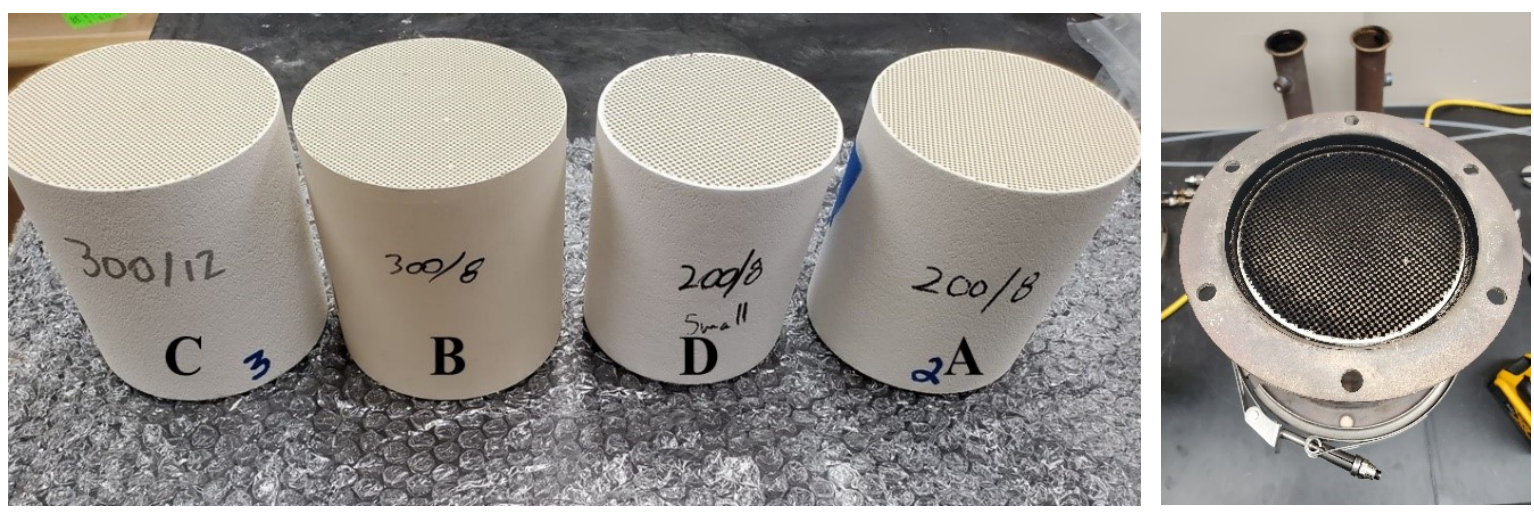

Figure 14: Gasoline Particulate Filters (GPFs) used during testing both canned and uncanned.

The GPFs were fitted in a steel can in order to mount on the bench setup and on the engine.

\subsection{Bench Testing Methodology}

\subsubsection{Soot Generation using miniCAST}

A miniCAST model 5201 soot generator (manufactured by Jing Ltd., Switzerland) is used to produce soot with soot particle sizes (electric mobility diameters as measured using the TSI Engine Exhaust Particle Sizer) ranging from 20 to $200 \mathrm{~nm}$ and a concentration of $10^{7}$ to $10^{8}$ particles $/ \mathrm{cm}^{3}$. In the miniCAST, soot is produced by the pyrolysis process where propane is mixed with insufficient air. As insufficient air is supplied to the fuel during combustion, the formation of soot is formed. Nitrogen $\left(\mathrm{N}_{2}\right)$ is then used as a quench gas to stop further combustion. The formed soot is then mixed with dilution air and expelled from the mini-CAST. The size of the soot particles is controlled by changing the flow rate of the quench gas. Figure 15 shows the principle of the $\operatorname{miniCAST}$. 


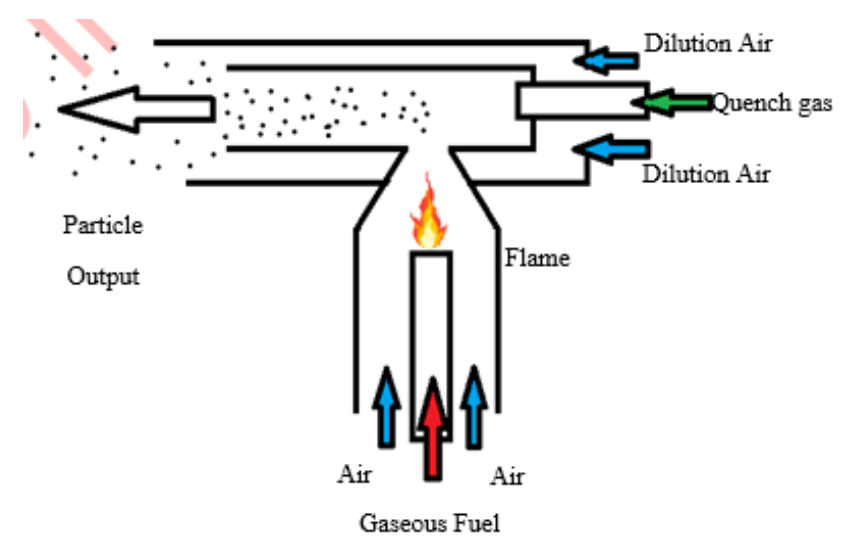

Figure 15: miniCAST soot generator principle [30]

In this study, the settings for the soot generator were chosen in order best represent Gasoline Direct Injection Engine particulate matter emissions. The soot generator was operated in automatic mode high Elemental Carbon (EC) low Organic Carbon (OC) flame conditions (preset operating point 1 (OP1) as indicated in the manual [30]). Operating point 1 produces the largest electric mobility diameter particles. Discussions with particulate matter experts at the National Research Council revealed that any set points other than operating point 1 do not represent the emissions of an engine or a real-world flame.

Studies have shown that the miniCAST soot generator using propane as a combustion source for soot is a suitable device to investigate particle emissions [31]. Figure 16 shows a comparison between the particle size distributions of soot generated using gasoline direct injection and propane injection. Results show a comparable trend where the electric mobility diameter mode was $163 \mathrm{~nm}$ for the gasoline injection and $157 \mathrm{~nm}$ for the propane injection. Other studies have shown Elemental Carbon and Organic Carbon composition of the soot generator at the different preset operating points [32]. Figure 17 shows the EC/OC ratio for four operating points including 
operating point 1 used in this study. OP1 was selected due to its high EC and low OC flame conditions.

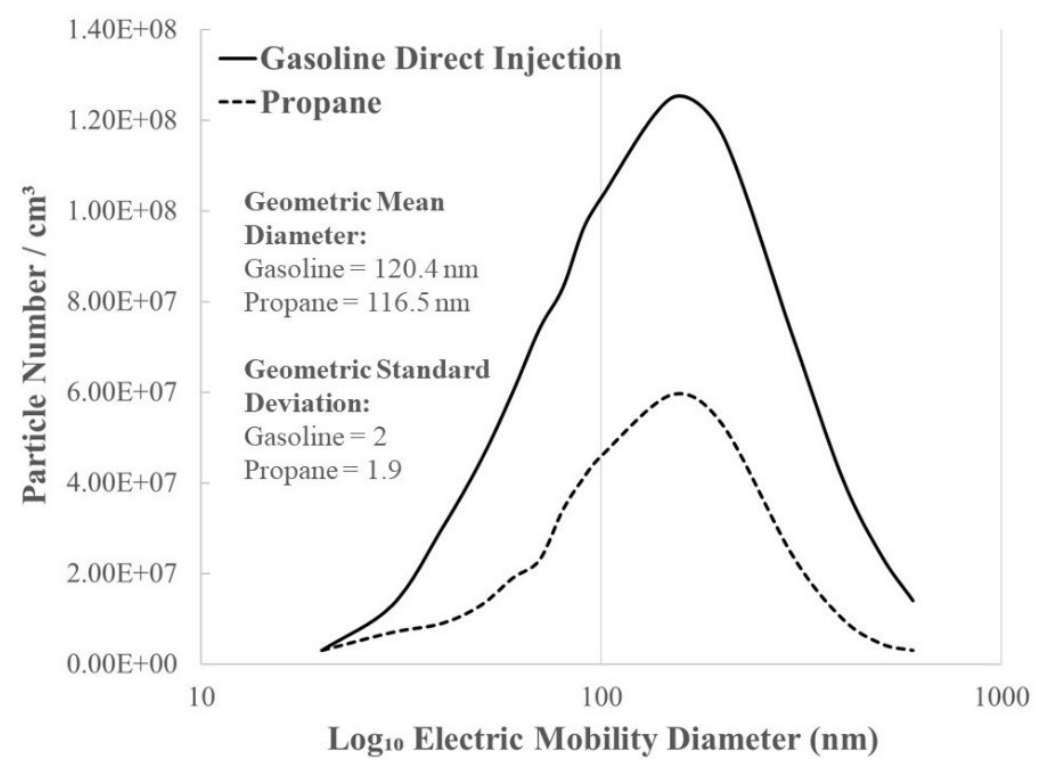

Figure 16: Particle size distribution for gasoline direct injection compared to propane [31]

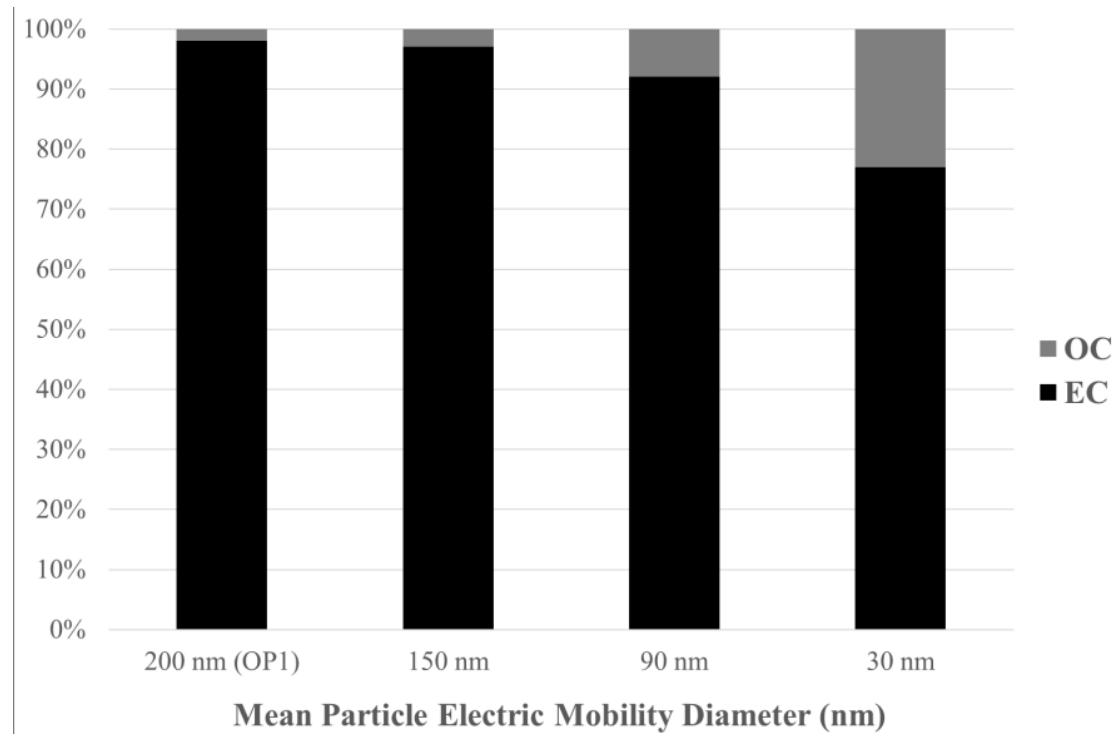

Figure 17: EC/OC soot ratios at different mean particle electric mobility diameter for the soot generator [32] 


\subsubsection{Bench Test Procedure using miniCAST}

All four filters were tested first with a bench setup using the miniCAST soot generator as the source of particulate matter. The filters were connected to the exhaust stream using a filter holder with instrument sample probes as shown in Figures 18 and 19.

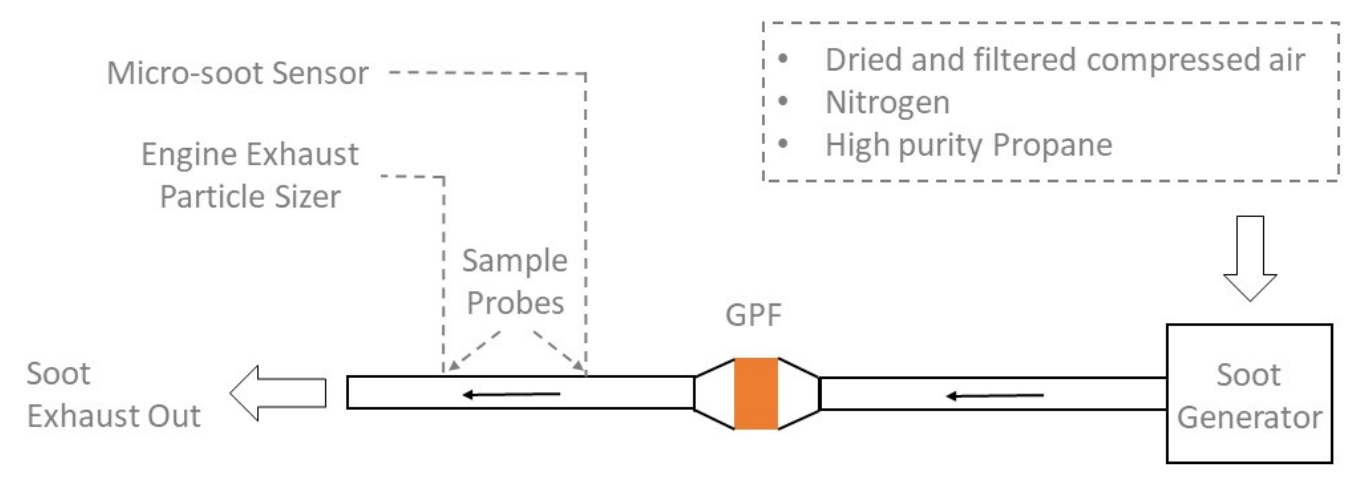

Figure 18: Soot generator bench setup diagram

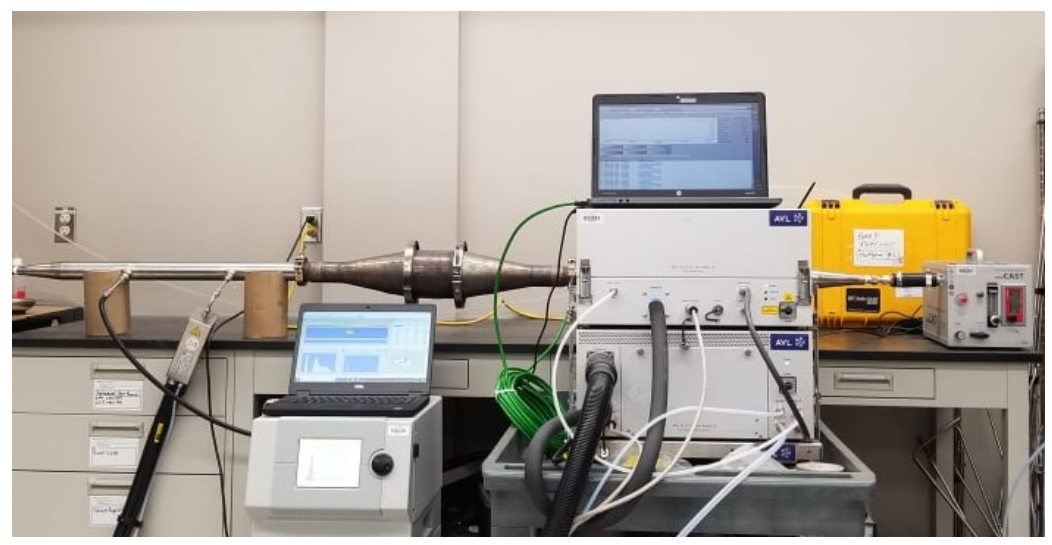

Figure 19: Soot generator bench setup picture. The setup was designed by the current investigator and the components built with the help of the machine shop at the Emissions Research and Measurement Section of Environment Canada. 
Pre-filter or raw miniCAST emissions were first collected as a basis for filtration efficiency (FE) calculations. Post-filter emissions were then collected according to the following testing sequence:

1) All instruments were started prior to directing the miniCAST exhaust stream through the filters in order to capture the clean slate FE.

2) Each steady state test was run for 10 minutes.

3) After every test the filters were heated in an industrial oven at $700{ }^{\circ} \mathrm{C}$ for 5 hours in order to burn off the accumulated soot and return the filter to "as-received" state in order to ensure repeatability. The oven program is described in Figure 20. The filters were inserted in the oven at ambient temperature and then heated gradually (automatic through the oven program), over a span of two hours, to $700{ }^{\circ} \mathrm{C}$. The filters were left in the oven at $700{ }^{\circ} \mathrm{C}$ for 5 hours. After the 5 hours, the oven was programed to turn off automatically to allow for the filters to cool slowly back to ambient temperature (typically around $22{ }^{\circ} \mathrm{C}$ ). This method to burn off any soot, in addition to any volatile material accumulated on the filter was developed through consultation with the GPF manufacturer. It is considered to be the standard method used during GPF development.

4) Filtered and dry compressed air was then blown into the filters to clean any lingering soot.

5) Testing of each filter was repeated three times i.e. the same filter was used for all three tests at each specifications. In total, four filters were used in the bench testing with a total of 12 tests overall. 


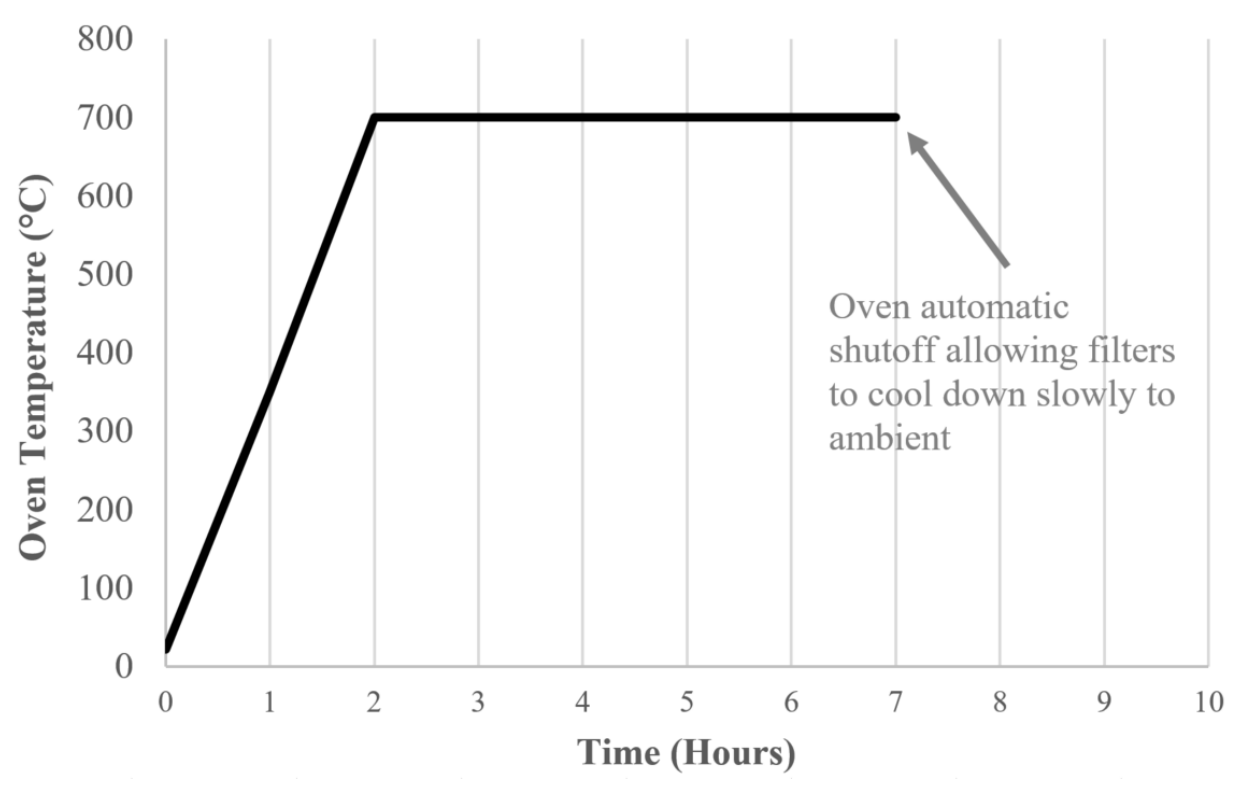

Figure 20: Gasoline Particulate Filter (GPF) baking sequence

\subsubsection{Soot and Total Particulate Matter Measurements using the Micro-Soot Sensor}

The AVL MSS uses a photoacoustic technique to capture the soot mass concentrations (AVL is the manufacturer of the MSS). With the photoacoustic measurement method, shown in Figure 21, the exiting gas containing soot particles is exposed to a modulated laser $(808 \mathrm{~nm})$. The expansion and contraction of the particles due to the periodic warming and cooling generates a sound wave that can be detected by microphones inside the module [33]. 


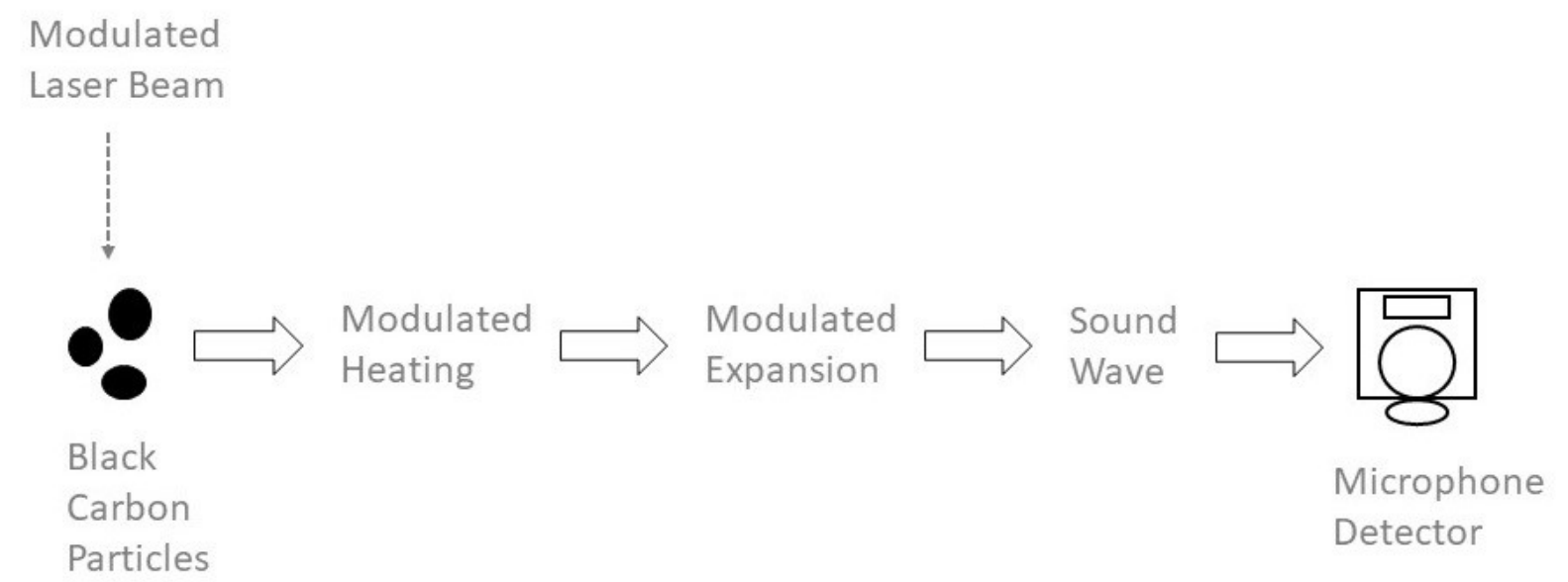

Figure 21: Photoacoustic measurement method diagram

\subsubsection{Particle Size Distribution Using the TSI Engine Exhaust Particle Sizer}

The EEPS measures the distribution of particle electric mobility diameter from 5.6 to $560 \mathrm{~nm}$ [34]. After the sample in the exhaust enters the EEPS, it is charged by a negative unipolar charger to bring the charge state of the aerosol to a uniform polarity and then by a positive unipolar charger [34] (one theory to explain the charged particles is the ion-induced nucleation theory in the formation of exhaust particulate matter. It is believed that it is essential for nuclei mode particles to possess a significant charge in order to achieve stable and observable sizes [35]). The sample aerosol is then transported down an annular region by a stream of clean sheath air [34]. As the aerosol moves down the column, the positively charged particles are repelled from the center column and impact the electrometers ( 22 in total) that make up the outer column, transferring their charge [34]. Depending on the electric mobility of particles (diameter and state of charge), they impact on specific electrometers [34]. The electrostatic principle in the EEPS is shown in Figure 22. 


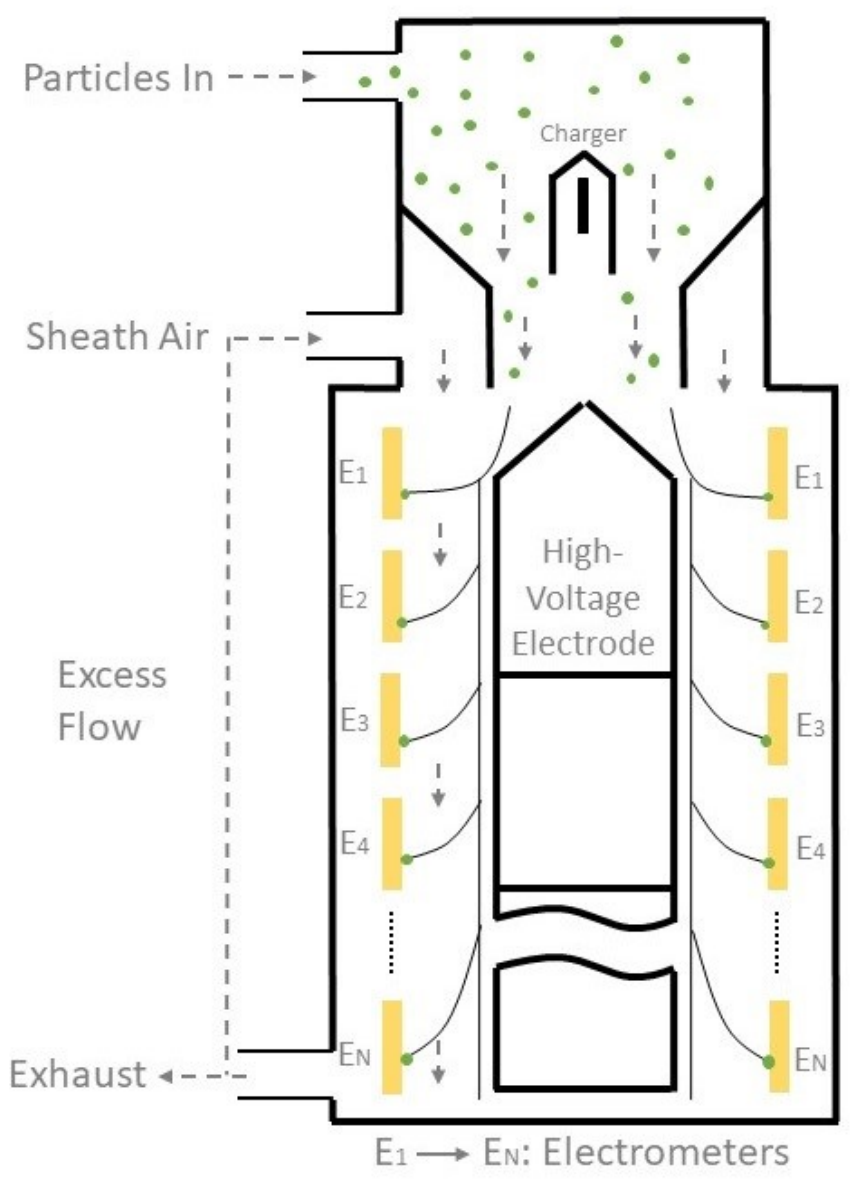

Figure 22: EEPS electrostatic principle diagram

\subsubsection{TEM Grid Collection Using the ESPnano}

In an Electrostatic Precipitator (ESP) particle sampler, the exhaust sample is directed through a flow channel in an intense electric field [36]. Any charged particles that enter the electric field drift towards the collection grid at a velocity determined by their electric mobility [36]. The grids are then analyzed using a transmission electron microscope. Figure 23 shows an image of the ESP Nano device. The Copper grids were mounted in the TEM Grid Holder and the Exhaust In 
connection was connected to the ESP Nano on one side and to the exhaust stream in the Constant Volume Sampling (CVS) system which is in turn connected to the engine.

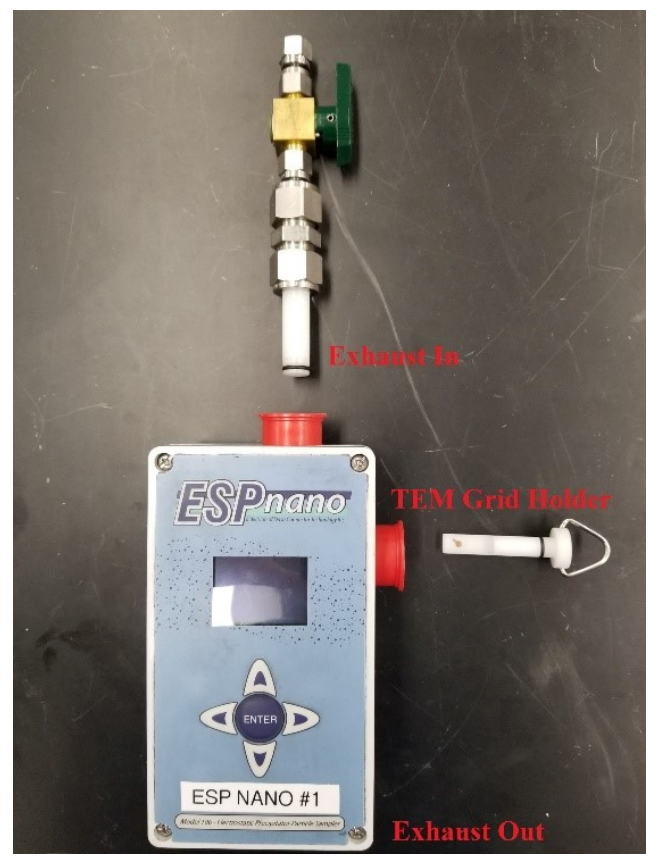

Figure 23: Electrostatic precipitator instrument for PM collection on TEM copper grids

\subsection{Engine Testing Methodology}

\subsubsection{Engine Specifications}

New filters with the same specifications as the ones used in the soot generator testing were installed on a Gasoline Direct Injection Engine. Engine specifications are shown in Table 3. 
Table 3: Engine specifications

\begin{tabular}{|c|c|}
\hline Make & General Motors \\
\hline Model & Ecotec 2.5L I4 VVT DI \\
\hline Displacement & $2384 \mathrm{cc}$ \\
\hline Fuel System & Direct Injection \\
\hline Horsepower (hp) @ rpm & $182(136 \mathrm{~kW}) @ 6700 \mathrm{rpm}$ \\
\hline Torque (lb-ft) @ rpm & $172(233 \mathrm{Nm}) @ 4900 \mathrm{rpm}$ \\
\hline Compression Ratio & $11.2: 1$ \\
\hline Maximum Engine Speed (rpm) & 7000 \\
\hline
\end{tabular}

\subsubsection{Testing Sequence}

Each filter was tested according to the following test sequence:

1) The instruments were set to measurement and recording before the engine was turned on in order to capture cold start emissions.

2) Mode 1: the engine was turned on and let idle for 15 seconds.

3) Mode 2: over the span of 10 seconds, the engine speed was ramped up to $1978 \mathrm{rpm}$ at approximately 119 N.m. (Note: 1978 rpm and 119 N.m were chosen based on an average engine speed and torque from a test typically used on light duty vehicles and developed in-house at the Emission Research and Measurement Section of Environment and Climate Change Canada).

4) Mode 3: a steady state was maintained at $1978 \mathrm{rpm}$ for 15 minutes.

5) Mode 4: over the span of 10 seconds, the engine speed was ramped down to idle speed and the engine was turned off.

6) The test cycle ended after mode 4 was completed. 
7) After every test, the filters were heated following the procedures highlighted in Section 3.3.2 of this thesis in order to burn off the accumulated soot and return the filters to clean slate condition.

8) The test sequence was repeated 3 times for each filter i.e. the same filter was used for all three tests at each specifications. In total, four filters were used in the engine testing with a total of 12 tests overall. Note that the four filters used in the engine testing were different from the ones used in the bench testing but had identical specifications.

\subsection{Test Cell Constant Volume Sampling (CVS) System}

All engine dynamometer testing was conducted at the Emissions Research and Measurement Section (ERMS) laboratories of Environment and Climate Change Canada (ECCC) in Ottawa, Ontario. The engine was set up on an engine dynamometer and the exhaust pipe was connected to a Constant Volume Sampling (CVS) system. The exhaust from the engine was diluted by ambient air in the CVS and then passed through a Critical Flow Venturi (CFV). A sample of that diluted

exhaust was directed into Tedlar ${ }^{\mathrm{TM}}$ bags, to a gaseous analyzer bench in addition to Particulate Matter measuring instruments all listed in Table 4. A schematic of the engine dynamometer setup is shown in Figures 24 and 25. The engine was connected to a water break dynamometer through which speed and torque were measured. The engine-out exhaust was connected to a catalytic converter. The Gasoline Particulate Filters (GPFs) were connected downstream of the catalytic converter. The exits of the GPFs were then connected into the Constant Volume Sampling (CVS) system where the exhaust was diluted and directed to the sampling probes of the instruments and the analyzer bench. 
Table 4: Exhaust components measured in engine testing

\begin{tabular}{|c|c|c|}
\hline $\begin{array}{l}\text { Exhaust } \\
\text { Compound } \\
\text { Measured }\end{array}$ & Measurement Method & Instrument \\
\hline $\begin{array}{l}\text { Carbon Monoxide } \\
\text { (CO) }\end{array}$ & $\begin{array}{l}\text { Non-Dispersive Infrared Detection } \\
\text { (NDIR) (Continuous) }\end{array}$ & Horiba Model AIA-210 LE \\
\hline $\begin{array}{l}\text { Carbon Dioxide } \\
\qquad\left(\mathrm{CO}_{2}\right)\end{array}$ & $\begin{array}{l}\text { Non-Dispersive Infrared Detection } \\
\text { (NDIR) (Continuous) }\end{array}$ & Horiba Model OPE-115 \\
\hline $\begin{array}{l}\text { Nitrogen Oxides } \\
\left(\mathrm{NO}_{x}, \mathrm{NO}, \mathrm{NO}_{2}\right)\end{array}$ & $\begin{array}{l}\text { Heated Chemiluminescence Detection } \\
\text { (CLD) (Continuous) }\end{array}$ & $\begin{array}{c}\text { California Analytical } \\
\text { Instruments Model 300M- } \\
\text { HCLD }\end{array}$ \\
\hline $\begin{array}{l}\text { Total Hydrocarbons } \\
\text { (THC) }\end{array}$ & $\begin{array}{l}\text { Heated Flame Ionization Detection } \\
\text { (FID) (Continuous) }\end{array}$ & $\begin{array}{c}\text { California Analytical } \\
\text { Instruments Model 300M- } \\
\text { HFID }\end{array}$ \\
\hline Methane $\left(\mathrm{CH}_{4}\right)$ & $\begin{array}{c}\text { Gas Chromatography - Flame } \\
\text { Ionization Detection (GC-FID) (Tedlar } \\
\text { Bags) }\end{array}$ & $\begin{array}{l}\text { Agilent Technologies } \\
\text { Model 6890GC \& } \\
\text { 7890GC }\end{array}$ \\
\hline Black Carbon & Photo-Acoustic (Continuous) & AVL Micro-soot Sensor \\
\hline Particulate Matter & Electrostatic Precipitation & ESP Nano \\
\hline $\begin{array}{l}\text { Particle Number/ } \\
\text { Particle Size }\end{array}$ & Electrical Mobility Classification & $\begin{array}{l}\text { TSI Model } 3090 \text { Engine } \\
\text { Exhaust Particle Sizer }\end{array}$ \\
\hline
\end{tabular}




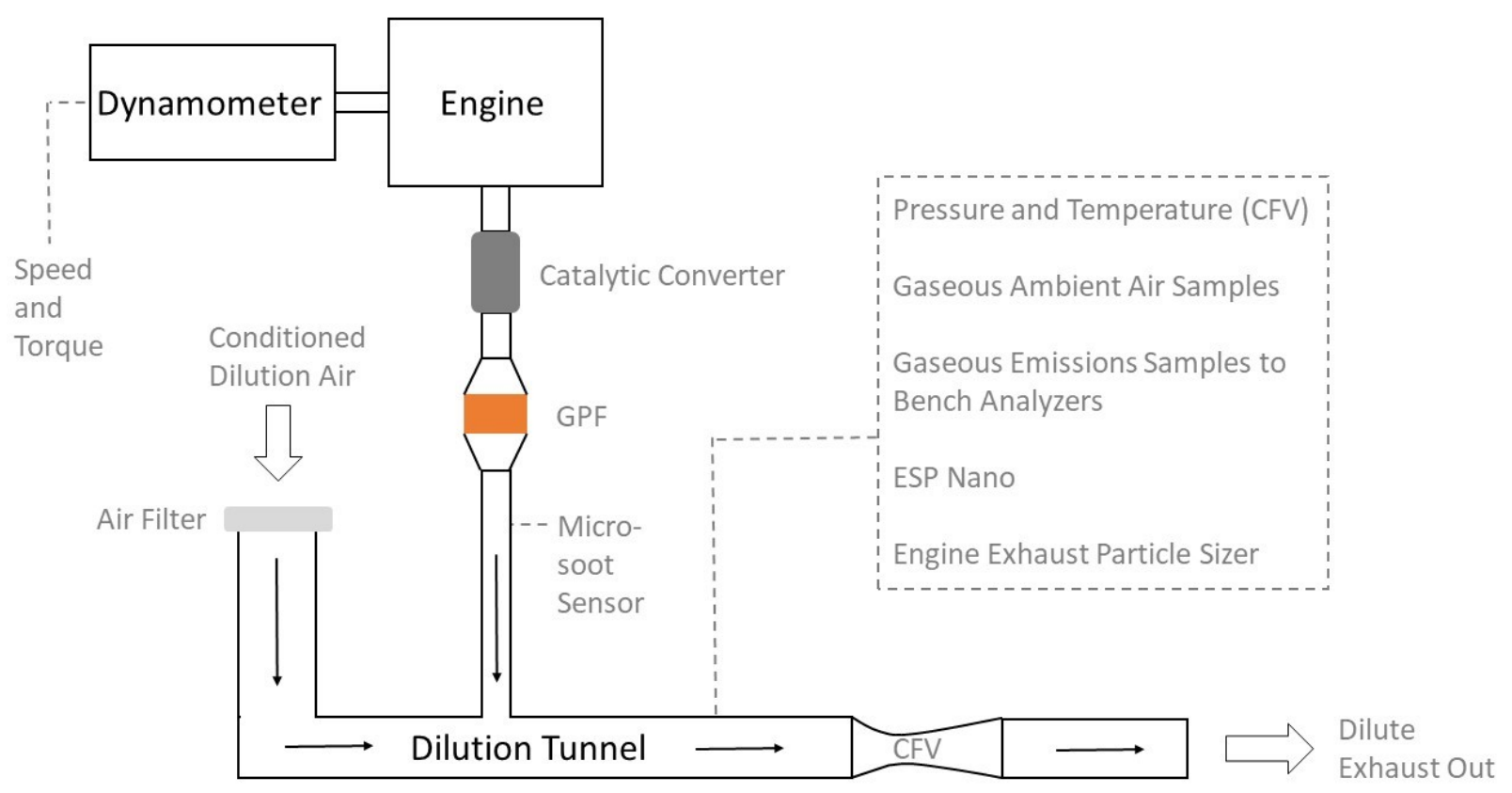

Figure 24: Dynamometer test cell sampling system
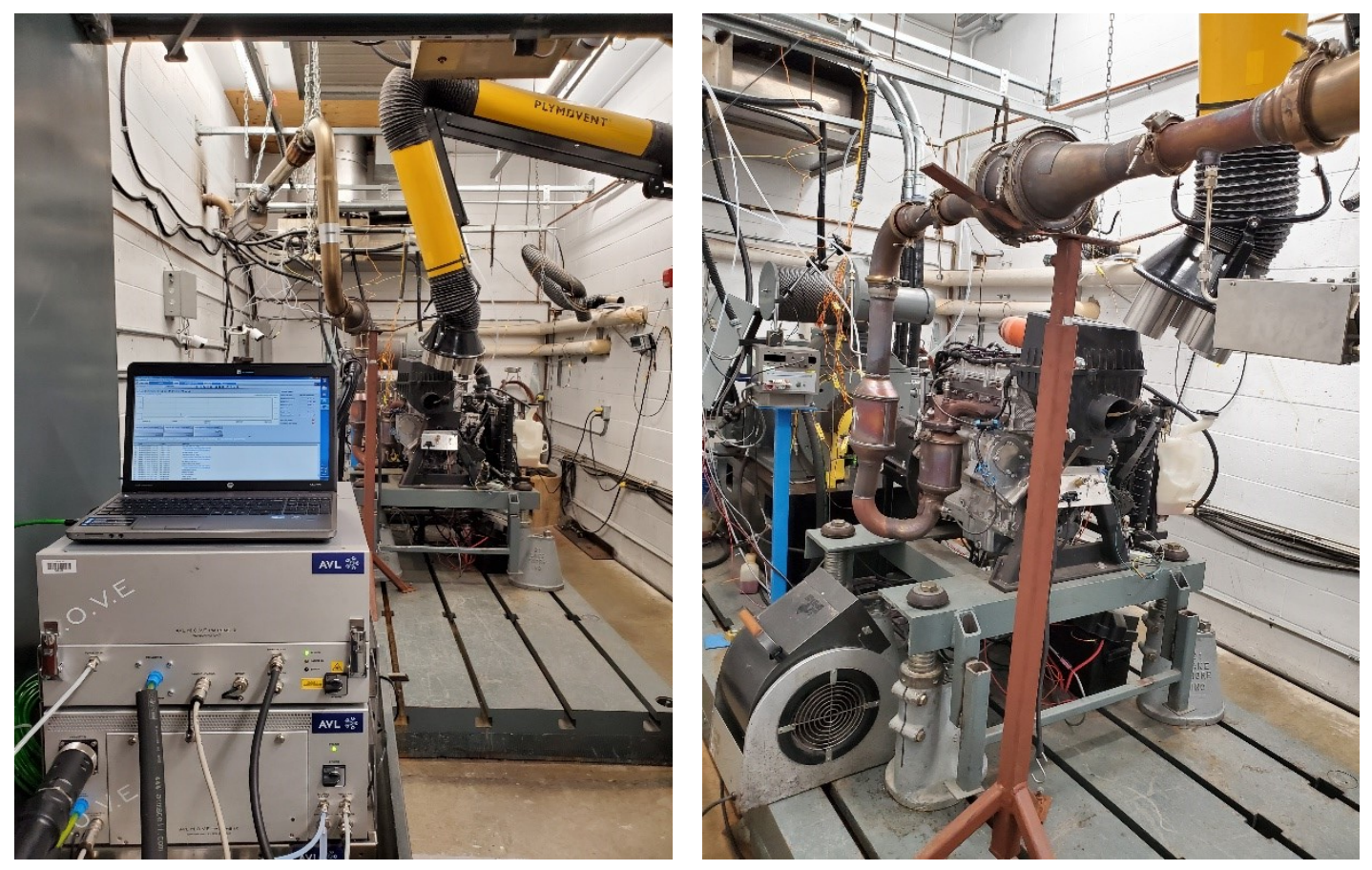

Figure 25: Engine testing setup 


\subsection{TEM and SEM Analysis}

\subsubsection{TEM Analysis Method}

As shown in Section 3.2.2.3, particles from the exhaust in the CVS system were collected on 300 mesh copper grids using an ESP Nano electrostatic precipitation instrument. No coating was required on the copper grids as the early results showed and even deposition of particulate matter on the grid surface. The copper grids were then placed on ESP Nano grid holder (shown in Figure 23) and then the holder was placed in its designated spot in the ESP Nano. The ESP Nano was then connected to the exhaust stream in the CVS system and sampling was performed on each test through its automatic program.

The samples were then taken to the Carleton University Nano Imaging Facility and analyzed on a model FEI Tecnai G2 F20 Transmission Electron Microscope (TEM). The grids were carefully placed on the TEM sample holder using sanitized tweezers and then placed inside the designated spot inside the TEM. The sample was centered and the images collected had a resolution of $1 \mu \mathrm{m}$ and $50 \mathrm{~nm}$ in order to observe both the particle clusters and the individual particles. Six images at different spots across each grid and at each magnification were taken.

Inside the TEM, an electron beam is produced in a vacuum chamber and focused into a thin beam using electromagnetic lenses [37]. The electron beam passes through the sample and then impacts on a detector [37]. Depending on the density and crystal orientation of the sample the electrons in the beam are scattered, and the un-scattered electrons give a shadow image of the specimen [37]. The parts of the sample with higher density appear darker (less transmitted electrons) and the parts with lower density (more transmitted electrons) appear brighter on the image. 


\subsubsection{SEM Analysis Method}

Scanning Electron Microscope analysis was performed on the GPFs themselves in order to observe the particle deposition in and on the surface of the wall of the filters. The instrument used was a Tescan Vega-II XMU SEM.

Due to space limitation in the SEM, the GPFs were cut using diamond tip blades to cubes of $5 \mathrm{~cm}$ in edge size. The samples were then coated with gold using physical vapour deposition where the samples covered in gold strips (shown in Figure 42) were heated in vacuum chamber. The heat causes the gold to convert to vapour and then condense on the solid surface of the samples resulting in the deposition of a thin layer which improved conductivity and SEM image quality.

In an SEM, the sample is mounted in a vacuum chamber and then scanned with a high energy electron beam to produce secondary electrons, backscattered electrons and characteristic X-Rays [38]. Different detectors collect the signals from the electrons and produce the images [38]. 


\subsection{Results and Discussion}

\subsection{Bench Testing Results}

\subsubsection{Soot Filtration Efficiency Results}

Bench tests were performed. The filtration efficiency (FE) was calculated taking into consideration the soot concentration pre and post GPF according to the following equation:

$$
F E=\frac{C_{\text {pre-filter }}-C_{\text {post-filter }}}{C_{\text {pre-filter }}} \times 100 \%
$$

where: $C_{\text {pre-filter }}$ is the soot concentration pre-filter in $\mathrm{mg} / \mathrm{m}^{3}$ and $C_{\text {post-filter }}$ is the soot concentration of post-filter in $\mathrm{mg} / \mathrm{m}^{3}$.

Figure 26 shows a summary of filtration efficiency versus soot loading of all five filters tested. The average of the tests performed on each filter was displayed, in addition to the standard deviation error bars. At $0 \mathrm{~g} / \mathrm{L}$ soot loading, the filters were in clean slate condition meaning no soot was accumulated in the pores or on the wall surface of the filters. Soot loading is the collection and accumulation of soot in the filter pores and on the filter wall. Several factors affect the soot loading including soot concentrations in the exhaust stream in addition to the time the filter is loaded. As the time in the test progressed more soot was accumulated to reach $0.054 \mathrm{~g} / \mathrm{L}$ after 10 minutes. As mentioned before, the filtration efficiency of each filter was compared to that of filter A as it was optimized for light duty vehicle application. 
As Figure 26 shows, the plots for all filters show the same trend, i.e., this is due to the increasing soot loading inside the filters leading to an improved FE. Soot loading was calculated using the raw miniCAST soot concentrations measured using the AVL Micro-Soot Sensor (MSS). The AVL MSS utilizes a modulating laser of $808 \mathrm{~nm}$ wavelength which is absorbed by the soot particles as described in Section 3.2.2.1. The Mass Absorption Cross-Section (MAC) was assumed to be the "wavelength-adjusted Bond MAC" and was calculated for $808 \mathrm{~nm}$ to be $5.1 \pm 0.8 \mathrm{~m}^{2} / \mathrm{g}$ (The Bond MAC is approximately $7.5 \mathrm{~m}^{2} / \mathrm{g}$ at $550 \mathrm{~nm}$ [39], the wavelength adjustment assumes (550/808) with an exponent of 1 and hence $\mathrm{MAC}_{808 \mathrm{~nm}}=7.5 *(550 / 808)=5.1 \mathrm{~m}^{2} / \mathrm{g}$ with an uncertainty of 0.8 $\mathrm{m}^{2} / \mathrm{g}$ ). This is an assumed MAC due to the unavailability of a manufacturer indicated MAC which would be a more accurate value for any further calculations. The MSS automatically converts the absorption information into a soot mass concentration displayed in $\mathrm{mg} / \mathrm{m}^{3}$. The average measured raw soot concentration was $89.23 \mathrm{mg} / \mathrm{m}^{3}$ which equals to $8.923 \times 10^{-5} \mathrm{~g} / \mathrm{L}$. Adding the soot loading cumulatively every second gives the total soot loading in $\mathrm{g} / \mathrm{L}$ over the span of each test.

Filters $\mathrm{A}$ and $\mathrm{B}$ were tested to investigate the effects of changing porosity on the filtration efficiency. Both filters had the same wall thickness of $8 \mathrm{mil}(0.2 \mathrm{~mm})$, filter A had a $55 \%$ porosity with 200 cells per square inch (cpsi) and filter B had a 65\% porosity with 300 cpsi. For example, filter A with the designation of "Filter A (200/8 55\%)", refers to $200 \mathrm{cpsi}, 8$ mil wall thickness and $55 \%$ porosity. The same naming convention was used for all the filters and all the graphs. 


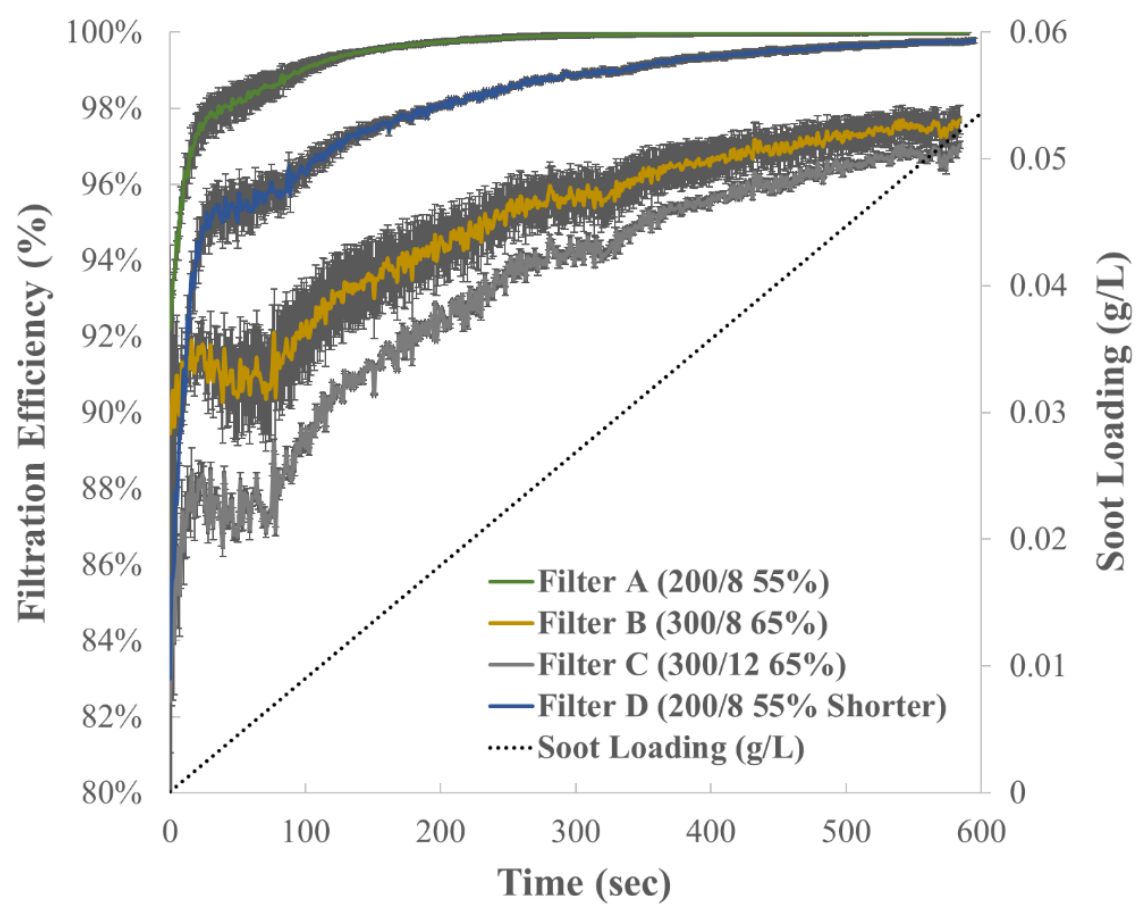

Figure 26: Filtration efficiency and soot loading versus time

Filter A, which has a lower porosity, reaches $100 \% \mathrm{FE}$ faster after around $0.022 \mathrm{~g} / \mathrm{L}$ soot loading. After 10 minutes, or $0.054 \mathrm{~g} / \mathrm{L}$ of soot loading, filter B reaches a maximum FE of $97.7 \%$. Results also showed that filter A has a higher clean slate FE of $92.2 \%$ compared to $89.4 \%$ for filter B.

The lower porosity in filter A led to a higher pressure drop across the filter and therefore a faster blocking of the pores as the soot cake is formed (as shown by Konstandopoulos et al., [40]). A faster developing soot cake resulted in a better FE as the soot cake is itself considered a very efficient particle filter [41]. This indicates that filter A, with the lower porosity, is more efficient as a clean slate filter with no ash accumulation and reaches $100 \% \mathrm{FE}$ faster than filter B which has a higher porosity. However, in practical applications, a higher pressure drop in the exhaust system will affect the overall performance of the engine and may have a detrimental effect on fuel 
efficiency. These concerns were investigated when the filters were fitted on a GDI engine and tested on an engine dynamometer.

Filter $\mathrm{C}$ was tested to investigate the effects of changing wall thickness on the filtration efficiency. With a 12 mil (12 thousands of an inch or $0.3048 \mathrm{~mm}$ ) wall thickness, filter $\mathrm{C}$ had a $65 \%$ porosity and a cell density of 300 cpsi. Overall results showed filter $\mathrm{C}$ having the lowest clean slate FE (82.4\%) and the lowest FE after $0.054 \mathrm{~g} / \mathrm{L}$ of soot loading (97\%) compared to the other filters. This could be attributed to the sole depth filtration due to the larger wall thickness. In particulate filters the filtration mechanism is a combination of depth filtration and cake filtration [42]. In a clean slate filter, depth filtration, which is the deposition of the particles inside the pores of the filter wall, is the dominant mechanism [42]. Cake filtration becomes the main mechanism as the soot loading increases and a particle layer is formed on the surface of the filter wall [42]. In filter $\mathrm{C}$, due to the larger thickness of the wall, the prevailing mechanism is depth filtration and the lack of developments of cake filtration led to a lower overall filtration efficiency.

Based on a discussion with industry experts and the manufacturers of the GPFs, it was believed that the lower filtration efficiency in filter $\mathrm{C}$ could also be attributed to the larger pore size of 19 $\mu \mathrm{m}$ compared to that of filter A $(13 \mu \mathrm{m})$. Several studies have shown that filtration efficiency decreases with increasing pore size [14]. The pore size was larger in filter $\mathrm{C}$ due to some manufacturability constraints. In the case of filter $\mathrm{C}$, mean pore size had a larger effect on filtration efficiency than wall thickness. As the pore size increased, the soot particles having Brownian motion were less likely to collide with the channel walls inside the porous wall of the filter and therefore more particles were likely to pass through unfiltered. 
Filter D was tested to investigate the effects of changing filter length. Filter D was identical to filters A except having a shorter overall length of 4 in $(101.6 \mathrm{~mm})$. The clean slate filtration efficiency of filter D was found to be $83 \%$. Filter D reached a maximum FE of $99.8 \%$ after 0.054 $\mathrm{g} / \mathrm{L}$ of soot loading compared to Filter A which reached $100 \% \mathrm{FE}$ after approximately 340 seconds. There are several reasons that could have attributed to this considering that both filters possess similar specifications except for length. The shorter length of filter D led to a smaller overall physical size and consequently fewer smaller pores than filter A. This meant that the particles going through filter D saturated the smaller pores faster and once the smaller pores are saturated, the larger pores enable a higher chance of particles slipping through unfiltered. Filtration Efficiency results for all the filters is summarized in Table 5. An experimental uncertainty analysis for the soot Filtration Efficiency is detailed in Appendix A of this thesis.

Table 5: Summary of GPF filtration efficiency for the bench setup

\begin{tabular}{|c|c|c|}
\hline Filter & $\begin{array}{c}\text { Minimum Filtration } \\
\text { Efficiency (\%) }\end{array}$ & $\begin{array}{c}\text { Maximum Filtration } \\
\text { Efficiency (\%) }\end{array}$ \\
\hline A & 92.2 & 100 \\
\hline B & 89.4 & 97.7 \\
\hline C & 82.4 & 97 \\
\hline D & 83 & 99.8 \\
\hline
\end{tabular}

Another way to look at the data is to observe the changing soot concentration with time. The soot concentration is shown in Figure 27. 


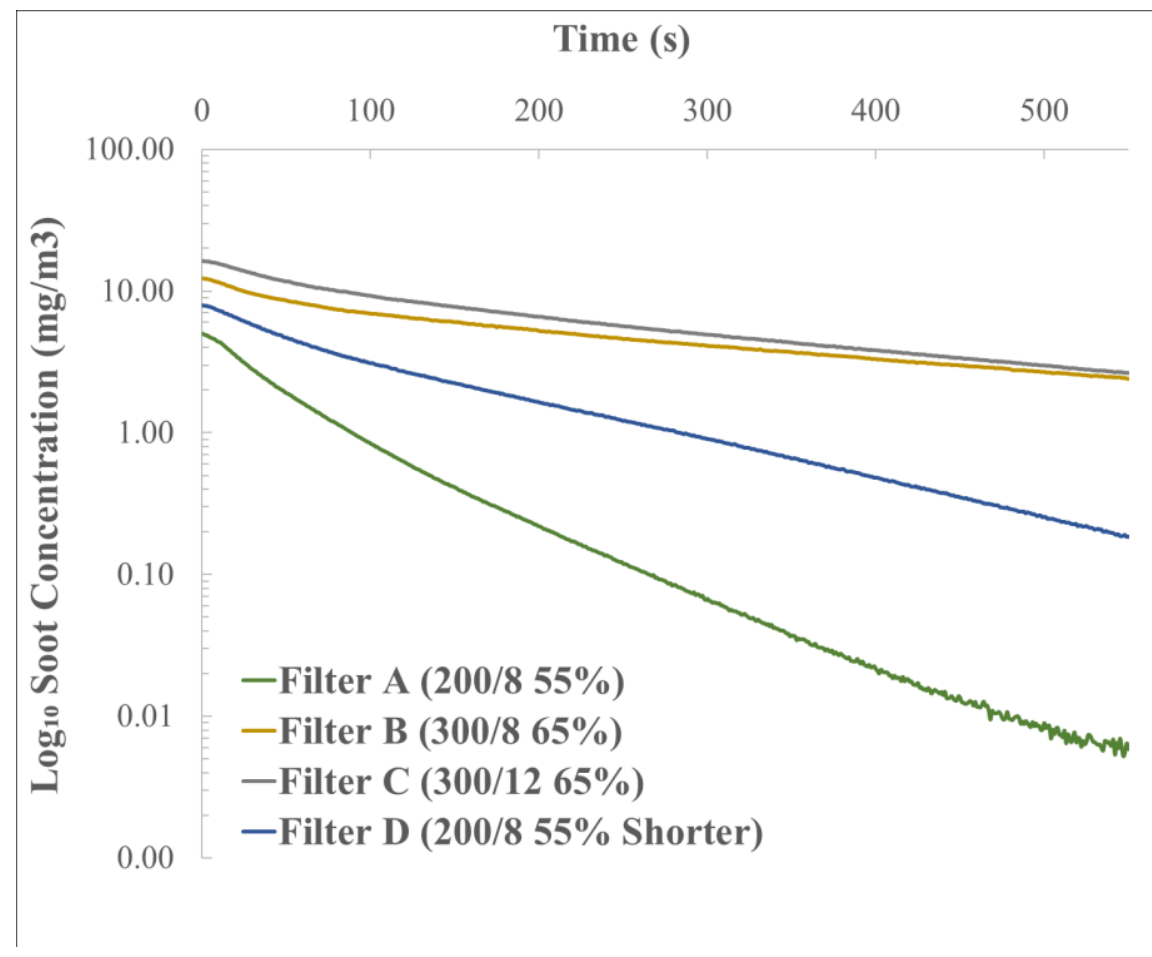

Figure 27: Changing soot concentration with time for bench setup

As expected, the soot concentration was observed to decrease with time due to improving efficiency for all the filters as the test progressed (resulting from the accumulated soot which, as explained, acts as a highly efficient filtration medium). Soot concentration results for filters $\mathrm{B}, \mathrm{C}$ and D indicated that particles were slipping through the GPF unfiltered by the end of the 10 minute tests (thus supporting the results shown in Figure $\mathbf{2 6}$ and the corresponding discussion).

\subsubsection{Particle Size Distribution}

Particle size distribution is a representation of the number of particles at specific particle electric mobility diameters. Figure $\mathbf{2 8}$ shows the particle size distribution of the filters measured using a TSI EEPS. The measurements were taken post filters and they represent the particle size 
distribution throughout the entire test. The geometric mean particle diameters and the geometric standard deviations were also calculated based on equations in Hinds (1999) [43].

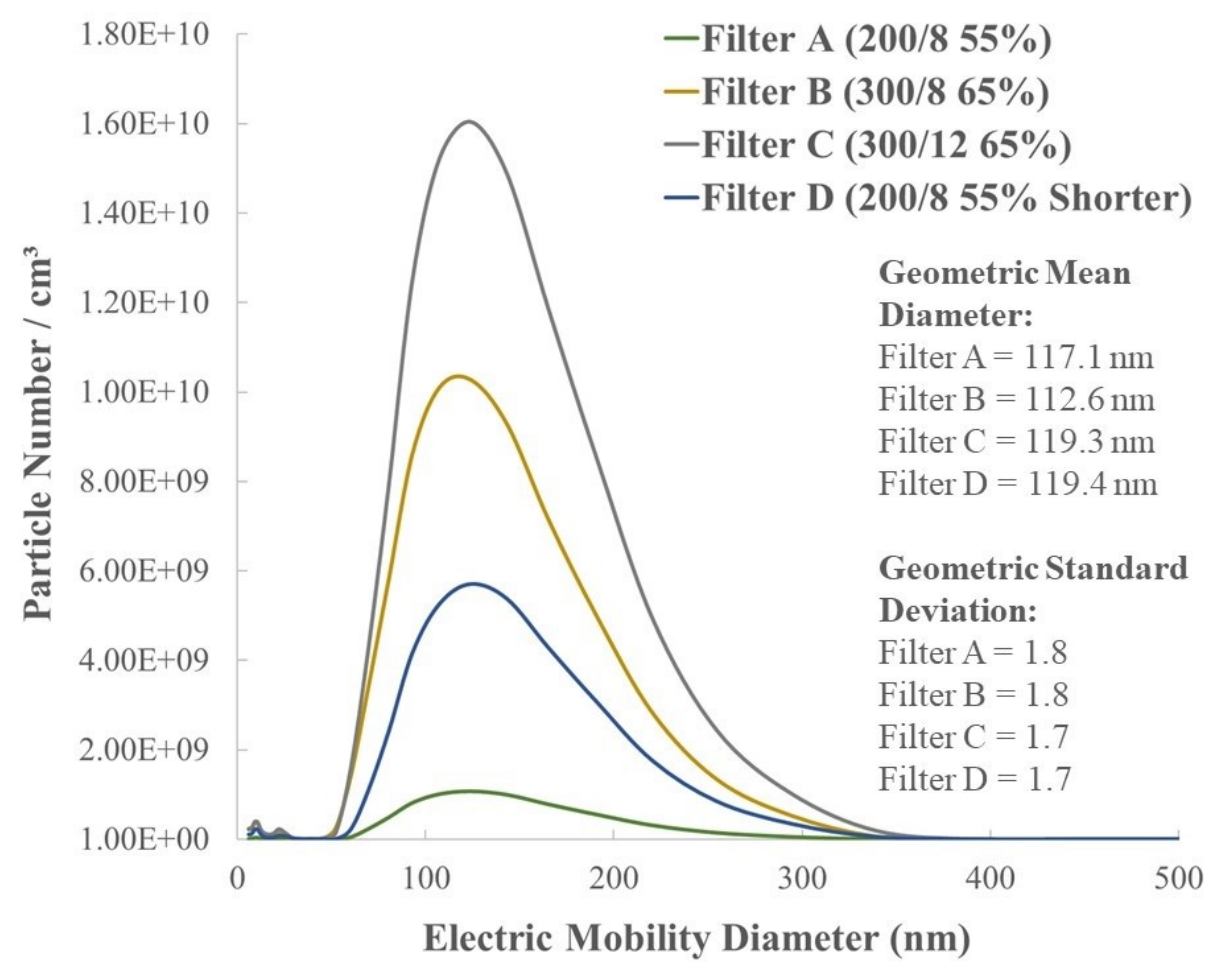

Figure 28: Particle Size Distribution post filters

Particle size distribution charts for all filters show a peak between $90 \mathrm{~nm}$ and $120 \mathrm{~nm}$ which is consistent with the GDI engine particle number emission profile shown in other studies [44]. This indicates that the chosen parameters on the soot generator are appropriate to simulate GDI engine particle number emissions. Figure 28 also shows minimum detected particles below $50 \mathrm{~nm}$ and above $360 \mathrm{~nm}$ for all the filters.

Particle number results followed a similar trend to that from Black Carbon in the sense that filter A had the smallest overall particle number and the smallest peak, indicating that filter A had the highest overall efficiency among the filters examined in this study. Filter $\mathrm{C}$ had the highest particle 
number peak which translated into the lowest efficiency among the four filters, similar to what was observed in the soot results. In addition, the change of the particle number emissions over time can also be observed in Figure 29.

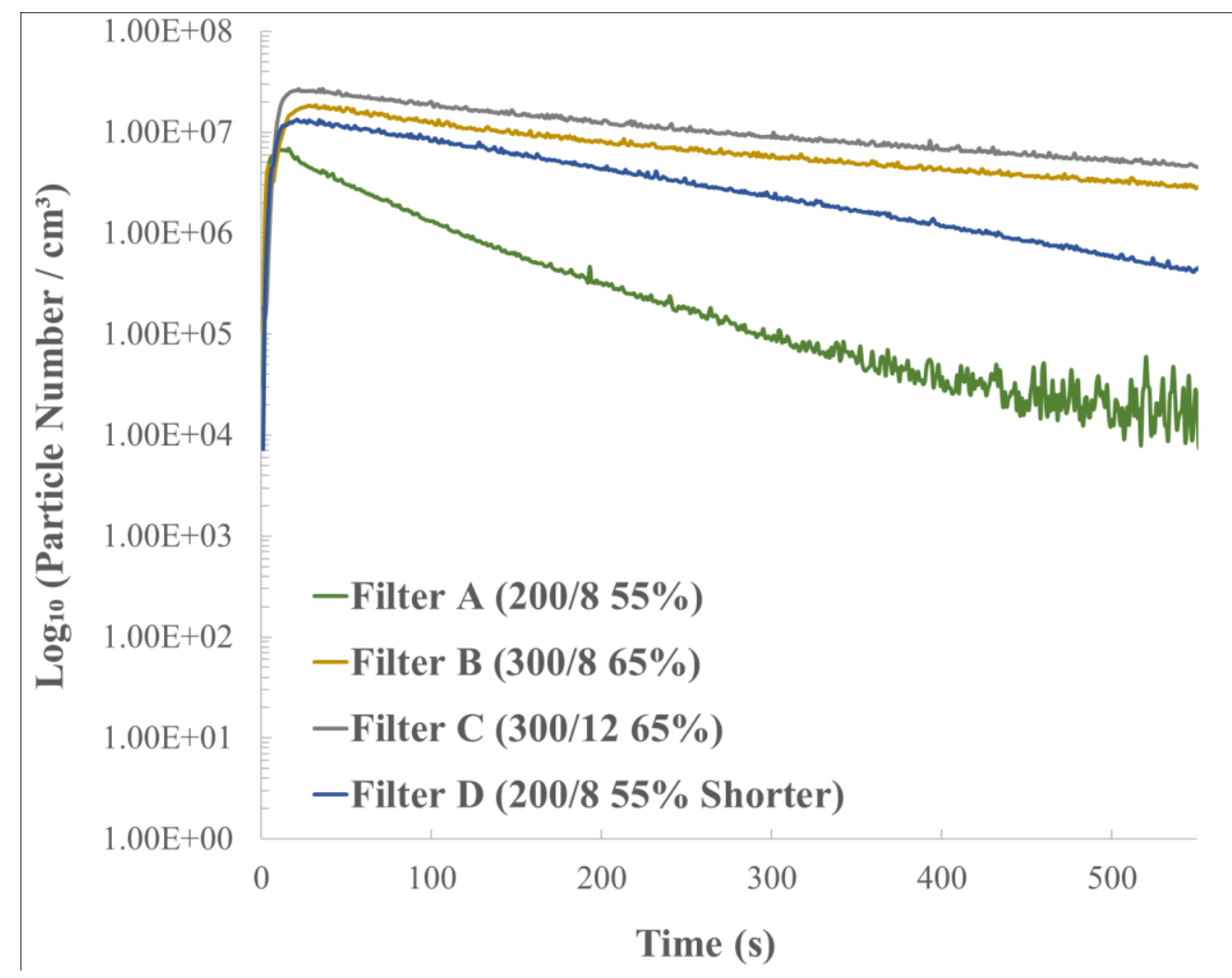

Figure 29: The change of particle number emissions with time for the bench setup

Figure 29 shows a decrease in particle number emissions (shown in log scale) over time for the filters tested indicating an increase in filtration efficiency as more soot is loaded. Similar to the particle size distribution trends, post Filter A results showed the lowest overall PN with values reaching near ambient levels after 500 seconds. Note that the measurement noise increased as Filter A reached 100\% filtration efficiency and PN values reached near ambient levels. Results also showed Filter $\mathrm{C}$ having the highest overall $\mathrm{PN}$ and the lowest filtration efficiency. 


\subsection{Engine Testing Results}

After testing on a bench setup, the four filters were fitted on a 2.4 L GM ECOTEC GDI engine installed on an engine dynamometer. The filters were fitted along the exhaust stream downstream of the catalytic converters. Each filter was tested three times following the test sequence highlighted in Section 3.3.2. Each test was considered a cold start test as the engine component temperatures were monitored closely and insured to be at ambient temperature before every test. Two tests were performed every day with sufficient time between the two tests to ensure a cold start. After every test, the filter tested was baked at $700{ }^{\circ} \mathrm{C}$ for 5 hours in order to ensure that all the soot accumulated in the filter during the test was burned. The baking sequence is highlighted in Section 3.3.2 as well. Note that the filters were not baked after the final test in order to allow for SEM analysis and to observe the soot deposition inside the filters.

\subsubsection{Soot Filtration Efficiency Results for Engine Testing}

The filtration efficiency was calculated in a similar way to the bench setup as highlighted in Section 4.1.1. The results are shown in Figure 30. 


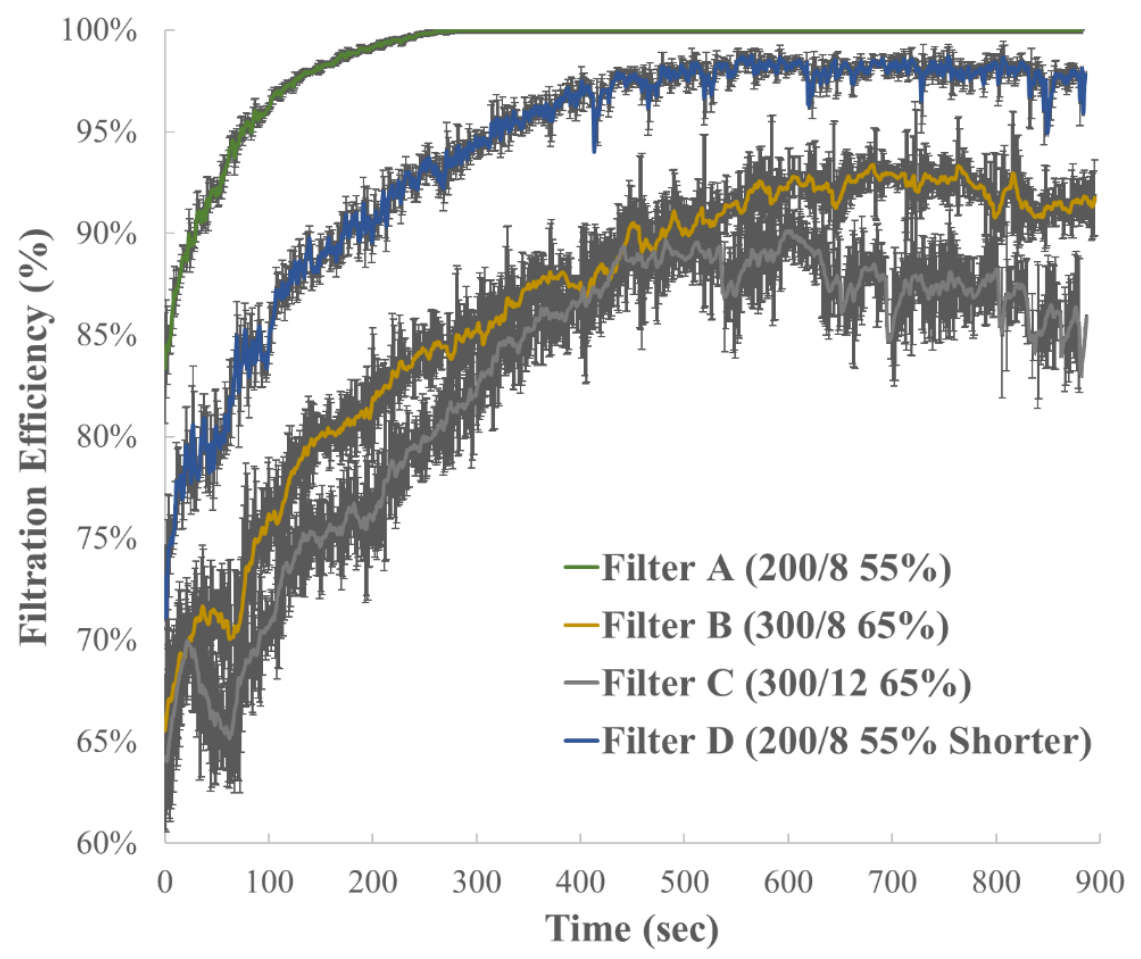

Figure 30: Soot filtration efficiency versus time for the engine setup

The average results were exponentially smoothened in order to better represent the trends. The trends observed in general were similar to what was seen with the bench setup, with some differences discussed as follows.

Similar to the bench setup, filter A possessed the highest overall filtration efficiency with a clean slate $\mathrm{FE}$ of $83 \%$ (compared to $92.2 \%$ in the bench setup) and reached $100 \%$ filtration efficiency after only 230 seconds (compared to 340 seconds in the bench setup). Also comparable to the bench results, filter D had the second highest overall FE with a clean slate FE of $73 \%$ (compared to $83 \%$ in the bench setup) and reached a maximum FE of $97.8 \%$ at the end of the tests. Results of Filters $\mathrm{B}$ and $\mathrm{C}$ were closer compared to what was observed during the bench testing. By observing the overall average trends, Filter B showed the third highest FE with a clean slate FE of $65.6 \%$ (89.4\% in the bench setup) and reached a maximum FE of 91.8\%. Filter $\mathrm{C}$ had the lowest overall 
FE starting at $64.2 \%$ clean slate and having a maximum of $85.8 \%$. Filtration efficiency results for all the filters is shown in Table 6.

Table 6: Filtration efficiency results for engine setup. The minimum filtration efficiency was calculated at beginning of the test and the maximum filtration efficiency at the end of the test based on Equation 2 of this thesis.

\begin{tabular}{|c|c|c|}
\hline Filter & $\begin{array}{c}\text { Minimum Filtration } \\
\text { Efficiency (\%) }\end{array}$ & $\begin{array}{c}\text { Maximum Filtration } \\
\text { Efficiency (\%) }\end{array}$ \\
\hline A & 83 & 100 \\
\hline B & 65.6 & 91.8 \\
\hline C & 64.2 & 85.8 \\
\hline D & 73 & 97.8 \\
\hline
\end{tabular}

In order to understand the differences between the bench results and the engine results, several factors were considered. First of all, the soot loading on the filters was assumed with no passive regeneration occurred. The maximum exhaust temperature observed during engine testing was around $530{ }^{\circ} \mathrm{C}$ (as observed on the engine control data acquisition system) making it unlikely for high temperature soot regeneration to have occurred, especially when the testing was for its majority in steady state with no fuel cuts (Thorsten Boger and Willard Cutler described in their book "Reducing Particulate Emissions in Gasoline Engines" [8] that fuel cutoffs resulted in increases in exhaust temperatures associated with soot regeneration and that no regeneration was observed with no fuel cutoffs. The book also describes an exponential increase in soot regeneration rate at temperatures exceeding $550{ }^{\circ} \mathrm{C}$.). No passive regeneration was desired as it adds a degree of variability to the results (due to its passive nature and occurrence under specific exhaust 
conditions throughout the test cycle). Cumulative soot loading versus time for the engine setup is shown in Figure 31.

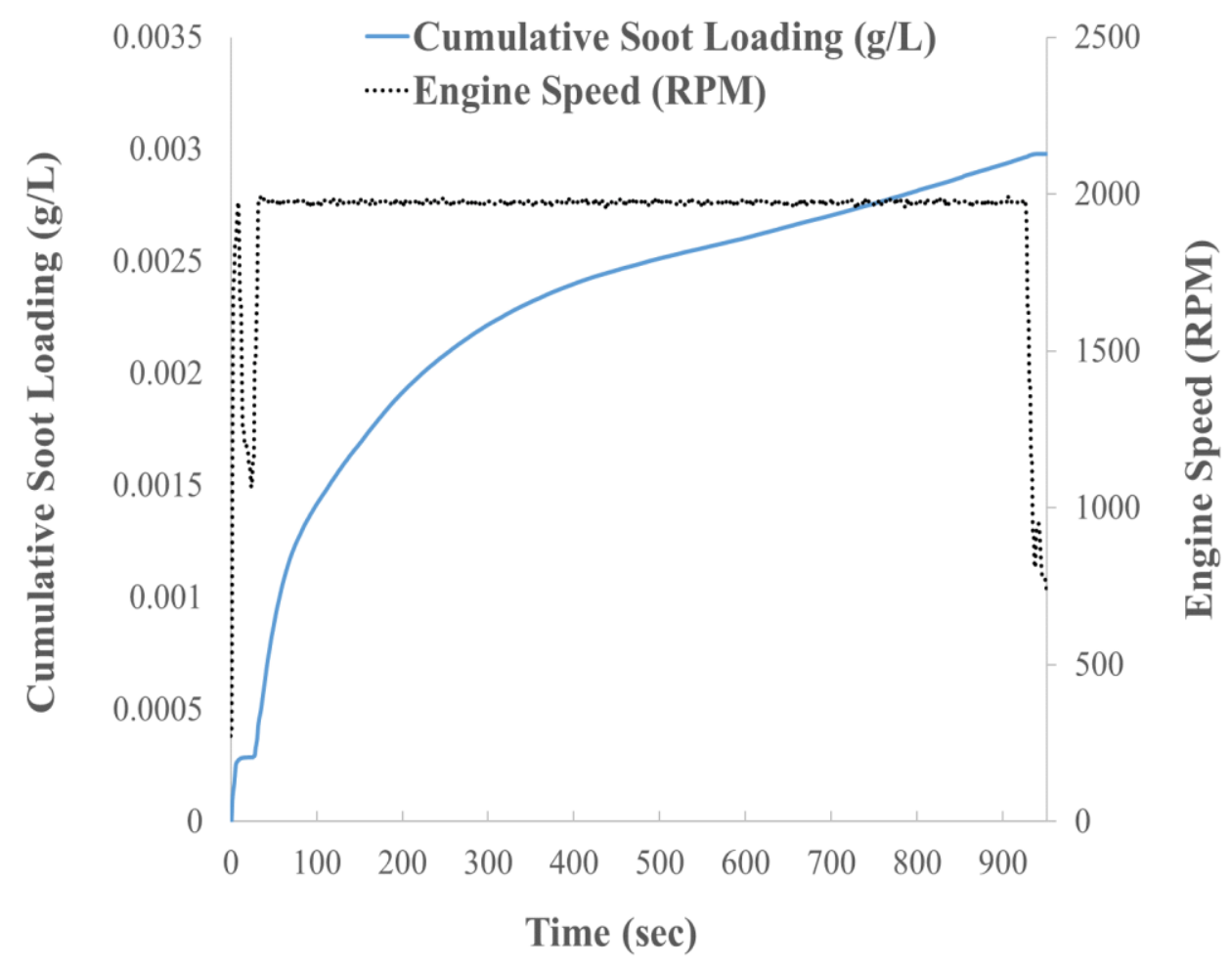

Figure 31: Engine cumulative soot loading and engine speed versus time

The maximum soot loading observed in the engine after 10 min was $0.0026 \mathrm{~g} / \mathrm{L}$ which was about 19 times lower than what was seen with the bench setup $(0.054 \mathrm{~g} / \mathrm{L})$. The lower soot loading does not explain the lower clean slate FE (considering that a higher soot loading is typically associated with a higher FE as described in Section 2.4.3 of this thesis) with the engine setup and therefore further investigation into the particle size distribution was required. 


\subsubsection{PN Filtration Efficiency Results for Engine Setup}

The particle size distribution post filters for the engine setup is shown in Figure 32.

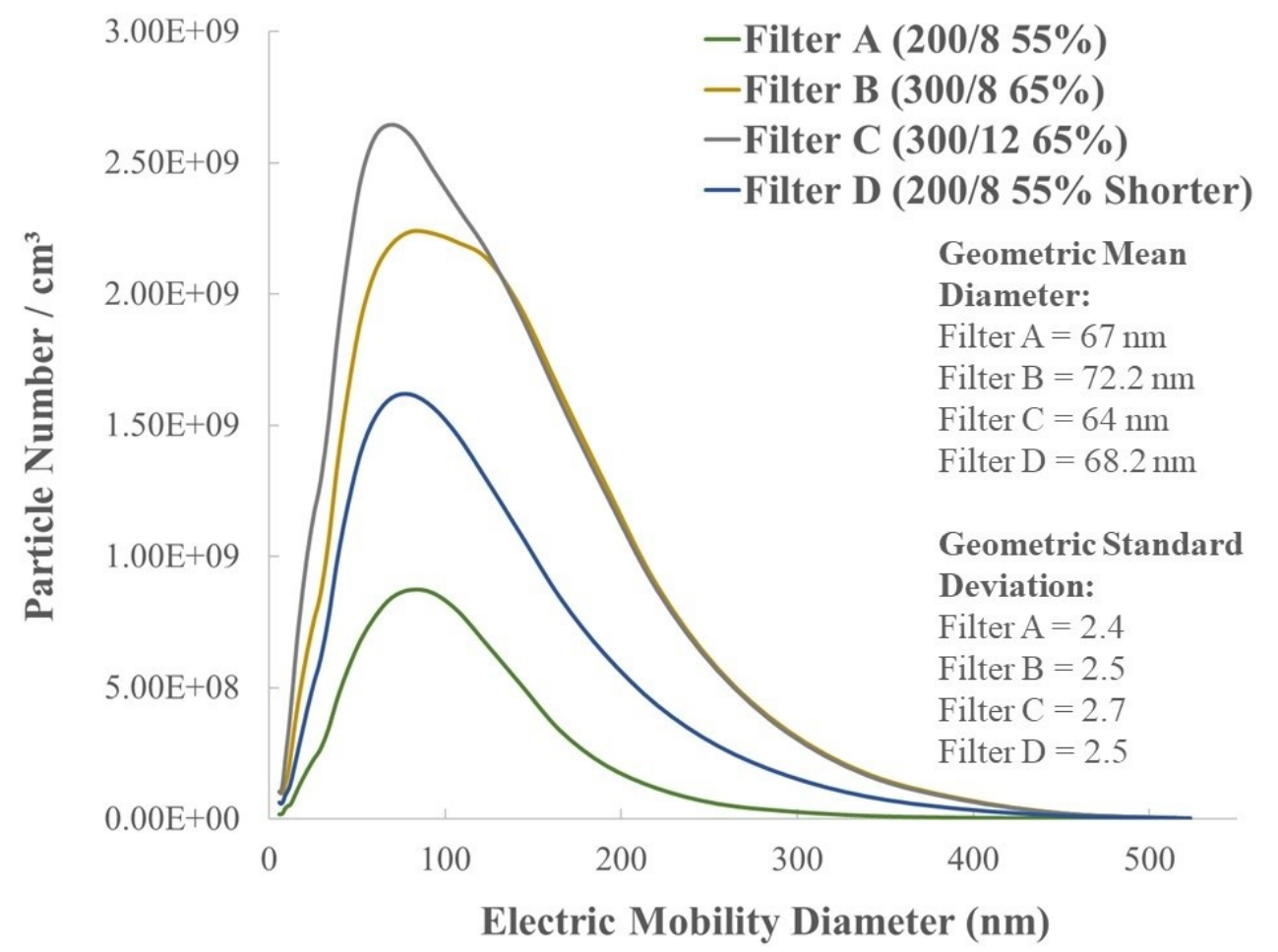

Figure 32: Particle size distribution post filters for engine setup

Comparing the particle size distribution of the bench setup to the engine setup, it is observed that for the engine setup the particle peaks are at around $80 \mathrm{~nm}$ for all filters as compared to around $120 \mathrm{~nm}$ for the bench setup. The filtration mechanism inside the filters can differ according to several factors including particle size. The three filtration mechanisms that can be observed in a particle filter are Brownian diffusion, interception and impaction [12]. Diffusion is due to the random collision of air molecules on the particles causing random motion and colliding with each other and with the filter material therefore getting captured. Interception is when the particles in 
the gas streamline come within one particle radius of the filter material fibers and get captured by the fibers $[45,13]$. Inertial impaction is when the particles are large and not able to modify their direction in the gas streamline around a filter fiber and impact on the fiber and get captured [45, 13]. For particles under $100 \mathrm{~nm}$ in diameter, diffusion is the dominant filtration mechanism which is highly efficient. Between $100 \mathrm{~nm}$ and $400 \mathrm{~nm}$ in diameter, the particles are typically too big for diffusion and too small for impaction which leads to reduced efficiency. For particles over $400 \mathrm{~nm}$ in diameter, inertial impaction is the dominant mechanism which is again highly efficient $[45,13]$. This is reinforced by observing the particle number filtration efficiency results of the engine setup as shown in Figure 33.

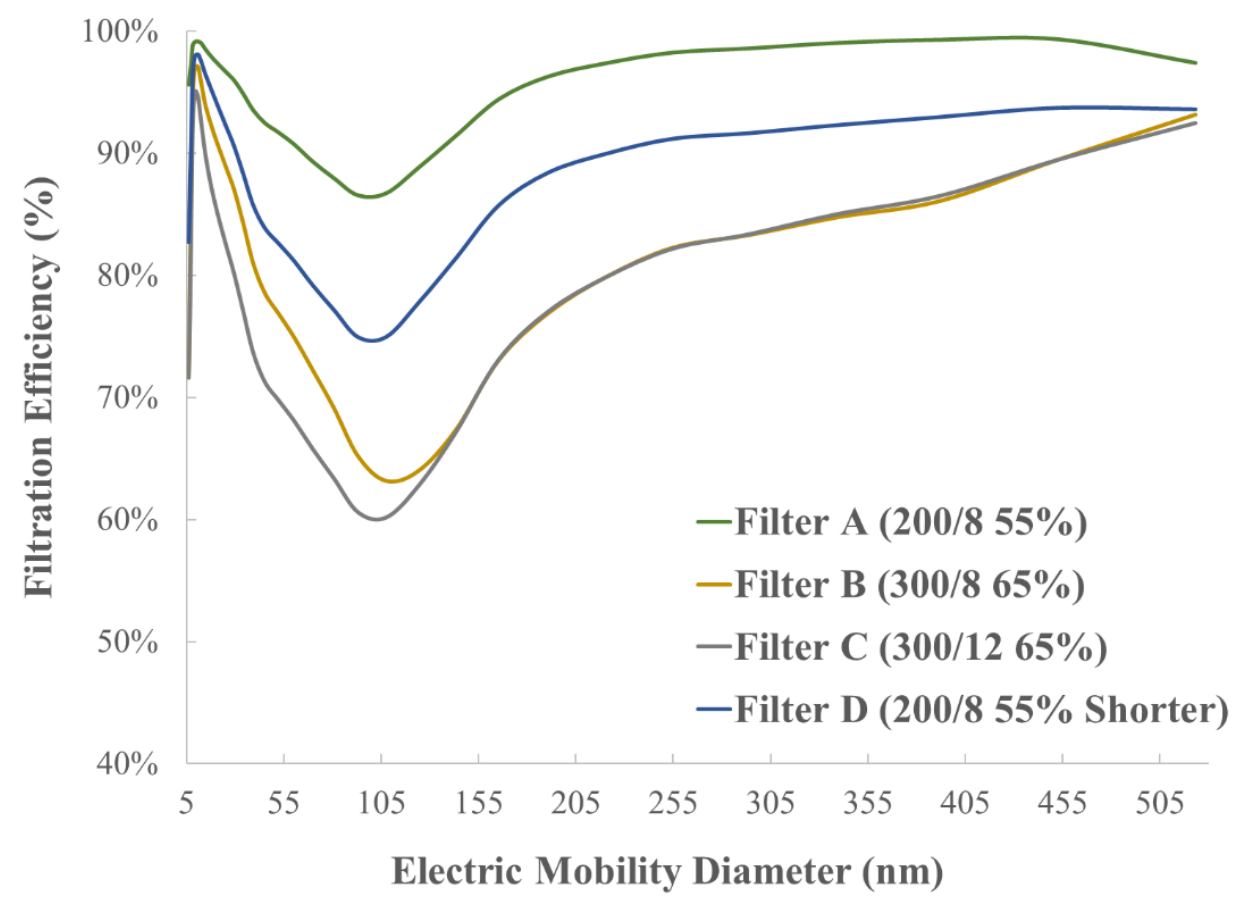

Figure 33: Filtration efficiency per particle size for the engine setup 
The lowest filtration efficiency of all the filters was observed at a particle electric mobility diameter between $90 \mathrm{~nm}$ and $125 \mathrm{~nm}$. For the engine setup, the particle number for all the filters peaked at around $80 \mathrm{~nm}$ which is within the highly efficient diffusion mechanism region. For the bench setup, the particle number peaked around $120 \mathrm{~nm}$ which is within the region of lowest FE for all the filters. This could explain why the filters reached maximum filtration efficiency faster in the engine setup. Due to the overall smaller particles emitted by the engine, it was likely that the dominant filtration mechanism in the GPFs was Brownian diffusion [45] (the particle size peak was determined to be below $100 \mathrm{~nm}$ ). In the bench setup, the particle size peak was measured at $120 \mathrm{~nm}$ and between $100 \mathrm{~nm}$ and $400 \mathrm{~nm}$ the particles are typically too large for diffusion and too small for impaction resulting in a reduced efficiency [45]. The particle size distributions for both the bench and engine setup were determined using a TSI Engine Exhaust Particle Sizer.

However the different filtration mechanism does not explain the second discrepancy between bench results and engine results which is the overall lower clean slate filtration efficiency observed in the engine results. This could be attributed to the different composition of particulate matter in the soot generator compared to the engine. In the soot generator the majority of the particles produced are classified as soot or elemental carbon [32] whereas in the engine it is a combination of elemental carbon, organic carbon, sulfates, nitrates and ash [9].

\subsubsection{TEM Analysis}

TEM analysis was performed on copper mesh grids with particulates collected during the bench tests, as explained in Section 3.2.2.3. The results are shown in Figures 35, 36, 37, 38 and 39. The three frames were collected from random spots across the grids to provide a generalized view. 
Comparing the pre-GPF results to post-GPF results for all the filters indicates an overall reduced particle size (primary particle diameter) in the exhaust having passed the filters. In order to further investigate this observation, the particle size distribution of pre-GPFs (obtained using the TSI EEPS) is shown in Figure 34. Compared to the particle size distribution post filters shown in Figure 32, there appears a second peak in electric mobility diameter around $170 \mathrm{~nm}$. This agrees with the larger particle sizes observed in the pre-GPF TEM images.

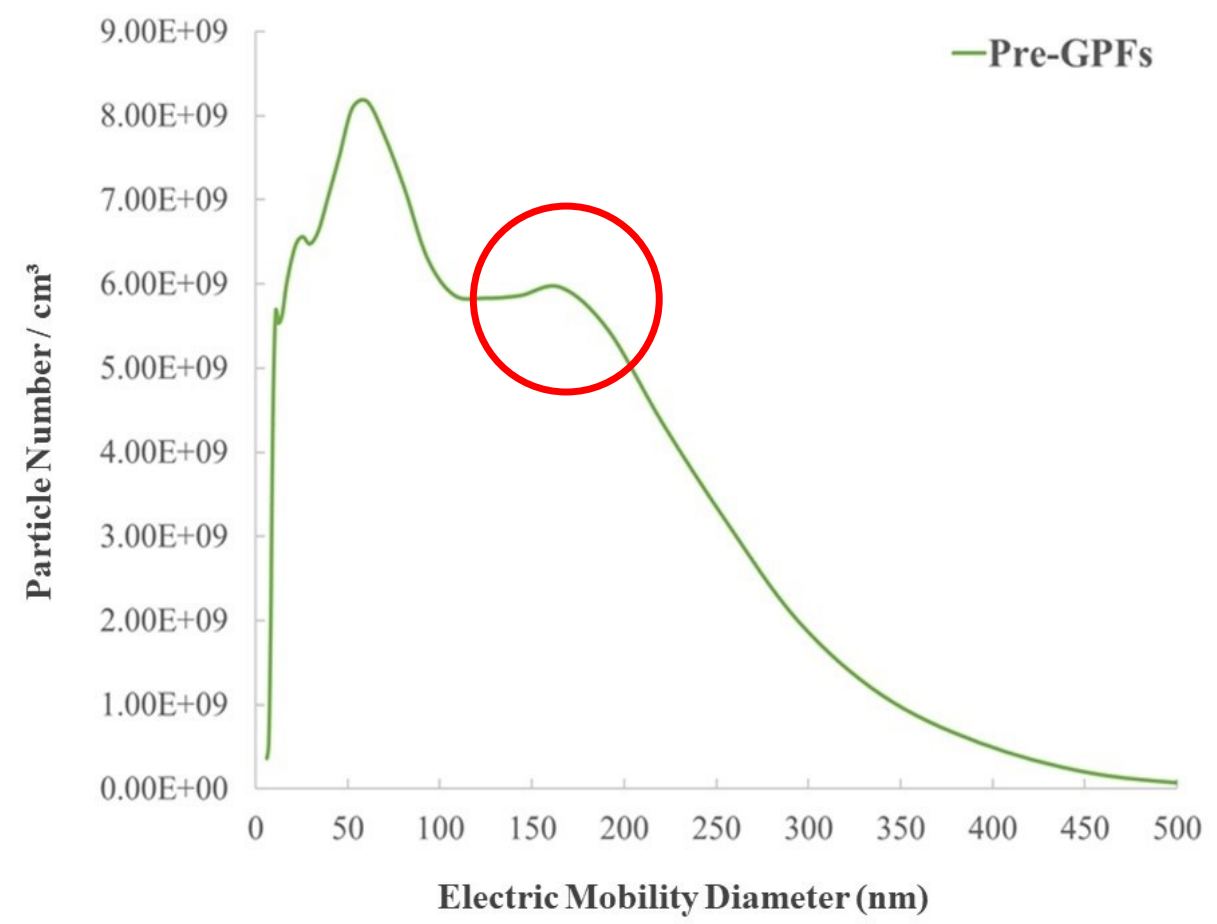

Figure 34: Pre-GPF particle size distribution (obtained using the TSI EEPS) 


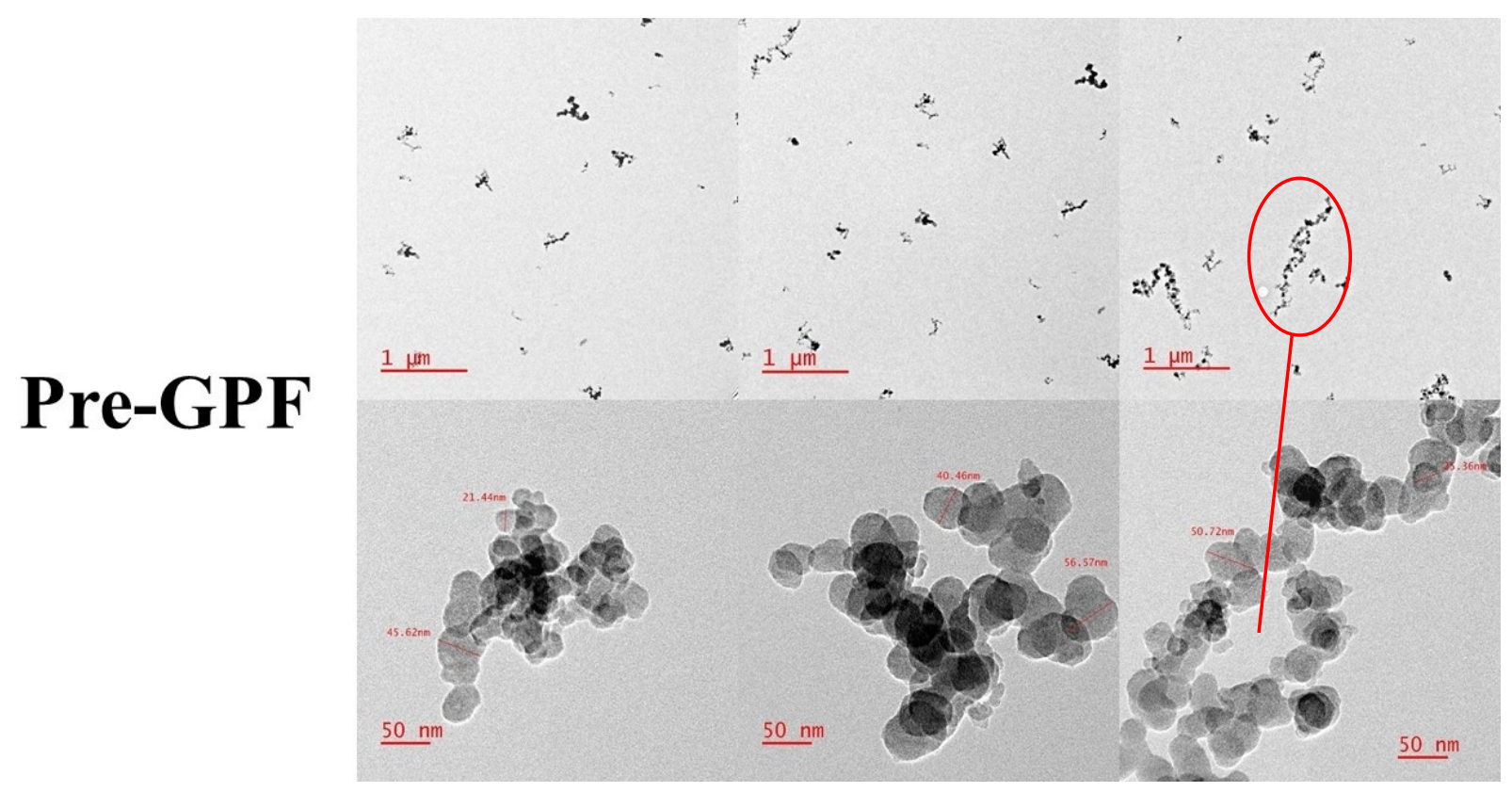

Figure 35: TEM grid analysis showing pre-GPF emissions

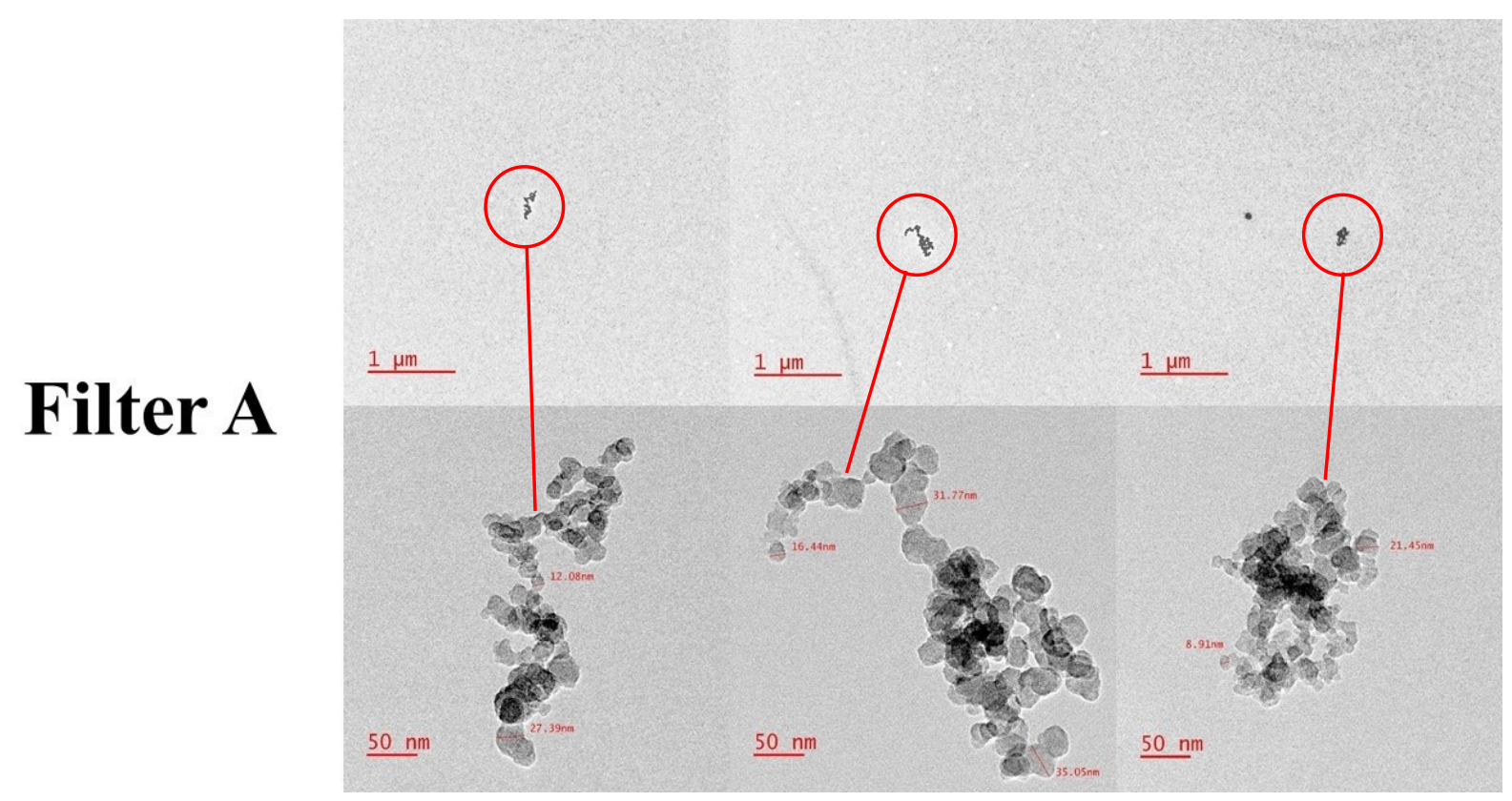

Figure 36: TEM grid analysis showing post GPF A emissions 


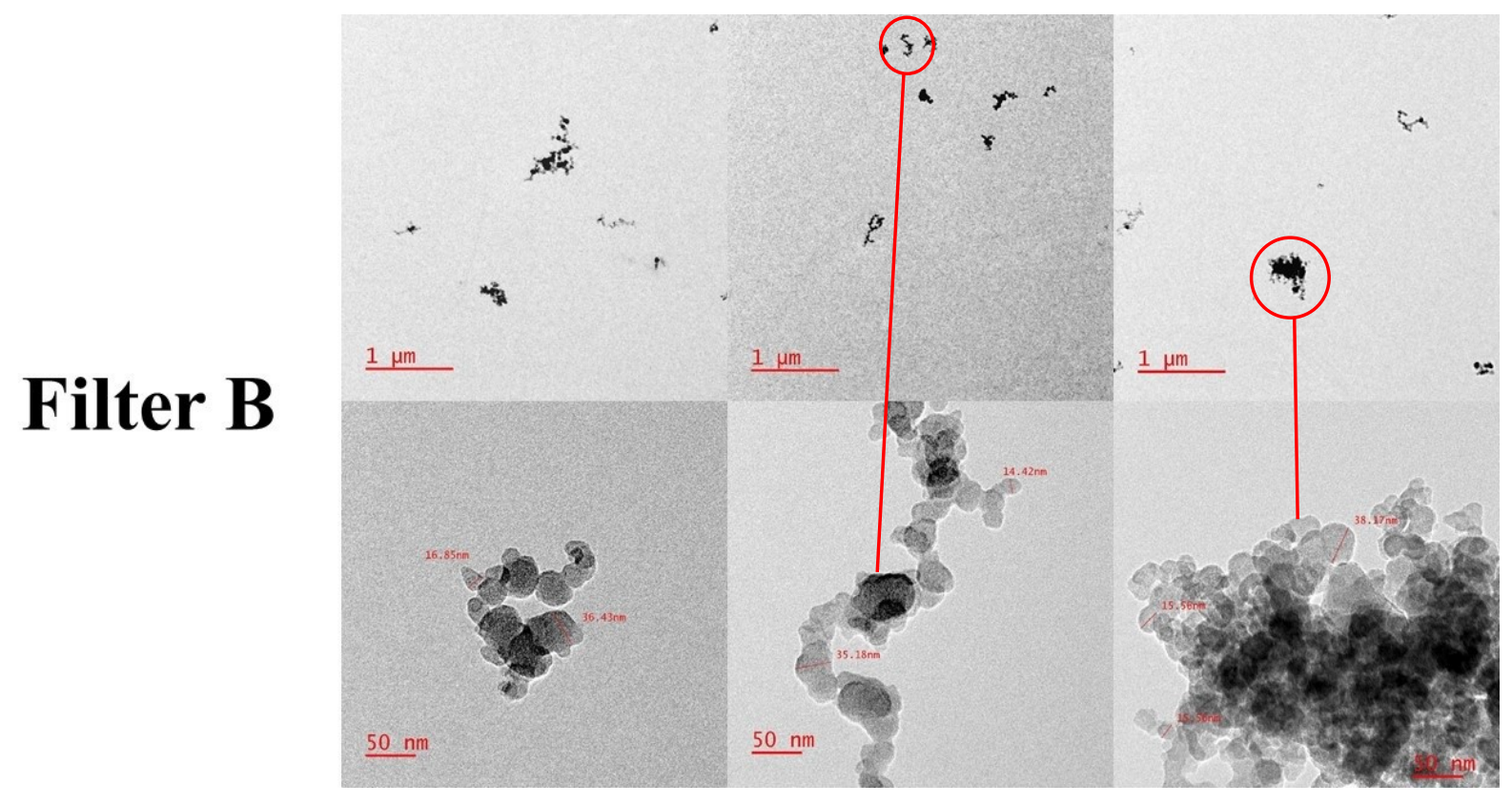

Figure 37: TEM grid analysis showing post GPF B emissions

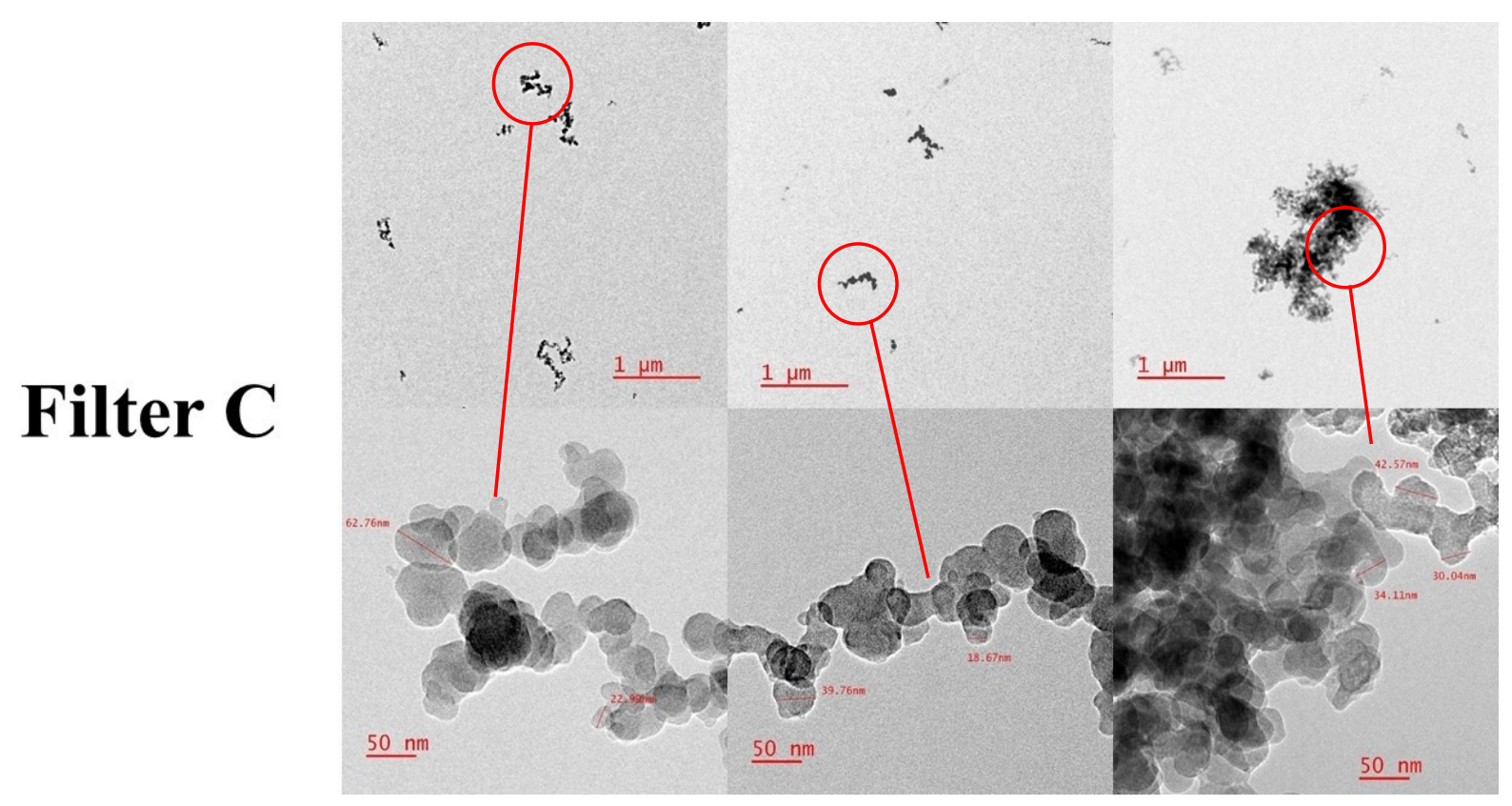

Figure 38: TEM grid analysis showing post GPF C emissions 


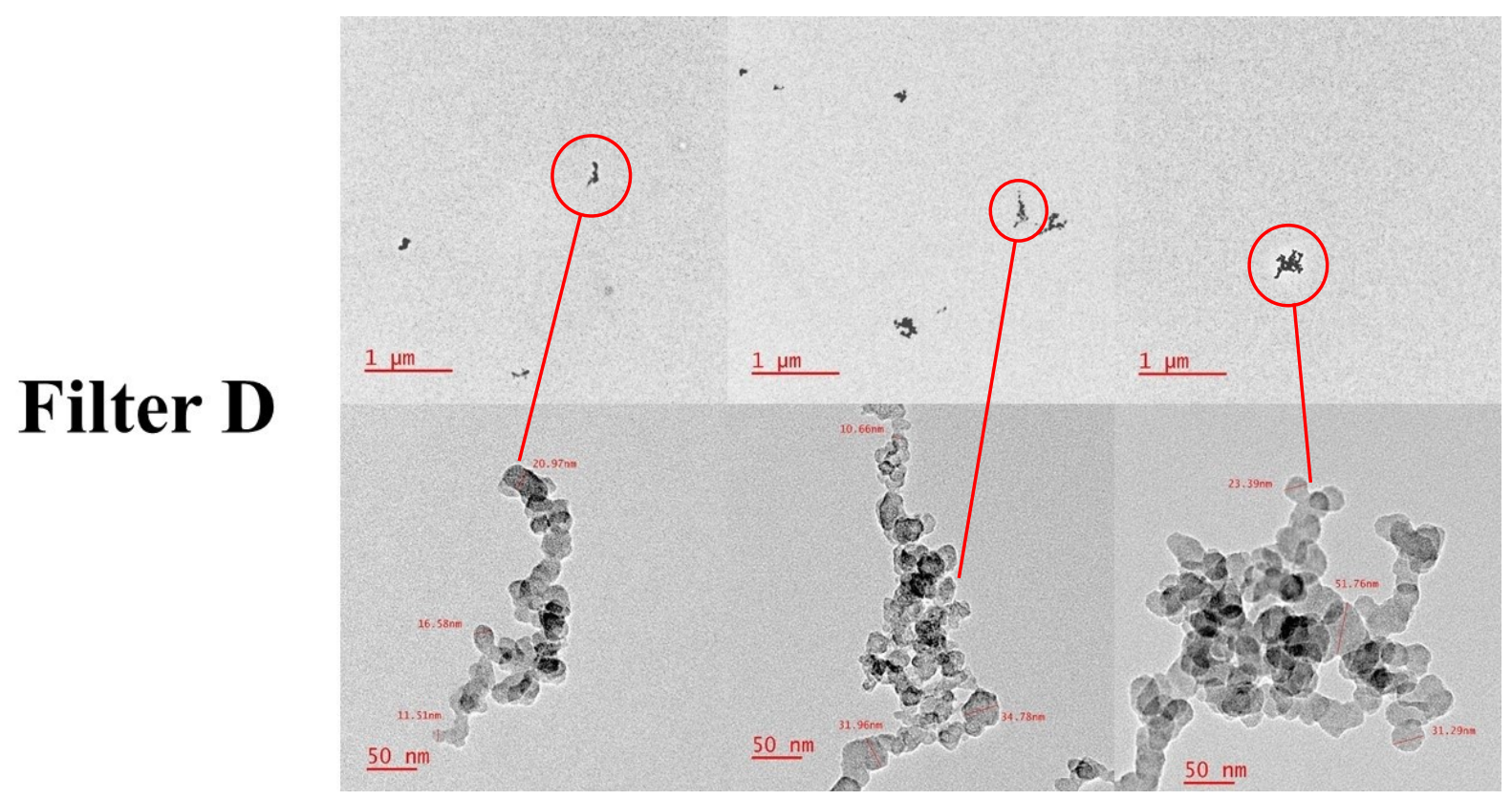

Figure 39: TEM grid analysis showing post GPF D emissions

From the TEM analysis, the following observations were made:

Filter A: The images show the smallest particle number on the $\mathrm{Cu}$ mesh from exhaust gas passing Filter A, indicating the highest filtration efficiency. This observation agrees with the results shown in Section 4.2.2. The particle clusters were also observed to be smaller compared to the pre-GPF images. The smaller primary particle diameter observed in Filter A images in further discussed in

\section{Section 4.2.3.1.}

Filter B: The images show a reduction in the number of particles deposited compared to pre-GPF images. The primary size of the particle clusters observed were larger than the one seen in Filter A.

Filter C: The size of the particle clusters observed was comparable to what was seen in Filter B (possibly attributed to the larger pore size in Filters B and C, $19 \mu \mathrm{m}$, compared to $13 \mu \mathrm{m}$ in Filters 
$\mathrm{A}$ and D). TEM images for Filter $\mathrm{C}$ also showed a particle number lower than that in the pre-GPF but higher than Filter A.

Filter D: Images also exhibit a reduction in the number of particles in addition to the size of the particle clusters deposited on the $\mathrm{Cu}$ mesh. The degree of reduction indicates a FE higher than Filters B and C but lower than Filter A.

\subsubsection{TEM Image Analysis Using ImageJ}

Image J is a Java based image editing, processing and analyzing program. Using ImageJ, the 50 nm TEM images were analyzed for primary particle diameter (3 images per sample). Figure 40 shows an image analysis performed on the TEM image of Filter D.

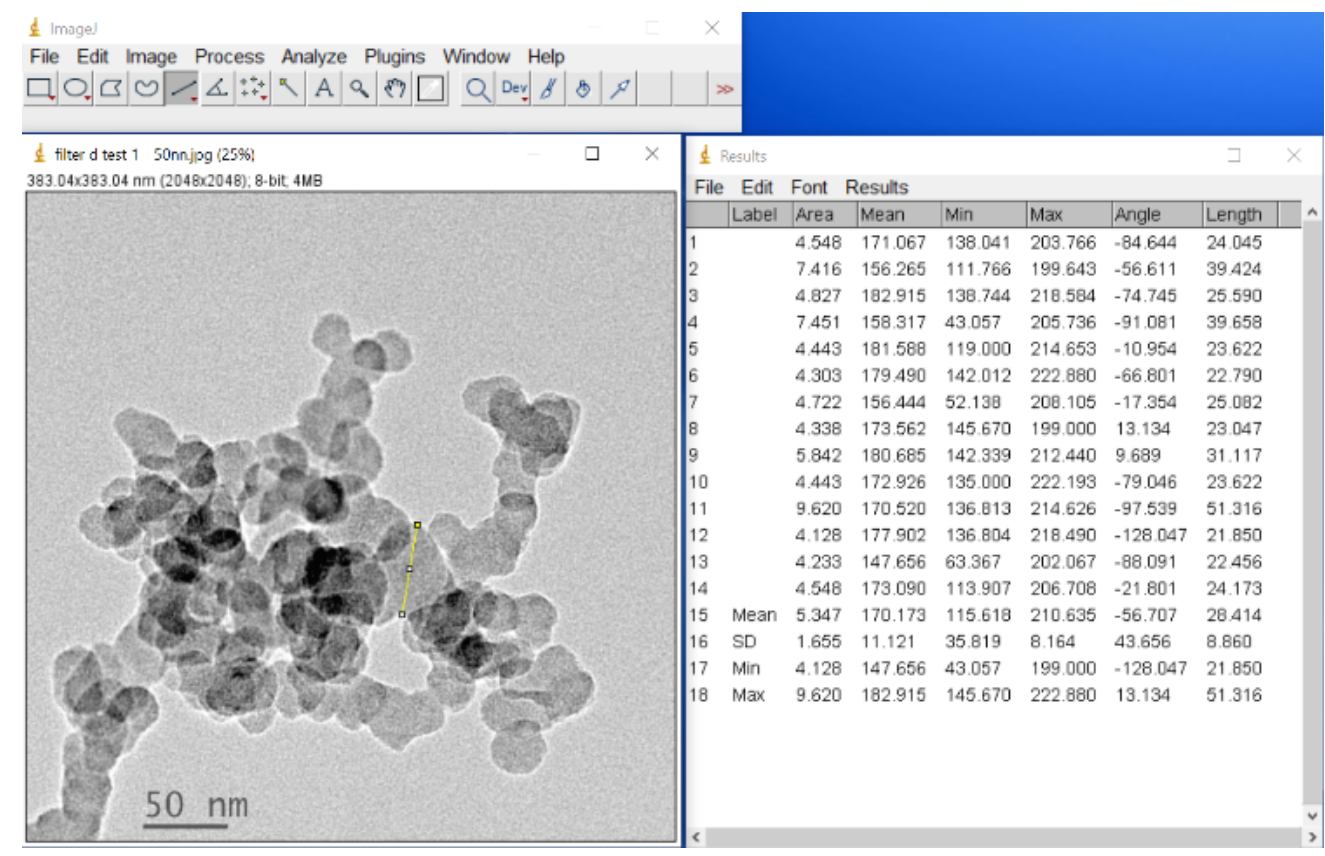

Figure 40: ImageJ analysis 
By customizing the scale and performing random particle diameter measurements across the image, ImageJ produced the average primary particle diameter. The image analysis results for all the filters is shown in Figure 41.

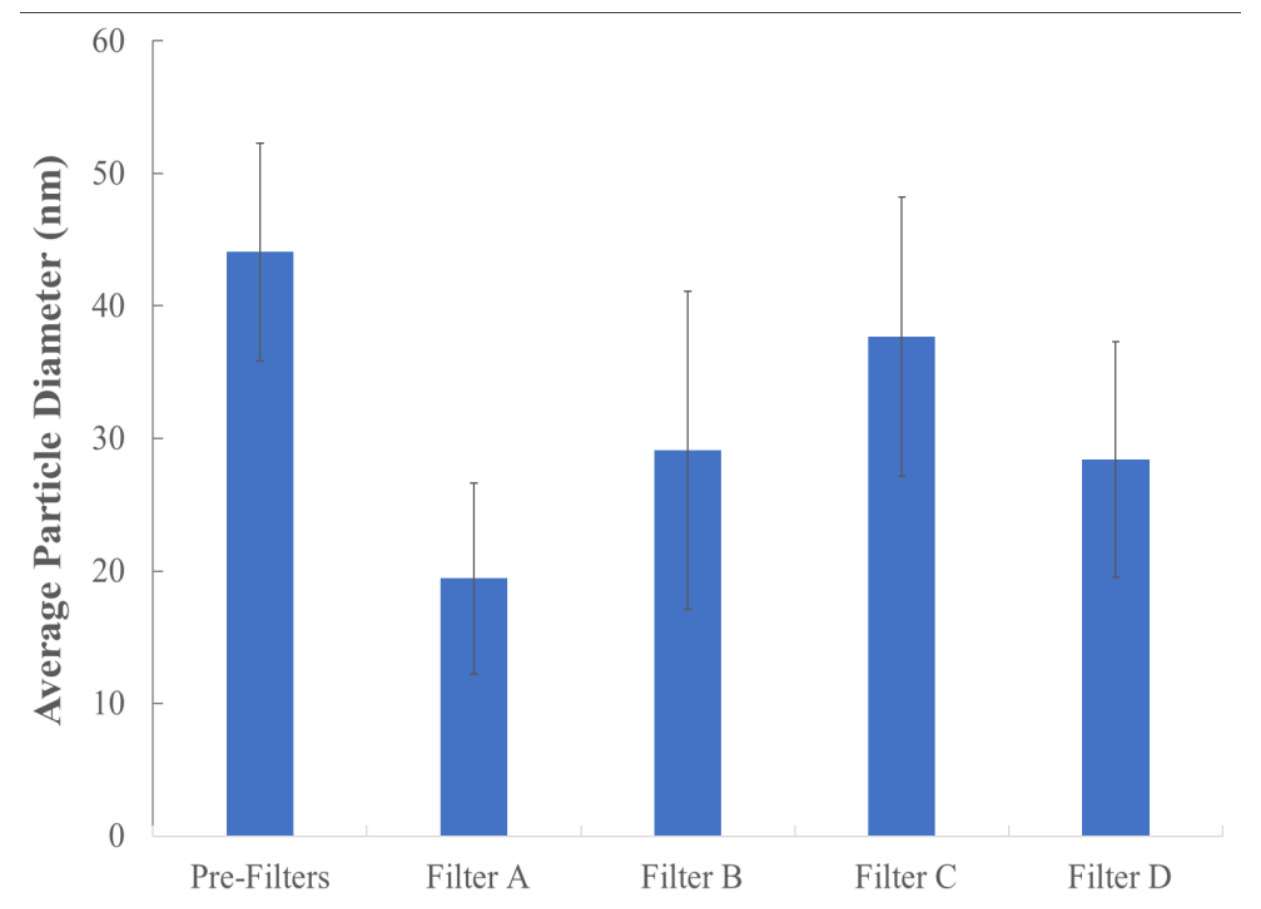

Figure 41: Average primary particle diameter using ImageJ analysis tool for both pre-filters and post filters

The ImageJ analysis was used to further support the general observation of particle sizes (primary particle diameters) being larger on average pre-filters. This also supports the theory discussed in Section 4.2.3. Results showed the smallest average primary particle diameter post GPF for Filter A. Filter D results showed the second highest average primary particle diameter post GPF. Due to the smaller Mean Pore Size (MPS) in Filters A and D (13 $\mu \mathrm{m}$ compared to $19 \mu \mathrm{m}$ in Filters B and C), the primary particle diameter post filters was observed to be smaller. Smaller pores get blocked faster as more soot is accumulated in the filter resulting in narrowing of the pores as more soot is 
deposited in them. This only allows for smaller particles to slip through unfiltered thus explaining the smaller primary particle diameter observed post Filters A and D. Studies [46] have shown that below approximately $550^{\circ} \mathrm{C}$, only low temperature soot oxidation is likely to occur without having a significant effect on the primary particle diameter and electric mobility. This indicates that it is not likely for oxidation to have been the reason for the differences in primary particle diameter, however further investigation is required to prove that. Filter $\mathrm{C}$ showed the highest average primary particle diameter post GPF followed by Filter B due to the larger MPS. Results followed the same trend (in terms of primary particle diameter) as seen in filtration efficiency where the smallest particle diameter seen post GPF was attributed to the highest filtration efficiency and the largest particle diameter to the lowest.

\subsubsection{SEM Analysis}

SEM Analysis was performed on the GPFs where a sample was cut from the inlet side of the filters and mounted in an SEM as shown in Figure 42. 


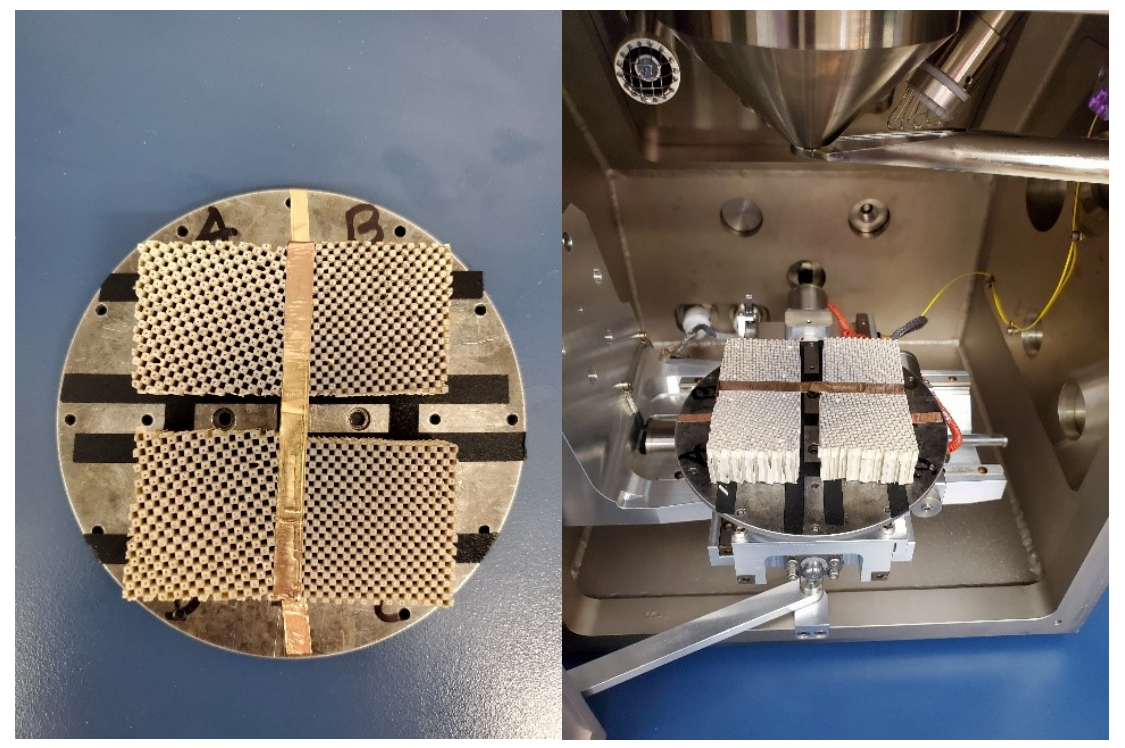

Figure 42: GPF SEM samples

Figures 43, 44, 45 and $\mathbf{4 6}$ show the SEM images of the four GPFs tested. Filters A and D showed similar SEM images in terms of particle deposition in the pores and on the wall which was expected considering they share similar properties (200 cpsi, 8 mil wall thickness and 55\% porosity) with the difference being the length of the filters.

An enlarged view of the filter A shows the soot deposits in the red circle in Figure 43. Typically black carbon or soot, having a smaller atomic number would appear darker in the SEM images. In this case, the filters were coated with gold in order to increase conductivity which would improve SEM image resolution. The lighter color particles observed in the images represent gold coated carbon. Due to the limited resolution of SEM, the detailed particulates cannot be observed; however, some clusters, in the range of several micrometers, can be seen in Figure 43 (b). Around 
the wall where the incoming gas enters the filter, there is a surface layer of darker contrast, indicating the deposit of low atomic number matters.

(a)

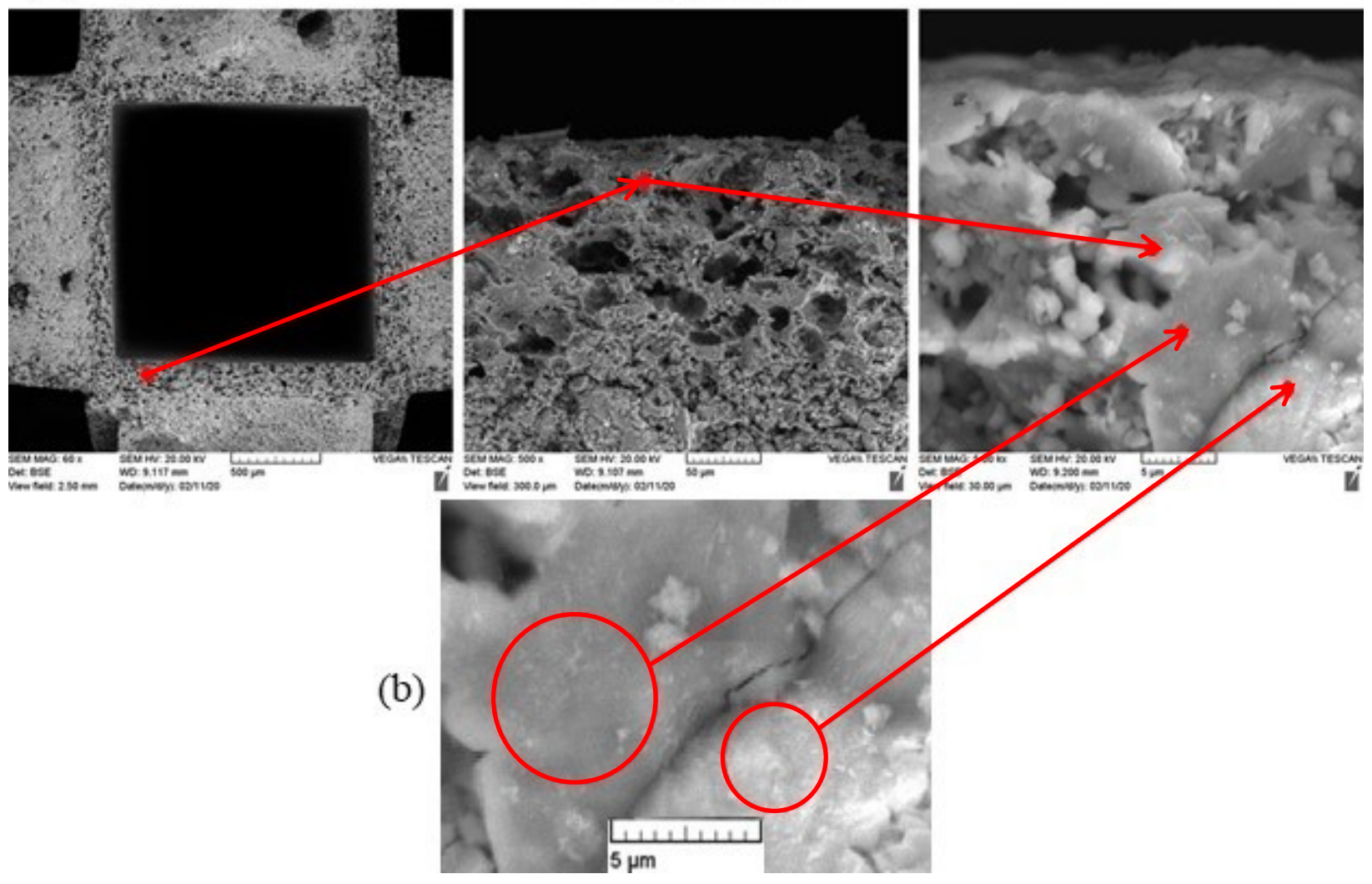

Figure 43: Soot deposition on filter A

Images for filter B showed the formation of fiber-like substances on the surface of the filter, as shown in Figure 44, marked in the red circles. Performing X-Ray Energy Dispersive Spectrometry (EDS) analysis on the fiber showed a composition including primarily Calcium (Ca) (as Ca is not expected to be observed in an EDS analysis of the GPF material Cordierite), as shown in Figure 47. A possible source for the Ca fibers observed is the mat material that situates between the ceramic filter and the metal can. The mat material can sometimes get frayed and dislodged thus settling on the filter material. The mat material is Si containing vermiculite, an engineered fiber 
all pressed/bound with an organic binder (proprietary). Again there is a surface layer exhibiting dark contrast, illustrating the deposit accumulation on the walls.

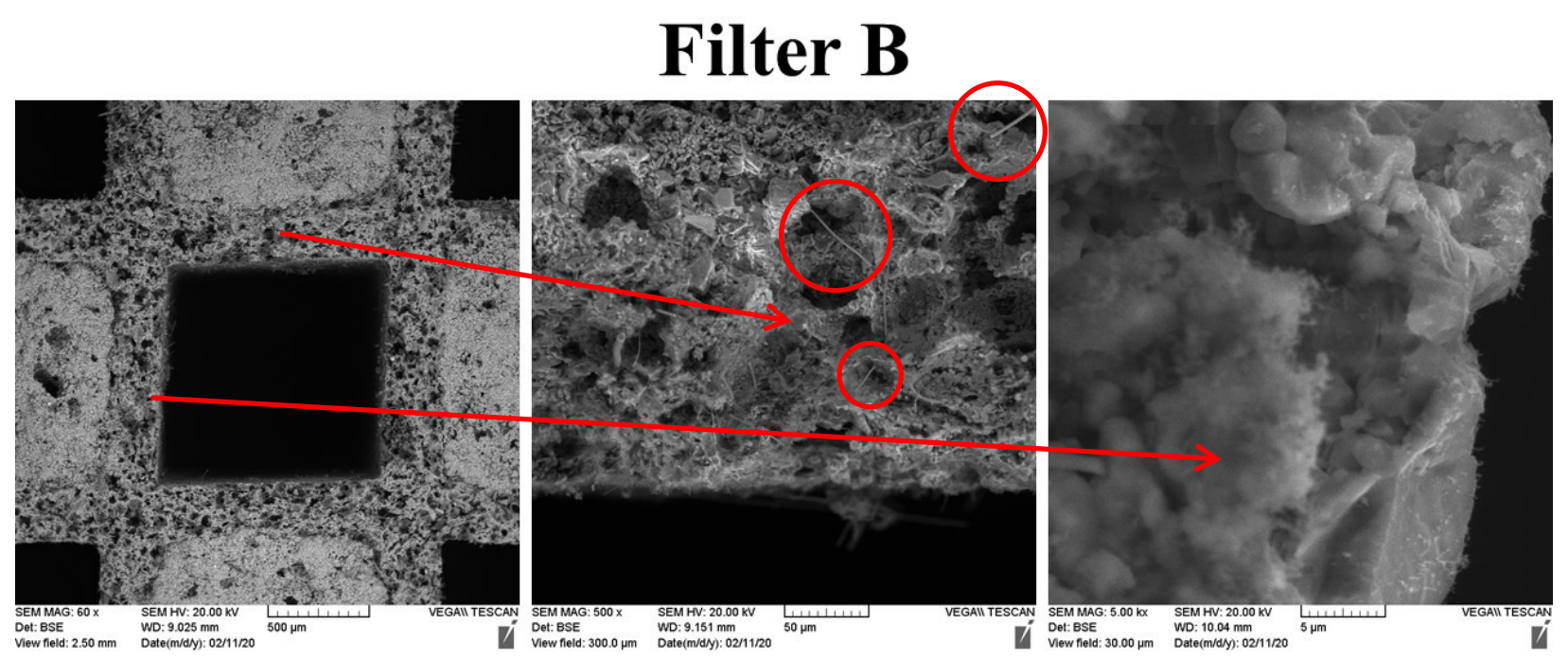

Figure 44: Filter B SEM images

Images for filter $\mathrm{C}$ showed the presence of clusters as shown in Figure 45. EDS analysis on the clusters revealed the presence of Cerium $(\mathrm{Ce})$ and Barium $(\mathrm{Ba})$ as shown in Figure 48. A possible source for the Cerium and Barium is likely from the upstream of the engine, where coolant or oil leakage can entrain lubricant or component that can consist of $\mathrm{Ba}$ and $\mathrm{Ca}$ (several studies have shown engine lubricating oil and additives to be a source of $\mathrm{Ca}$ and $\mathrm{Ba}$ [47], [48]). In addition, comparing Figure 44 and Figure 45, it seems that the particulate deposition is less on filter C. 


\section{Filter C}

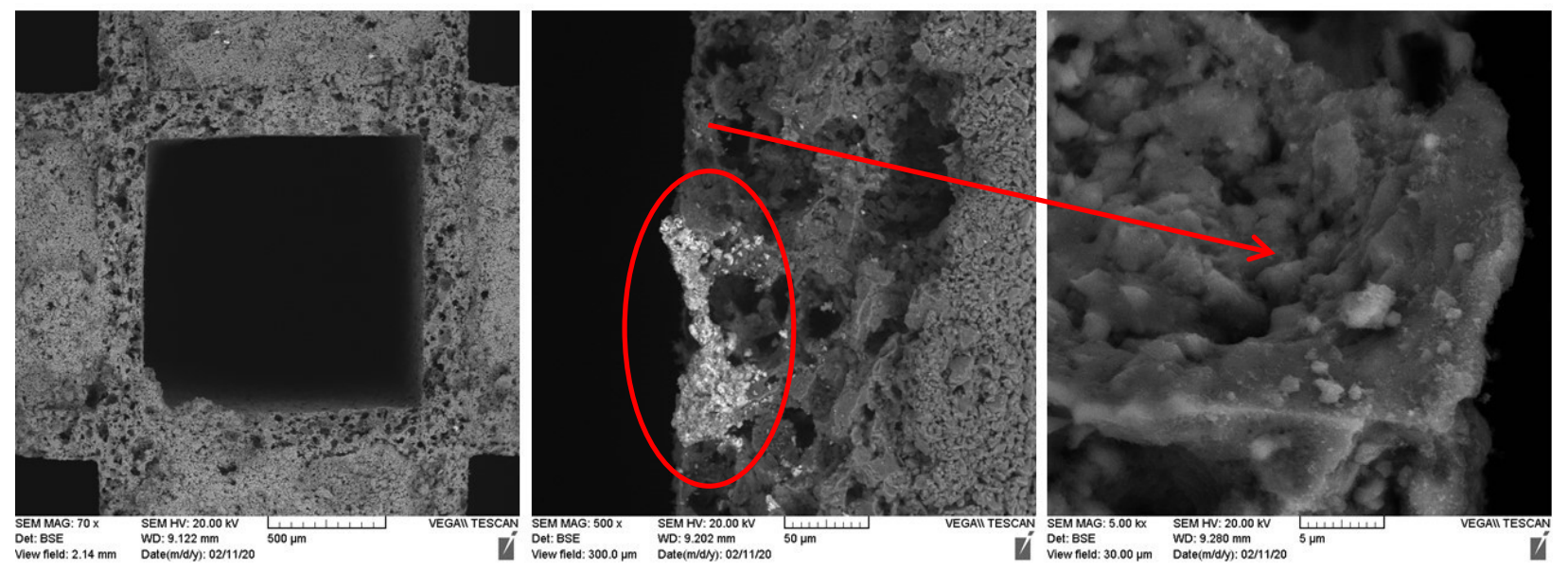

Figure 45: Filter C SEM images

\section{Filter D}

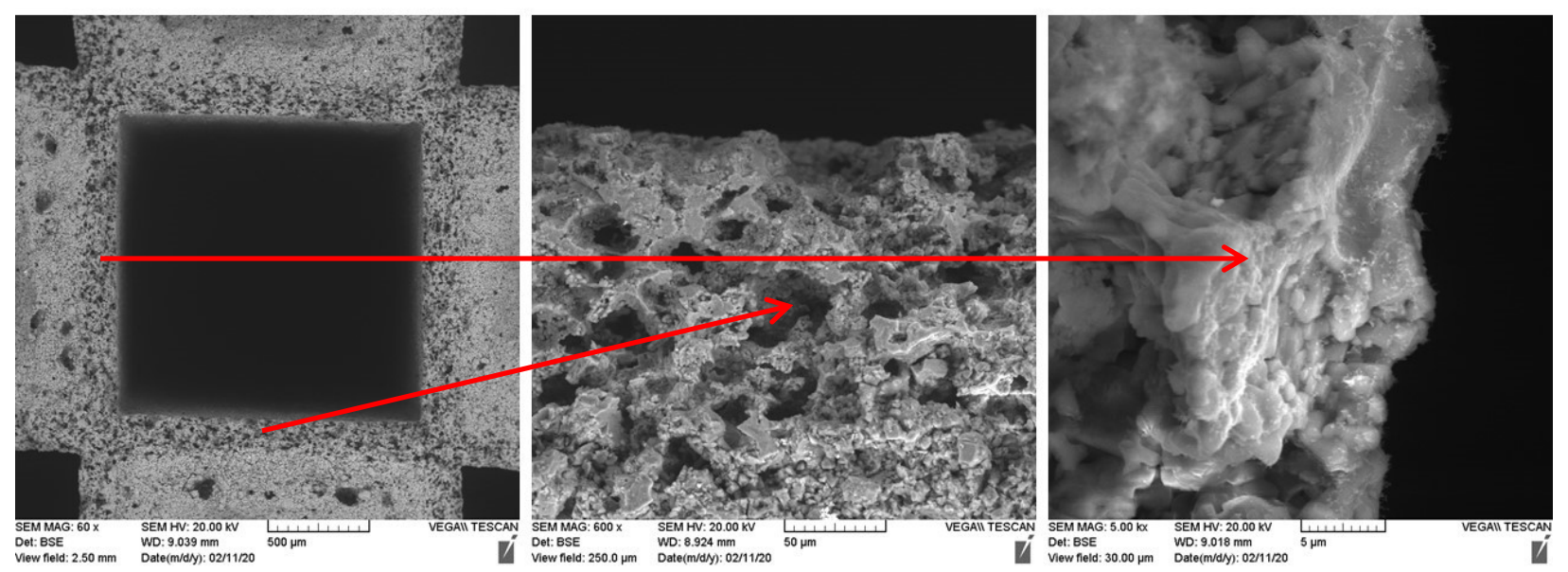

Figure 46: Filter D SEM images

For filter D, the particulate accumulation on the walls is about $150 \mu \mathrm{m}$. Within the pores, some minuscule particulate (less than $1 \mu \mathrm{m}$ ) can be seen as white particles. 


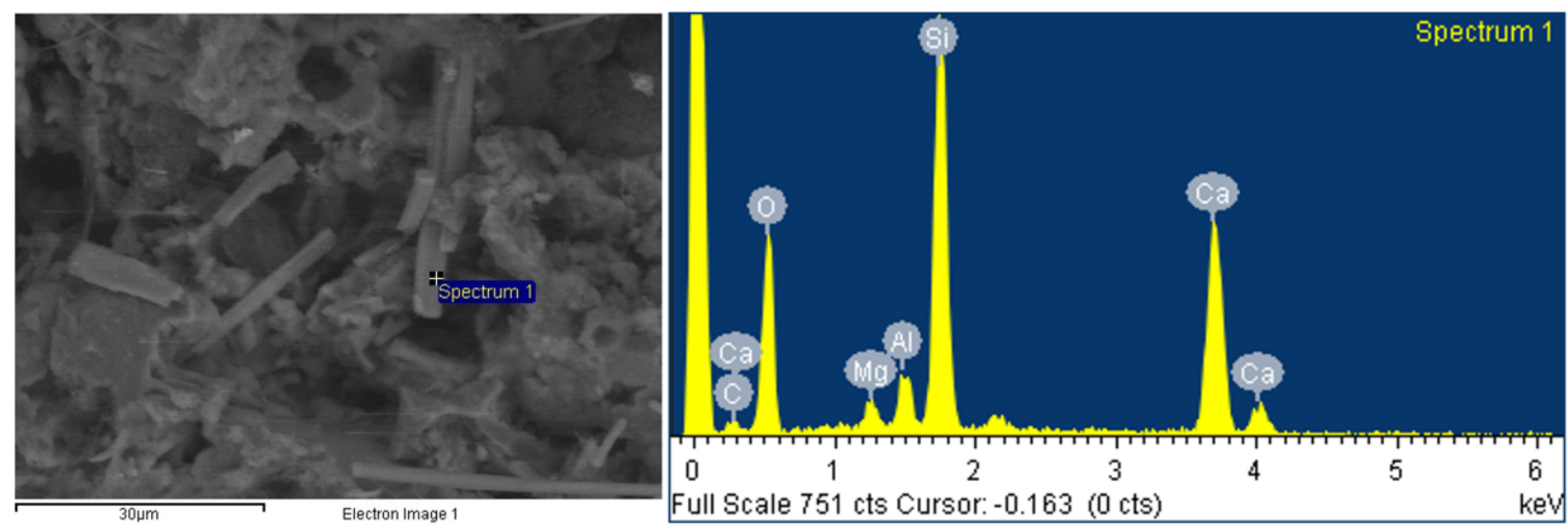

Figure 47: EDS analysis of filter B
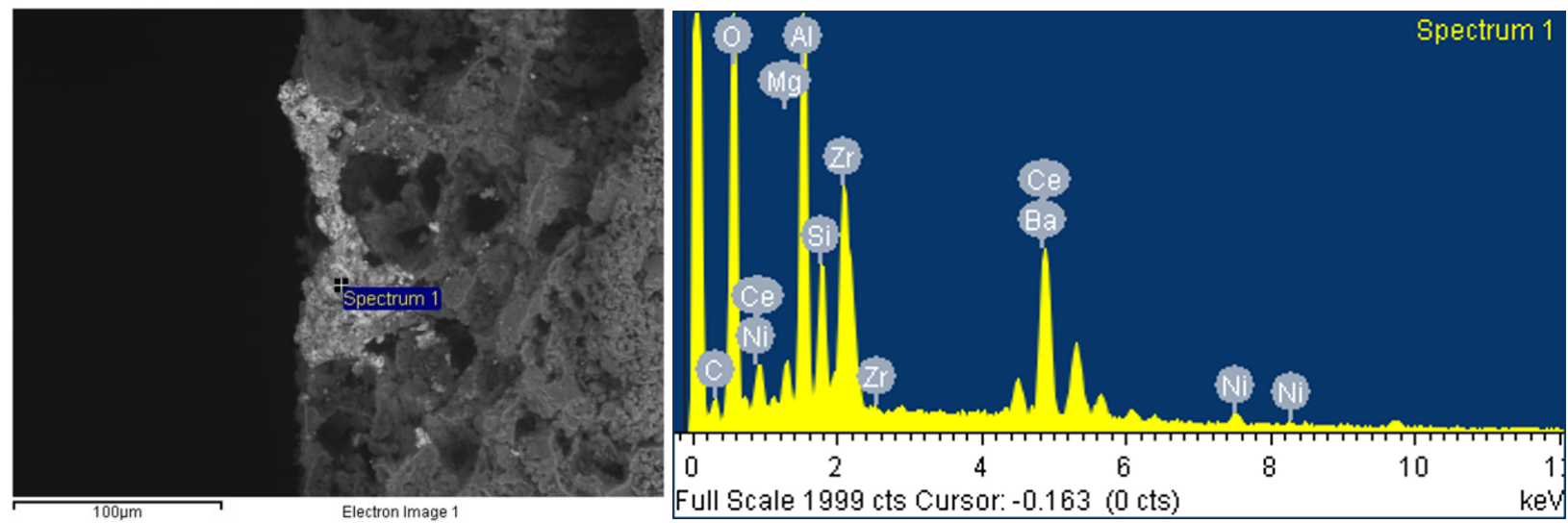

Figure 48: EDS analysis on filter $\mathrm{C}$

\subsubsection{High Soot Loading Effects on Soot Layer Formation}

In order to better observe the soot loading on the filters over long period of time, a filter with the same specifications as that of the most efficient filter tested (Filter A, 200/8 55\%) was chosen for further analysis. The clean slate filter was re-installed on the soot generator setup and loaded with a much higher concentration of soot $(3 \mathrm{~g} / \mathrm{L})$ in order to better observe the soot deposition in the filter pores and on the wall. Over the span of 9.8 hours, the filter was loaded with soot at an average 
concentration of $88 \mathrm{mg} / \mathrm{m}^{3}$ or $88 \times 10^{-6} \mathrm{~g} / \mathrm{L}$ for a total of approximately $3 \mathrm{~g} / \mathrm{L}$. The cumulative soot loading progression is shown in Figure 49.

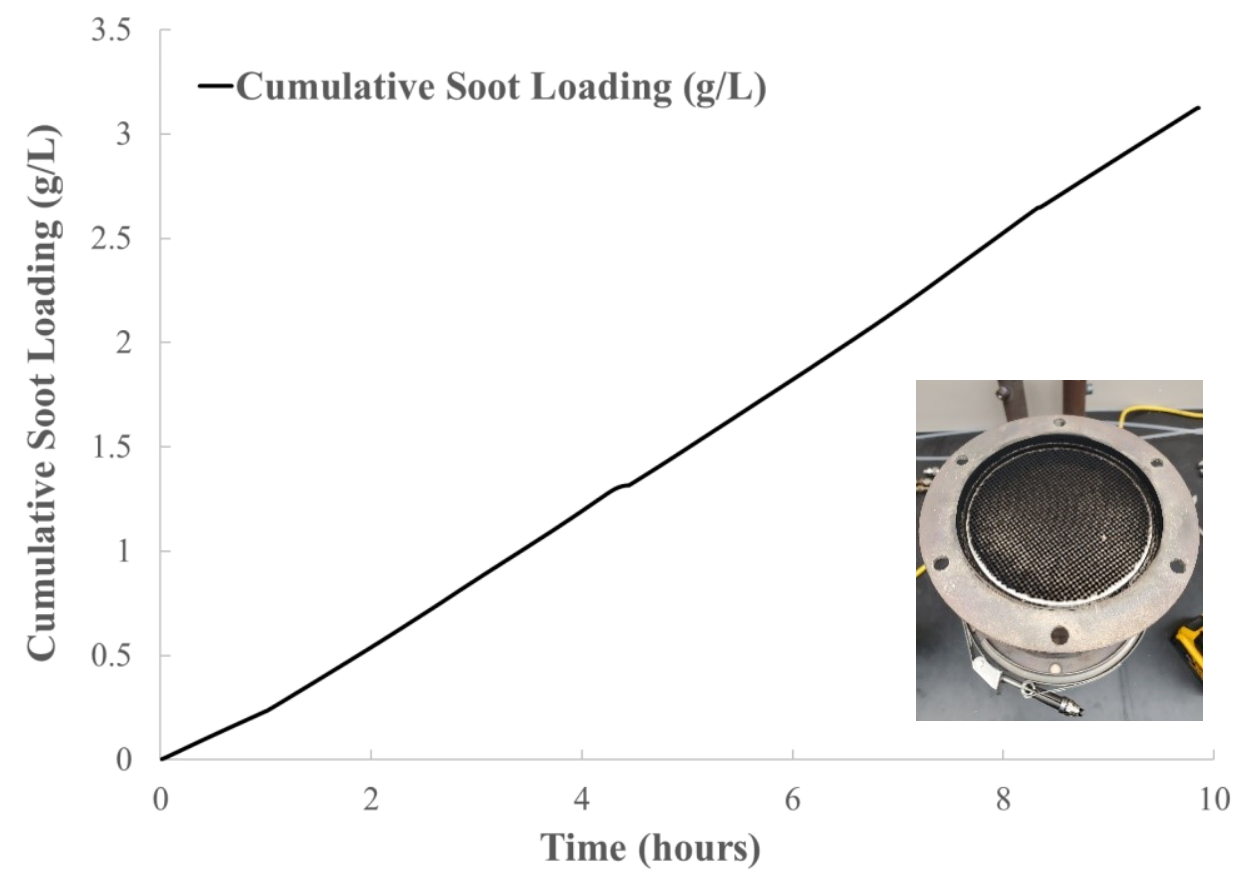

Figure 49: Bench soot loading for filter with 200/8 55\% specifications

After the test was completed, the filter was cut and analyzed using a Scanning Electron Microscope (SEM) and the resulting images are shown in Figures $\mathbf{5 0}$ and $\mathbf{5 1 .}$ 


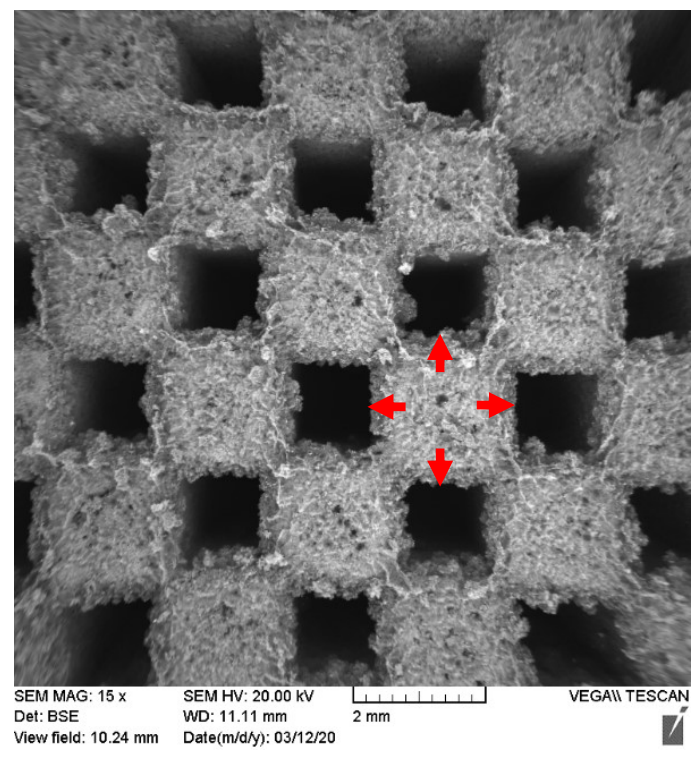

Figure 50: 15x magnification SEM image showing soot layer formation in the filter open channels from $3 \mathrm{~g} / \mathrm{L}$ of soot loading. The red arrows show the direction of accumulation of soot.

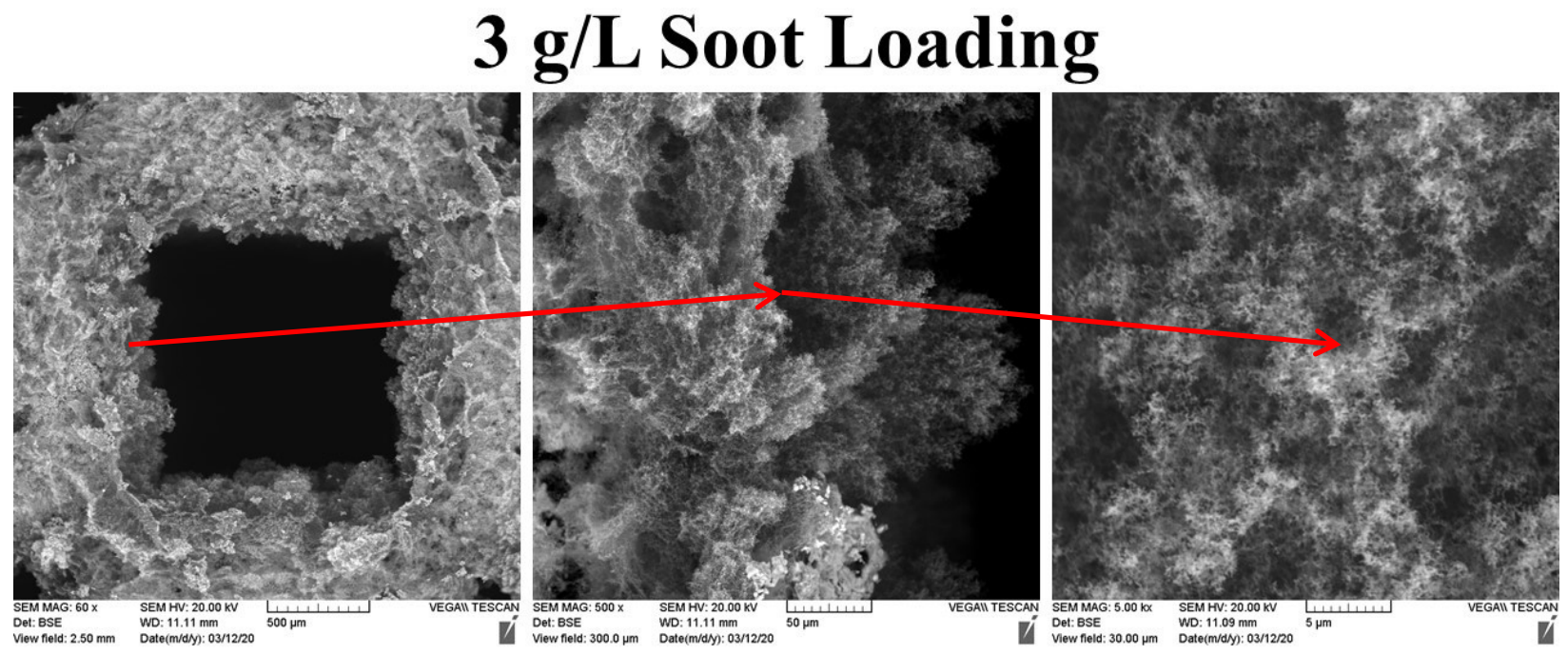

Figure 51: SEM images showing soot layer resulting from $3 \mathrm{~g} / \mathrm{L}$ of soot loading

As shown in Figures 50 and 51, the high soot loading resulted in blocking of the pores and the formation of a soot cake on the filter wall, as indicated in the figures. These images illustrate, as 
discussed in Section 4.1.1, that as the soot loading increased the filtration moved from the depth filtration in the pores to surface filtration on the surface of the walls where the soot cake itself acted as a highly efficient filter. In vehicle applications, this accumulated soot is burned off at the right conditions (oxygen and temperature) through passive regeneration reducing back pressure concerns. Figure 52 shows SEM image comparisons between a $0.054 \mathrm{~g} / \mathrm{L}$ soot loading scenario and a $3 \mathrm{~g} / \mathrm{L}$ soot loading scenario. It is apparent that the blocking of the pores and the formation of soot layer on the surface of the wall occurred for the higher soot loading scenario. 


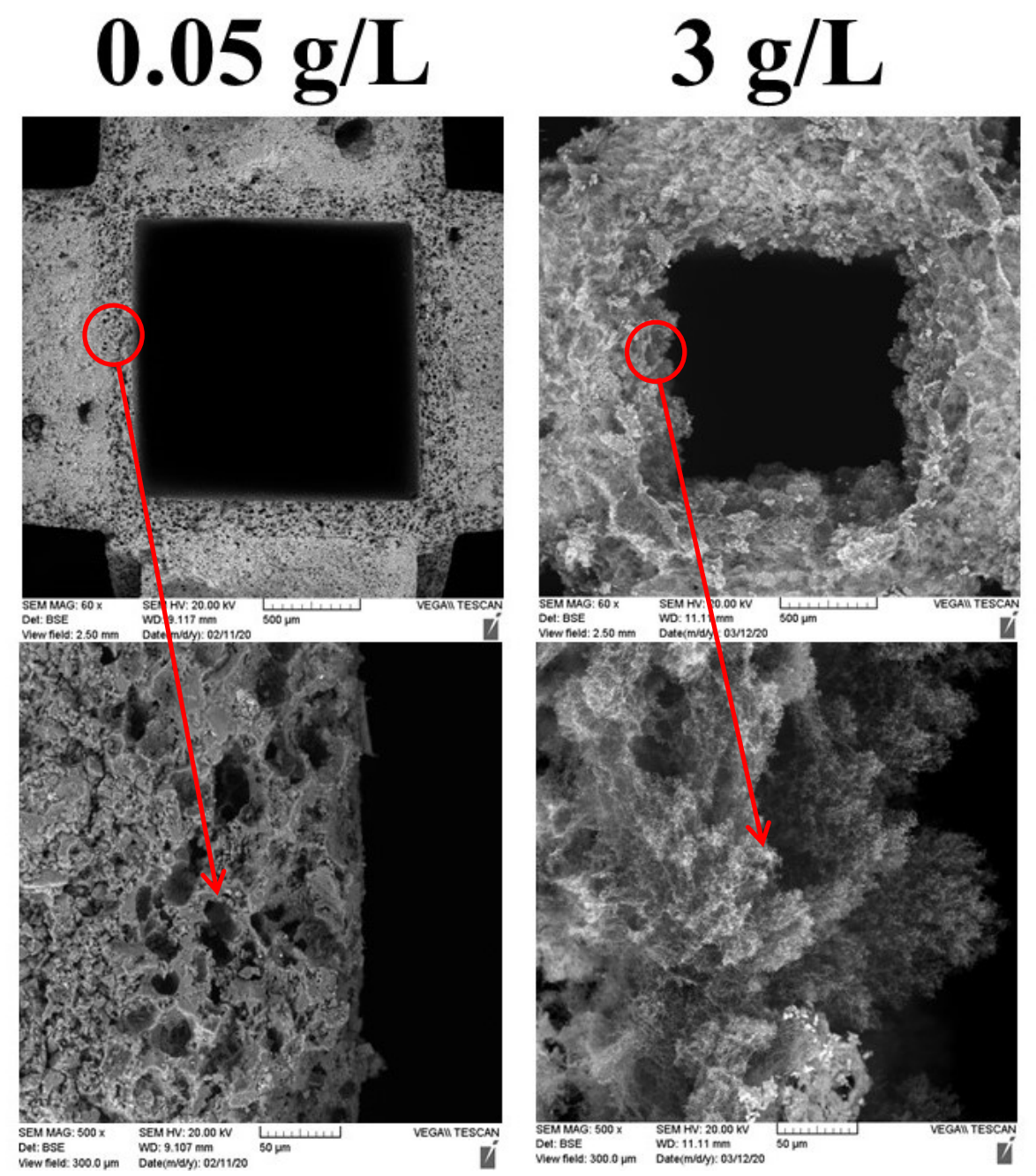

Figure 52: SEM image comparison between $0.05 \mathrm{~g} / \mathrm{L}$ soot loading and $3 \mathrm{~g} / \mathrm{L}$ soot loading

In terms of soot layer thickness, Tp, calculations, ImageJ was used to determine the parameters L1 and L2 needed for the calculation as highlighted in Section 2.7. Average L1 was determined to be 1713.6 $\mu \mathrm{m}$ and average L2 was determined to be $1422.5 \mu \mathrm{m}$ resulting in a soot layer thickness of $145.55 \mu \mathrm{m}$. 


\subsubsection{Engine Gaseous Results}

In the case of particle filters, it is important to realize the benefit of particle emission reduction without any negative effects on engine performance. These effects include: an increase in back pressure and a decrease in fuel efficiency that could result from GPF itself being added along the exhaust system and causing restrictions if not sized properly, in addition to the accumulation of soot and ash inside the GPF. For this research Carbon Dioxide $\left(\mathrm{CO}_{2}\right)$, Carbon Monoxide $(\mathrm{CO})$, Nitrogen Oxide $\left(\mathrm{NO}_{\mathrm{x}}\right)$ and Total Hydrocarbon (THC) concentrations were sampled from the CVS system and measured through a gaseous analyzer bench. $\mathrm{CO}_{2}$ concentrations as a function of time for different types of filters are shown in Figure 53.

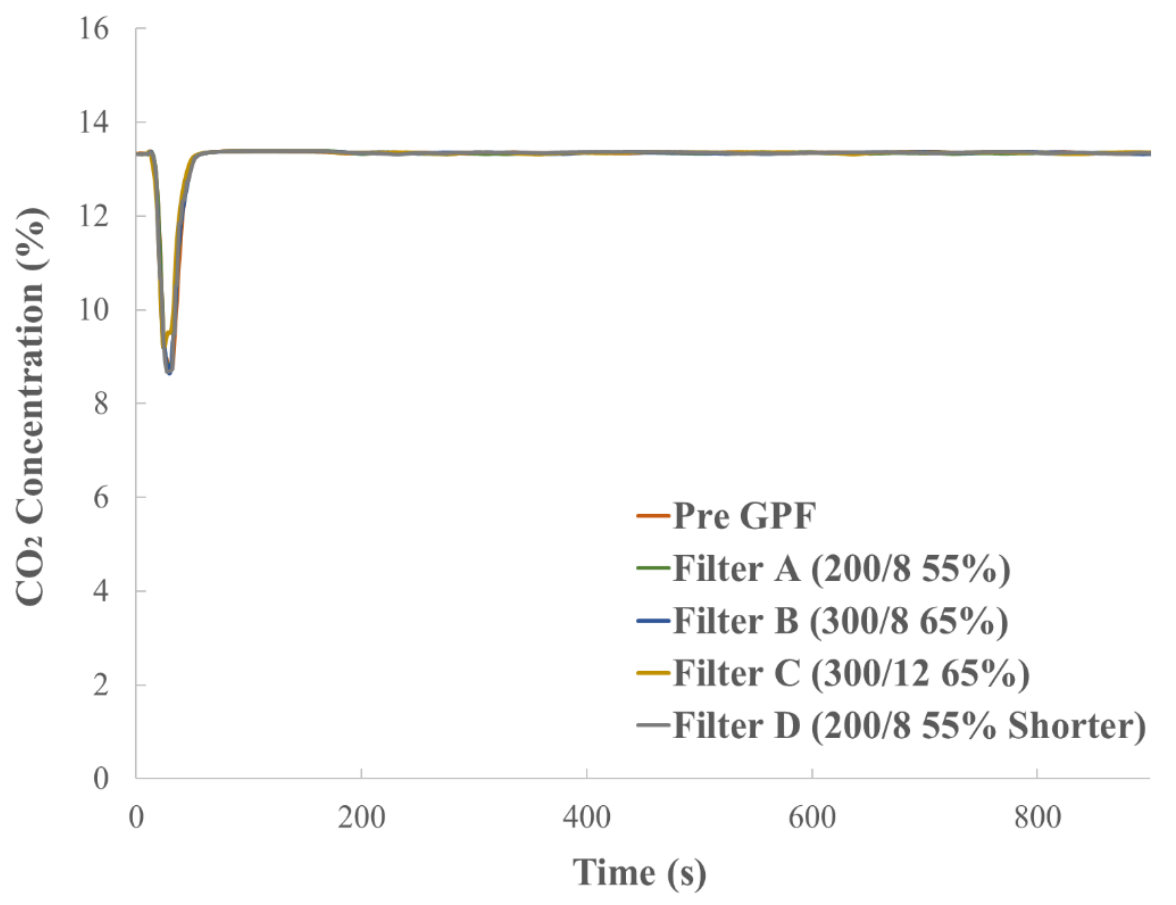

Figure 53: Carbon Dioxide concentrations versus time for the engine setup 
The $\mathrm{CO}_{2}$ concentration traces were almost identical for all four filters and identical to that of engine out or without any filter installed (there are some variations in the first 30 seconds which could be attributed to the slight variability of attaining idle rpm caused by the engine dyno controller. The slight difference had an insignificant effect on the average $\mathrm{CO}_{2}$ for the full cycle). Since $\mathrm{CO}_{2}$ emissions can be translated into fuel consumption the results indicated that the GPFs had no foreseeable negative effect on the fuel efficiency of the engine.

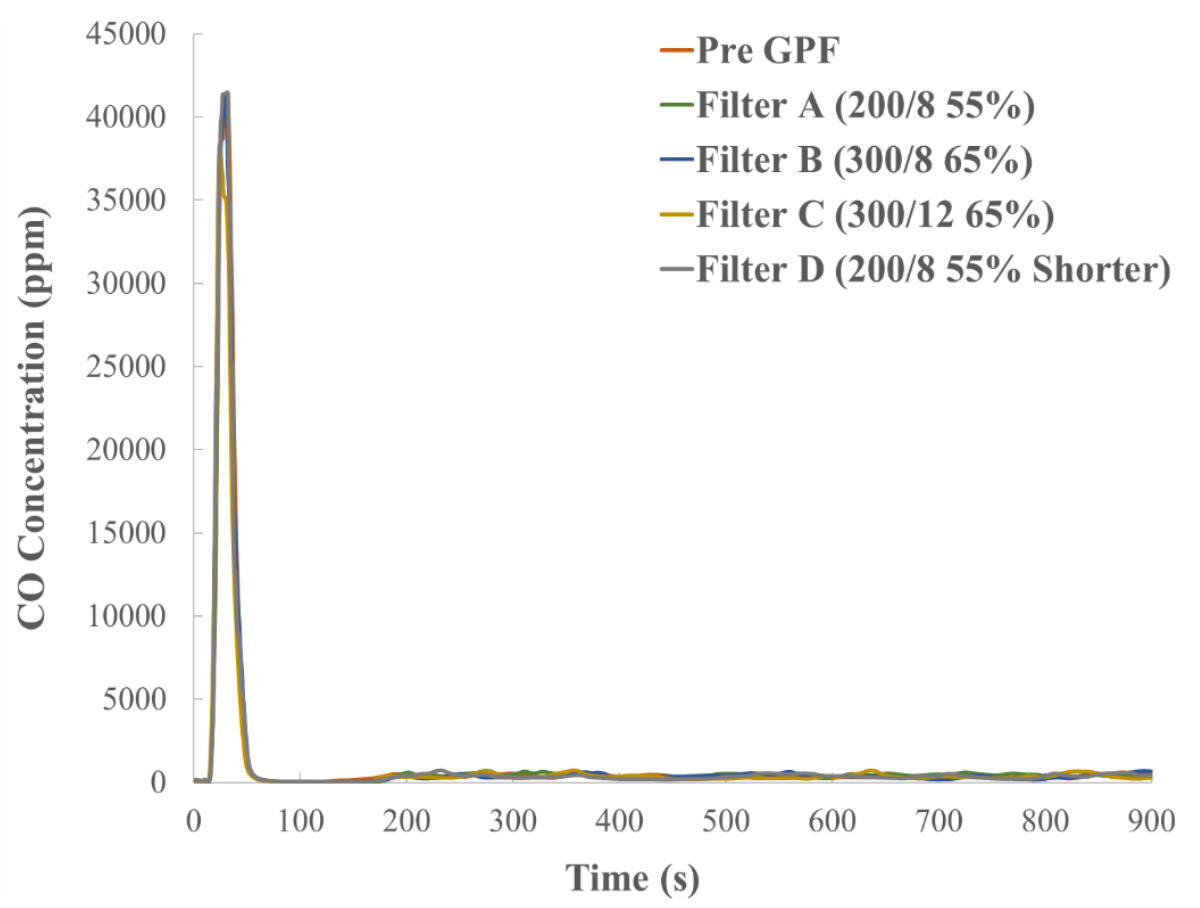

Figure 54: Carbon Monoxide concentrations versus time for the engine setup 


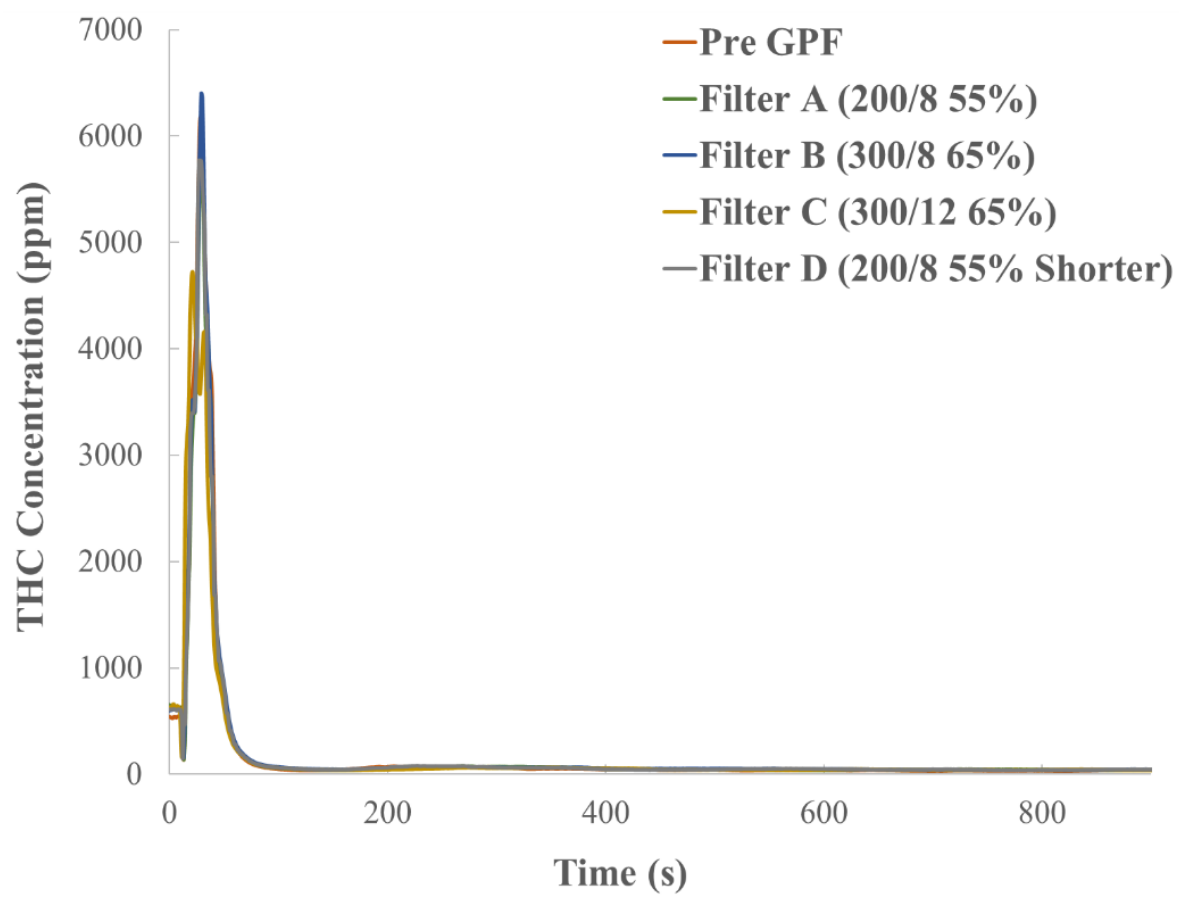

Figure 55: Total Hydrocarbon concentrations versus time for the engine setup

In terms of $\mathrm{CO}$ and $\mathrm{THC}$ (Figures 54 and 55), the same variability was observed at around 30 seconds into the test for possible reasons discussed above. The overall trend was almost identical for the remainder of the test for all the filters and almost identical to the pre-GPF configuration. 


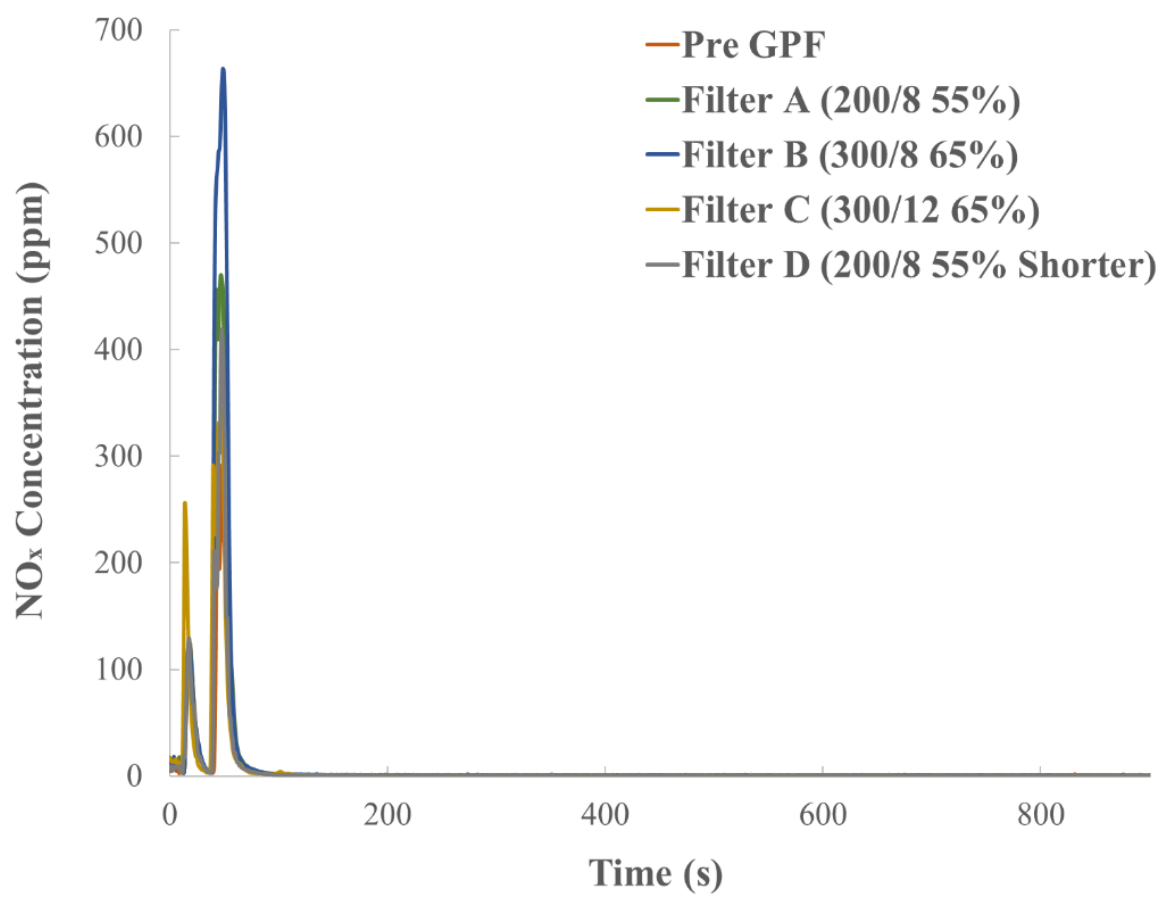

Figure 56: Nitrogen Oxide concentrations versus time for the engine setup

A larger variability was observed for the NOx results (Figure 56). This is dependent on the temperature of the catalytic converter which is also influenced by the ambient temperature inside the engine test cell during the test. After around 90 seconds, the NOx emissions drop to zero for all the filters. 


\subsection{Summary}

The purpose of this study was to investigate the effects of changing Gasoline Particulate Filter (GPF) specifications on the Particulate Matter (PM) Filtration Efficiency (FE) in addition to the particle size and morphology post-filters. Four filters were tested with varying specification with the first being filter A having an 8 mil wall thickness, 200 cells per square inch (cpsi) cell density and 55\% porosity. Filter B had an 8 mil wall thickness, $300 \mathrm{cpsi}$ and $65 \%$ porosity and was tested to investigate the effects of changing cell density and porosity (which are linked in the manufacturing process of the filters). Filter $\mathrm{C}$ had a 12 mil wall thickness, $300 \mathrm{cpsi}$ and $65 \%$ porosity and was tested to observe the effects of changing wall thickness. Filter D had similar specifications to filter A in terms of wall thickness, cell density and porosity but a shorter length in order to test the effects of a smaller physical size on the performance of the filters. The study was split into two parts, the first part being bench setup where the filters were tested with a set concentration of soot and create a model which was in turn verified through the second part of the study which was testing on a Gasoline Direct Injection (GDI) engine installed on an engine dynamometer setup.

Before the study was performed, filter A was expected to have the highest filtration efficiency as it was optimized for light duty vehicle applications (through the design and manufacturing process taking into consideration the optimum pore size, wall thickness, cell density and porosity). Filter D was expected to have a similar performance to filter A due to the close similarity of their specifications. Filters B and C were expected to have a lower filtration efficiency than filters A and $\mathrm{D}$, but the overall performance unknown due to the lack of literature available data for GPFs having those specifications. 


\subsection{Bench Setup Results Summary}

In the bench setup, the filter were loaded with soot for 10 minutes and the Filtration efficiency (FE) observed throughout the soot loading cycle and at the end of soot loading which adds up to around $0.054 \mathrm{~g} / \mathrm{L}$ (a typical unit designation for soot loading in particulate filters which is the cumulative mass loading per volume of exhaust). Results showed that, as predicted, filter A had the highest overall FE and reached 100\% after 340 seconds. Filters B and C did not reach $100 \%$ FE with maximum FE reached by filter B during the tests was $97.7 \%$ and that of filter C was 97 $\%$. The lower filtration efficiency in filter $\mathrm{C}$ was attributed to the bigger mean pore size (MPS) of $19 \mu \mathrm{m}$ (compared to $13 \mu \mathrm{m}$ in filters $\mathrm{A}$ and $\mathrm{D}$ ) which agreed with other studies showing decreasing FE with increasing MPS (refer to Section 4.1.1 of this thesis). The lower FE in filter B was attributed to the slower developing soot layer (called soot cake) resulting from the higher porosity. As for filter D, the smaller physical size and consequently the fewer smaller pores resulted in the particles slipping through the bigger pores faster than filter A resulting in a smaller overall FE.

In terms of the post-filter particle size distribution in the bench setup, results showed peaks between $90 \mathrm{~nm}$ and $120 \mathrm{~nm}$ for all the filters which was consistent with gasoline direct injection (GDI) particle size distribution indicating an appropriate representation of GDI engine particle number (PN) emissions. PN emission trends followed the black carbon (BC) trends with filter A having the lowest peak indicating the highest filtration efficiency $(\mathrm{FE})$ and filter $\mathrm{C}$ having the highest peak indicating the lowest overall FE.

Filter A, having the highest overall filtration efficiency was selected for higher soot loading of 3 $\mathrm{g} / \mathrm{L}$ (approximately 9.8 hours) in order to better observe the soot layer formation in the pores and on the filter wall. The formation of the soot layer was observed using SEM analysis where the 
analyzed sample of the GPF was cut using a diamond tip band saw from the inlet side of the filter. Results, in Figure 47, showed the difference between the low soot loading of $0.054 \mathrm{~g} / \mathrm{L}$ and a higher soot loading of $3 \mathrm{~g} / \mathrm{L}$ and the plugging of the filter pores with soot completely and the formation of the soot cake on the filter wall. That showed the transition between depth filtration in the filter pores to the surface filtration on the filter wall where the soot cake itself acted as a highly efficient soot filter.

\subsection{Engine Testing Summary}

The bench setup testing of the filters was followed by engine testing in order to investigate the GPF performance under more real world conditions and verify the results obtained from the bench testing. The filters were fitted on a 2.4 L GM ECOTEC GDI gasoline direct injection (GDI) engine installed on an engine dynamometer and tested following a steady state ramp up cycle representing an average of a federal test cycle used in vehicle certification (discussed in Section 3.3.2).

Soot Filtration efficiency results for the engine setup showed a similar trend as shown in the bench setup in terms of filter A having the highest filtration efficiency (FE) an filter $\mathrm{C}$ having the lowest FE due to reasons discussed in Section 5.1. Some discrepancies in the results were also observed in terms of filter A reaching $100 \% \mathrm{FE}$ after 230 seconds into the engine test compared to 340 seconds for the bench test. In order to understand the causes of the discrepancy the particle size distribution post filters was observed. Particle Number (PN) results showed a peak at around 80 $\mathrm{nm}$ particle size compared to $120 \mathrm{~nm}$ for the bench setup. This difference in particle size distribution peaks could explain the discrepancy in filtration efficiencies as the filtration mechanism inside the filters depends on multiple factors which include particle size, as discussed 
in Section 4.2.2. The filtration mechanism for the $80 \mathrm{~nm}$ particles was Brownian diffusion which has a higher efficiency than the filtration mechanism for the $120 \mathrm{~nm}$ particles which was transitional phase between diffusion and impaction.

Another discrepancy between bench results and engine results observed was the difference in clean slate filtration efficiency or the FE at the beginning of the test before any soot loading. Results showed lower GPF clean slate FE when tested on the engine setup. This could be attributed to the difference in composition of the particulate matter emitted by the soot generator compared to the GDI engine. In the soot generator, as the name indicates, generates primarily soot or elemental carbon or black carbon (typically refer to the same thing) which is only a fraction of the total PM emitted by the engine. It also generates a small fraction of organic carbon. In the engine, elemental carbon, organic carbon, sulfates, nitrates and ash are emitted which could have potentially affected the FE without any soot accumulated.

TEM analysis was also performed where particulate matter was collected on copper grids pre and post filters using electro-static precipitation and the grids were analyzed under different magnifications in order to observe the particle morphology. ImageJ was used to analyze the TEM images and results showed a larger average primary particle diameter pre-GPFs than what was observed post-GPFs. This could be explained by the particle size distribution analysis for pre-GPF particles. The analysis showed a second particle peak around $160 \mathrm{~nm}$ in addition to the primary peak at around $50 \mathrm{~nm}$. Particle size distribution analysis performed on particles post-filters did not show the second peak which could explain the smaller particle size post-filters. TEM image results also showed filter A having the lowest particle number indicating the highest filtration efficiency which supported both the soot and particle number results. 
Similar to the bench setup, SEM analysis was performed on all the GPFs tested where a sample was cut from the filter inlets and analyzed. The soot particles were observed as lighter color material specs in the filter pores and the filter wall. The lighter color was due to the gold coating for improved conductivity and image quality. Images of filter B showed tube or fiber like formations. X-Ray energy Dispersive Spectrometry (EDS) showed that the composition of the tubes included Calcium. The fibers could have been a result of the mat material wedged between the filter and the steel can which can become dislodged and deposit on the filter surface. EDS analysis for filter $\mathrm{C}$ images showed clusters including Calcium and Barium resulting from entrained lubricant or engine and exhaust system component coating.

Gaseous emissions from the engine were also measured and analyzed in order to investigate any effect of the GPFs on engine performance and fuel efficiency due to back pressure. No significant differences in results (specifically $\mathrm{CO}_{2}$ results) showed that the GPFs had no effect fuel efficiency (calculated from gaseous emissions through carbon balance). This indicated that back pressure was not a concern for the engine testing performed. Under engine operation and due to the high exhaust temperatures, the accumulated soot could be burned off by what is known as passive regeneration. This requires the heat from the exhaust and the excess air from a throttle closing event. This typically occurs in vehicles after a hard acceleration followed by accelerator pedal lift off. 


\subsection{Conclusions and Future Work}

This study reflected the effects of changing GPF specification like porosity, wall thickness and length on the filtration efficiency and the importance of having a balanced and optimized set of specifications in order to achieve the highest filtration efficiency from the start of the lifecycle of the filters. The analysis of the results highlighted some conclusions as listed below:

- A typical GPF wall thickness of 8 mil ( 8 thousands of an inch) is optimized by the GPF supplier for light duty vehicle applications and used by industry as the standard wall thickness for ceramic wall-flow filters.

- The mean pore size (MPS) of the filters had a greater effect on filtration efficiency (FE) than wall thickness. This was observed by comparing an 8 mil wall thickness filter having a $13 \mu \mathrm{m}$ MPS (filter A) to a 12 mil wall thickness filter having a $19 \mu \mathrm{m}$ MPS (filter C). In theory the larger wall thickness should have resulted in a higher FE whereas in the application of this study that effect on FE was outweighed by the larger MPS where lower FE was observed in filter $\mathrm{C}$.

- Reducing the physical length of the filter had a smaller effect on FE than changing porosity, wall thickness and MPS. In this study the length was reduced by $23 \%$ and the other specifications were kept the same. The shorter filter (filter D) still reached a maximum FE of $99.8 \%$.

- Increasing the porosity from $55 \%$ to $65 \%$ had a negative effect on FE due to the increased pore size that accompanies the increased porosity in the manufacturing process. Typically, a higher porosity is used when the filter is catalyzed (with a Platinum Group Metal (PGM) 
coating for gaseous conversion) in order to leverage the coating and reduce back pressure concerns.

- The GPFs used in this study (all un-catalyzed), did not show evidence of high back pressure and did not affect fuel efficiency. In light duty vehicles (using internal combustion engine without hybridization), accelerations and pedal lift off typically provides sufficient heat and $\mathrm{O}_{2}$ in order to burn off the accumulated soot inside the GPF through passive regeneration. Sufficient passive regeneration reduces any back pressure concerns.

- Deposits from coolant, oil and lubricant can impinge on the filter wall and be observed using scanning electron microscopy. The effect of such deposits was not studied but they may affect the durability of the filter. These deposits differ from the exhaust particulate matter which the GPFs were designed to reduce.

Research in the gasoline particulate filter field is still relatively new and more studies are needed in order to maximize their efficiency and longevity. Several opportunities could be considered to build upon the research conducted in this thesis which include:

- Catalyzing the GPFs used and investigating the effect of the PGM coating on the overall filtration efficiency of the filters.

- Accumulating ash (which consists of inorganic elements such as metals) on the filters and observing the effect on FE and back pressure. Studies have shown that ash accumulates on the filter wall surface as the filter ages (from usage in ICE vehicles) and that ash improves FE as it acts as a filtration medium itself. Ash on the other hand, does not oxidize like soot and does not burn off raising a back pressure concern in the extended life span of the GPFs. 
- Testing the GPFs on hybrid gasoline-electric engines and observing the effect on passive regeneration. Due to the intermittent operation of the ICE engine in hybrid vehicles, the exhaust temperature is typically lower and therefore may not provide enough heat for passive regeneration to occur. Without any passive regeneration of the soot, it continues to accumulate affecting the pressure drop across the exhaust system and ultimately the engine performance. 


\section{Appendix A: Filtration Efficiency Uncertainty Analysis}

An experimental uncertainty analysis was performed on the soot filtration efficiency (FE) calculations for the four filters tested in this thesis. Equation 5 was used:

$$
F E=\frac{C_{\text {pre-filter }}-C_{\text {post-filter }}}{C_{\text {pre-filter }}} \times 100 \%
$$

where: $C_{\text {pre-filter }}$ is the soot concentration pre-filter in $\mathrm{mg} / \mathrm{m}^{3}$ and $C_{\text {post-filter }}$ is the soot concentration of post-filter in $\mathrm{mg} / \mathrm{m}^{3}$.

The soot concentration measurements were the main source of bias in the above equation. FE uncertainty was calculated according to Equation 6:

$\sigma_{F E}=f\left(\sigma_{C_{\text {pre-filter }}}, \sigma_{C_{\text {post-filter }}}\right)=$
$\pm \sqrt{\left(\frac{\partial F E}{\partial C_{\text {pre-filter }}} \cdot \sigma_{C_{\text {pre-filter }}}\right)^{2}+\left(\frac{\partial F E}{\partial C_{\text {post-filter }}} \cdot \sigma_{C_{\text {post-filter }}}\right)^{2}}$

where:

$\sigma_{F E}:$ uncertainty of soot filtration efficiency in $\%$

$f\left(\sigma_{C_{\text {pre-filter }}}, \sigma_{C_{\text {post-filter }}}\right)$ : function of soot concentrations pre- and post-filters

$\frac{\partial F E}{\partial C_{\text {pre-filter }}}$ : partial derivative of Equation 5 determined to be $\frac{100 C_{\text {post-filter }}}{\left(C_{\text {pre-filter }}\right)^{2}}$

$\frac{\partial F E}{\partial C_{\text {post-filter }}}$ : partial derivative of Equation 5 determined to be $\frac{-100}{C_{\text {pre-filter }}}$

$\sigma_{C_{\text {pre-filter }}}$ : uncertainty of the AVL Micro Soot Sensor measurement pre-filters

$\sigma_{C_{\text {post-filter }}}$ : uncertainty of the AVL Micro Soot Sensor (MSS) measurement post-filters 
$\sigma_{C_{\text {pre-filter }}}$ and $\sigma_{C_{\text {post-filter }}}$ were determined from the AVL MSS instrument manual to be $\pm 5 \%$ of the soot measurement. The 5\% represents the threshold beyond which the instrument produces an error and requires calibration. In other words, the $5 \%$ is the maximum set bias allowed by the instrument before it produces a measurement error.

By substituting the partial derivatives, Equation 6 can be expanded to Equation 7:

$\sigma_{F E}= \pm \sqrt{\left(\frac{100 C_{\text {post-filter }}}{\left(C_{\text {pre-filter }}\right)^{2}} \cdot \sigma_{C_{\text {pre-filter }}}\right)^{2}+\left(\frac{-100}{C_{\text {pre-filter }}} \cdot \sigma_{C_{\text {post-filter }}}\right)^{2}}$

Example calculations were performed for Filter A where the average soot concentration pre-filter was measured to be $90.05 \pm 4.50 \mathrm{mg} / \mathrm{m}^{3}$ and the average soot concentrations post-filter was measured to be $0.53 \pm 0.027 \mathrm{mg} / \mathrm{m}^{3}$. Substituting these values in Equation 7 results in a $\mathrm{FE}$ uncertainty of $\pm 0.042 \%$. Results for Filters B, C and D are shown in Table 7.

Table 7: Filtration Efficiency uncertainty analysis results

\begin{tabular}{|c|c|}
\hline Filter & $\begin{array}{c}\text { Filtration Efficiency } \\
\text { Uncertainty (\%) }\end{array}$ \\
\hline A & 0.042 \\
\hline B & 0.392 \\
\hline C & 0.490 \\
\hline D & 0.137 \\
\hline
\end{tabular}




\section{References}

[1] J. Yang, P. Roth, T. D. Durbin, K. C. Johnson, D. R. Cocker, III, A. Asa-Awuku, R. Brezny, M. Geller and G. Karavalakis, "Gasoline Particulate Filters as an Effective Tool to Reduce Particulate and Polycyclic Aromatic Hydrocarbon Emissions from Gasoline Direct Injection (GDI) Vehicles: A Case Study with Two GDI Vehicles," Environmental Science \& Technology, vol. 52, pp. 32753284, 2018.

[2] B. Heinz and A. W. Majewski, "Particulate Matter Measurements," DieselNet, 03 2012. [Online]. Available: https://dieselnet.com/tech/measure_dpm.php. [Accessed 2512 2020].

[3] H. Yue, A. Lehmen, M. Van Nieuwstadt, G. Mason, M. Barwick, D. Warm and K. Pebley, "Impacts of Drive Cycle and Ambient Temperature on Modelled Gasoline Particulate Filter Soot Accumulation and Regeneration," SAE, 2018.

[4] J. Gong, S. Viswanathan, D. A. Rothamer, D. E. Foster and C. J. Rutland, "Dynamic Heterogeneous Multiscale Filtration Model: Probing Micro- and Macroscopic Filtration Characteristics of Gasoline Particulate Filters," Environmental Science \& Technology, vol. 51, pp. 11196-11204, 2017.

[5] G. Oberdorster, E. Oberdorster and J. Oberdorster, "Nanotpxicoligy: An Emerging Discipline Evolving from Studies of Ultrafine Particles," Environ Health Prospect, vol. 113, no. 7, pp. 823$839,2005$.

[6] M. J. Clift, P. Gehr and B. Rothen-Rutishauser, "Nanotoxicology: A Perspective and Discussion of Whether or Not In Vitro Testing is a Valid Alternative," Arch Toxicol, vol. 85, no. 7, pp. 723-731, 2011.

[7] P. S. Vinzents, P. Moller, M. Sorensen, L. E. Knudsen and et. al, "Personal Exposure to Ultrafine Particles and Oxidative DNA Damage," Environ Health Perspect, vol. 113, no. 11, pp. 1485-1490, 2005.

[8] T. Boger and W. Cutler, Reducing Particulate Emissions in Gasoline Engines, Warrendale, PA: SAE International , 2019.

[9] P. Eastwood, Particulate Emissions from Vehicles, Warrendale/Chichester: Published on behalf of SAE International/John Wiley: Wiley-PE Publishing Series , 2008.

[10] M. Bertsch, "Investigations to Reduce Particle Number Emissions from GDI Engines II," FVVAbschlussbericht, 2016.

[11] I. Glassman and R. A. Yetter, Combustion, San Diego, USA: Elsevier Inc., 2008. 
[12] "MECA," [Online]. Available: http://www.meca.org/technology/technology-details?id=6. [Accessed 19 November 2018].

[13] Air Cleaners , "Air Quality Engineering," 3005 2018. [Online]. Available: https://www.air-qualityeng.com/air-cleaners/filtration-mechanisms/. [Accessed 1203 2019].

[14] W. A. Majewski, "Gasoline Particulate Filters," DieselNet, 2019.

[15] C. Lambert, T. Chanko, D. Dobson, X. Liu and J. Pakko, "Gasoline Particulate Filter Development," Emission Control Science and Technology, vol. 3, no. 1, pp. 105-111, 2017.

[16] Corning Inc., "Corning," [Online]. Available: https:/www.corning.com/in/en/products/environmental-technologies/products/ceramic-particulatefilters/corning-dura-trap-gc-filters.html. [Accessed 2 February 2019].

[17] A. W. Majewski, "Diesel Particulate Filters," DieselNet, 06 2020. [Online]. Available: https://dieselnet.com/tech/dpf.php. [Accessed 2312 2020].

[18] Association for Emissions Control by Catalyst, "Gasoline Particulate Filter (GPF)," AECC, Brussels, 2017.

[19] C. Morga, "Platinum Group Metal and Washcoat Chemistry Effects on Coated Gasoline Particultate Filter Design," Johnson Matthey Technol. Rev., vol. 59, no. 3, 2015.

[20] P. Kattouah, K. Kato, D. Thier, E. Ohara, C. D. Vogt, Y. Ito, T. Shimoda, T. Aoki, K. Yuuki and H. Sakamoto, "Advanced Gasoline Particulate Filter for Effective Gasoline Emission Control Beyond Euro 6," Emission Control 2014, Dresden, 2014.

[21] DieselNet, "United States: Cars and Light-Duty Trucks: Tier 3," [Online]. Available: https://dieselnet.com/standards/us/ld_t3.php\#fuel. [Accessed 2808 2020].

[22] T. W. Chan, E. Meloche, J. Kubsh, D. Rosenblatt, R. Brezny and G. Rideout, "Evaluation of a Gasoline Particulate Filter to Reduce Particle Emissions from a Gasoline Direct Injection Vehicle," SAE Int. J. Fuels Lubr., vol. 5, no. 3, 2012.

[23] M. Shimizu, J. Park, S. He, J. Lv and et al., "Performance Evaluation of Gasoline Particulate Filters over Extended Vehicle and Engine Bench Operation," 17th Hyundai-Kia International Powertrain Conference, Gyeonggi-do, Korea, 2017.

[24] E. kladopoulou, S. Yang, J. Johnson, G. Perker and et al., "A Study Describing the Performance of Diesel Particulate Filters during Loading and Regeneration - A Lumped Parameter Model for Control Applications," SAE Technical Paper 2003-01-0842, 2003. 
[25] R. Sanui and K. Hanamura, "Scanning Electron Microscopic Visualization of Bridge Formation Inside the Porous Channels of Diesel Particulate Filters," SAE Technical Paper 2012-01-0363, 2016.

[26] University of Wisconsin-Madison, "Understanding Porosity and Density," University of Wisconsin Madison, [Online]. Available: https://wgnhs.wisc.edu/maps-data/data/rockproperties/understanding-porosity-density/. [Accessed 0910 2020].

[27] DieselNet, "Cellular Monolith Substrates," DieselNet, [Online]. Available: https://dieselnet.com/tech/cat_substrate.php. [Accessed 1410 2020].

[28] M. Saffaripour, T. W. Chan, F. Liu, K. A. Thomson, G. J. Smallwood, J. Kubsh and R. Brezny, "Effect of Drive Cycle and Gasoline Particulate Filter on the Size and Morphology of Soot Particles Emitted from a Gasoline-Direct-Injection Vehicle," Environmental Science \& Technology, vol. 49, pp. 11950-11958, 2015.

[29] T. J. Toops, J. A. Pihl, C. E. A. Finney, J. Gregor and H. Bilheux, "Progression of Soot Cake Layer Properties During the Systematic Regeneration of Diesel Particulate Filters Measured with Neutron Tomography," Emission Control Science and Technology, vol. 1, pp. 24-31, 2015.

[30] "Jing miniCAST Soot Generator Model 5201 B User Manual".

[31] L. Jing, "Comparison of PAH in the soot made by propane, gasoline and diesel using the CAST technique," 1608 2004. [Online]. Available: http://www.sootgenerator.com/documents/Jing.pdf. [Accessed 2912 2020].

[32] Jing Ltd., "Characteristics of Soot Particles from CAST," Jing, [Online]. Available: http://www.sootgenerator.com/soot_char.htm\#Morphology_. [Accessed 0909 2020].

[33] AVL, "MSS Plus - AVL Micro Soot Sensor," [Online]. Available: https://www.avl.com/-/mssplusavl-micro-soot-sensor. [Accessed 25 September 2019].

[34] TSI, "Engine Exhaust Particle Sizer Spectrometer Model 3090," [Online]. Available: https://www.tsi.com/getmedia/22bf0106-13d9-4503-b179bc76cb55e100/Updated_Inversion_Matrices_EEPS-005-A4-web?ext=.pdf. [Accessed 2509 2019].

[35] H. Jung and D. B. Kittelson, "Measurement of Electrical Charge on Diesel Particles," Aerosol Science and Technology, vol. 39, no. 12, pp. 1129-1135, 2005.

[36] A. Miller, G. Frey, G. King and C. Sunderman, "A Handheld Electrostatic Precipitator for Sampling Airborne Particles and Nanoparticles," Aerosol Science and Technology, vol. 44, no. 6, pp. 417-427, 2009. 
[37] University of Nottingham, "Transmission electron Microscopy (TEM)," University of Nottingham, [Online]. Available: https://www.nottingham.ac.uk/isac/facilities/tem.aspx. [Accessed 0702 2020].

[38] nanoScience Instruments , "Scanning Electron Microscopy," nanoScience Instruments, [Online]. Available: https://www.nanoscience.com/techniques/scanning-electron-microscopy/. [Accessed 07 02 2020].

[39] T. C. Bond and R. W. Bergstrom, "Light Absorption by Carbonaceous Particles: An Investigative Review," Aerosol Science and Technology, vol. 40, no. 1, pp. 27-67, 2005.

[40] A. G. Konstandopoulos , M. Kostoglou, E. Skaperdas, E. Papaioannou and et. al., "Fundamental Studies of Diesel Particulate Filters: Transient Loading, Regeneration and Aging," SAE Technical Paper 2000-01-1016, 2000.

[41] J. Swanson, W. Watts, D. Kittelson, R. Newman and R. Ziebarth, "Filtration Efficiency and Pressure Drop of Miniature Diesel Particulate Filters," Aerosol Science and Technology, vol. 47, no. 4, pp. 452-461, 2012.

[42] W. A. Majewski, "Wall-Flow Monoliths," DieselNet, [Online]. Available: https://www.dieselnet.com/tech/dpf_wall-flow.php. [Accessed 1111 2019].

[43] W. C. Hinds, Aerosol Technology, New York: Wiley \& Sons. Inc., 1999.

[44] J. Xue, Y. Li, X. Wang, T. D. Durbin and et al, "Comparison of Vehicle Exhaust Particle SizeDistributions Measured by SMPS and EEPS DuringSteady-State Conditions," Aerosol Science and Technology, vol. 49, no. 10, pp. 984-996, 2015.

[45] TSI, "MECHANISMS OF FILTRATION FOR HIGH EFFICIENCY FIBROUS FILTERS," TSI, 2012. [Online]. Available: https://www.tsi.com/getmedia/4982cf03-ea99-4d0f-a66042b24aedba14/ITI-041-A4?ext=.pdf. [Accessed 1101 2020].

[46] X. Ma, C. D. Zangmeister and M. R. Zachariah, "Soot Oxidation Kinetics: A Comparison Study of Two Tandem Ion-Mobility Methods," The Journal of Physical Chemistry , vol. 117, pp. 1072310729, 2013.

[47] Spectro Scientific Inc, Oil Analysis Handbook Third Edition, Spectro Scientific Inc, 2017.

[48] E. N. Davis and R. A. Van Nordstrand, "Determination of Barium, Calcium and Zinc in Lubricating Oils," Analytical Chemistry, vol. 26, no. 6, pp. 973-977, 1954.

[49] "Porosimetry by Mercury Intrusion," The United States Pharmacopeial Convention, 2011. 
[50] F. Liu, J. Yon, A. Fuentes, P. Lobo, G. J. Smallwood and J. C. Corbon, "Review of recent literature on the light absorption properties of black carbon: Refractive index, mass absorption cross section, and absorption function," Aerosol Science and Technology, vol. 54, no. 1, pp. 33-51, 2019. 